\title{
Comprehensive assessment of general practitioners : a study on validity, reliability and feasibility
}

Citation for published version (APA):

Ram, P. M. (1998). Comprehensive assessment of general practitioners : a study on validity, reliability and feasibility. [Doctoral Thesis, Maastricht University]. Universiteit Maastricht. https://doi.org/10.26481/dis.19981203pr

Document status and date:

Published: 01/01/1998

DOI:

10.26481/dis.19981203pr

Document Version:

Publisher's PDF, also known as Version of record

\section{Please check the document version of this publication:}

- A submitted manuscript is the version of the article upon submission and before peer-review. There can be important differences between the submitted version and the official published version of record. People interested in the research are advised to contact the author for the final version of the publication, or visit the DOI to the publisher's website.

- The final author version and the galley proof are versions of the publication after peer review.

- The final published version features the final layout of the paper including the volume, issue and page numbers.

Link to publication

\footnotetext{
General rights rights.

- You may freely distribute the URL identifying the publication in the public portal. please follow below link for the End User Agreement:

www.umlib.nl/taverne-license

Take down policy

If you believe that this document breaches copyright please contact us at:

repository@maastrichtuniversity.nl

providing details and we will investigate your claim.
}

Copyright and moral rights for the publications made accessible in the public portal are retained by the authors and/or other copyright owners and it is a condition of accessing publications that users recognise and abide by the legal requirements associated with these

- Users may download and print one copy of any publication from the public portal for the purpose of private study or research.

- You may not further distribute the material or use it for any profit-making activity or commercial gain

If the publication is distributed under the terms of Article $25 \mathrm{fa}$ of the Dutch Copyright Act, indicated by the "Taverne" license above, 


\title{
Comprehensive assessment of general practitioners
}

a study on validity, reliability and feasibility

\author{
Paul Ram
}


ISBN $90-5681=040-5$

Paul Ram, Maastricht 1998

Vormgeving: Karin Aretz en Karin Vaessen

Ontwerp omslag:

Druk: Unigraphic, Maastricht 


\section{Comprehensive assessment of general practitioners}

a study on validity, reliability and feasibility

Proefschrift

ter verkrijging van de graad van doctor

aan de Universiteit Maastricht op gezag van.

de Rector Magnificus, Prof. Dr. A.C. Nieuwenhuijzen Kruseman

volgens het besluit van het College van Decanen

in het openbaar te verdedigen

op donderdiag 3 december 1998 om 14.00 uur.

door

Paul Ram 


\section{Promotoren:}

Prof. Mr. Dr. R.P.T.M. Grol

Prof. Dr. C.P.M. van der Vleuten

\section{Co-promotor:}

Dr. J.J.E. Rethans

\section{Beoordelingscommissie:}

Prof. DI. J.P.M. Geraedts, (voorzitter)

Prof. Dr. W.H.M. Van den Bosch (Katholieke Universiteit Nijmegen)

Prof. Dr. H.J.M. Van Rossum (Rijksuniversiteit Groningen)

Prof. Dr. G.G.M. Essed

Dr. H.A.P. Wolfhagen 


\section{CONTENTS}

Preface

Introduction

\section{Chapter 1}

Comprehensive assessment of general practitioners: a theoretical and practical pyramid model.

\section{Chapter 2}

Assessment of General Practitioners by video observation of medical and communicative performance in daily practice: issues of validity, reliability and feasibility.

\section{Chapter 3}

Assessment of practising family physicians: comparison of observation in a station examination using standardized patients with observation of real surgery in daily practice.

\section{Chapter 4}

Assessment in General Practice: the predictive value of Written Knowledge Tests and a Multiple Station Examination for actual medical performance in daily practice.

\section{Chapter 5}

Structure and process: the relationship between practice management and actual clinical performance in general practice.

Chapter 6

General practitioners' communication with patients: quality assessment by peers, patients or standardized patients?

\section{Chapter 7}

General discussion

Conclusions and recommendations for research.

Summary

Appendix 



\section{Preface}

Are you looking for doctors' strengths and weaknesses in order to plan quality improvement activities as effectively as possible? No problem, comprehensive assessment is the panacea, by which you can evaluate your improvement activities as well! Comprehensive assessment you say? But what do you want to assess and why? The doctor's knowledge, skills or actual performance? And....which aspects of that broad domain of general practice care? Doctors ${ }^{t}$ communication with patients, medical performance or their practice management? And how, how much and where? By the way, who are the assessors? Questions, questions, questions! You better help me to find the answers!

Use knowledge tests, assessor, they are relatively cheap and feasible for use on a broad scale. Thank you, but that doesn't comply to my request. I need information about doctors' skills as well! Alright, observe doctors in a simulated standardized surgery. That enables a fair comparison of doctors' skills: they all met the same patients bringing in the same cases in the very same situation. That"s a fine idea! But how many consultations do I have to include? What is a fair assessment anyway? A valid and reliable one? But what is valid? By nature these simulated surgeries are unnatural! Do you think practicing doctors will accept the results of such a method? Doctors" performance in such a setting might be quite different from actual performance in daily practice. By the way, simulated surgeries require high resource investments. I don't have the money, do you? Okay, let me think. Yes, we do have an alternative. Let's start to assess doctors' practice management. A good management is associated with good care! So, improvement of doctors' practice management will result in better care directly. Are you sure? How weak or strong is the relationship between the doctor's quality of medical and communicative performance on the one hand and the quality of his practice management on the other?

No, I'm not sure. Therefore, we have to observe daily surgeries. We will open doctors' "black box" by video registrations. That's it, we will enter real life! Great, okay. But, do patients agree? And real surgeries are not standardized, all patients are different and present different problems. Moreover, I want to assess the consultations as a whole. Is that possible, I mean to observe physical examination?

You're driving me crazy! Okay, we do everything: knowledge tests, observation of simulated and real surgeries and the doctor's practice management as well. We analyze all psychometric aspects, such as validity, predictive values, reliability, generalizability, acceptability and feasibility! You're kidding! No, I'm not. I grant the money and you will answer all those questions in a thesis.

So I did. Now it's your turn. You have to read this book, in which all questions have been answered, except for ...... 


\section{Acknowledgement}

My name is a synonym for many people who worked with me on this thesis: professionals, patients and volunteers, lovers and friendls. I like to thank everyone for his or her contribution by quoting a referee of Academic Medicine: "a great piece of work!".

* Over 150 GPs showed their readiness to be assessed realizing a fantastic response rate.

* Over 5000 patients trusted our organization by giving informed consent.

* Thirty-five GPs observed near to 100 consultations each without loosing videotapes, scoring lists or their minds.

* Over 2000 real patients filled in "the patients' evaluation of communication". The standardized patients did the same and they presented their complaints very consistently.

* Over 100 practice assistants worked at the desk on the informed consent procedure, while taking care of the patients' questionnaires and being of assistance for all visiting consultants.

* Practice consultants visited over 100 practices an gathered many data on practice management.

* The electricians installed the video-equipment into the practices, making consultations observable and taking care of the transport of the videotapes from the practices to the university.

* "The MEMIC, which entered over 50.000 data on GPs" performance.

* The Dutch Government, which subsidized this great project.

Synonym isn't a synonym for anonym, so I want to call some supporters by their names:

* Jacques van Thiel and Jan van Dalen, the authors of the scoring list MAAS-Global, adjusted the list for observation of consultations both in daily practice and simulated surgeries.

* Pieter van den Hombergh and Jolanda van Haaren and "their" Visitation Instrument for Practice management (VIP) enabled me to study the relationship between process and structure.

* Marjan Pollemans, Yvonne van Leeuwen and Koos Jansen, the authors of the knowledge tests, contributed to the disclosure of the relationship between knowledge and actual performance.

* Herman Düsman of the SVUH, which represents the collaboration between the institutes for vocational training in the Netherlands, took care of the data-analysis of the knowledge tests.

* The external supervising committees: Josse Rutten, Lisa Tan, Karel Blanken, Johannes Dalhuysen, John Ehrhardt, Mrs. Walter, Mr. van Hall and Mr. Mulder were good advisers and gave logistical support.

* Annie Kuepers coordinated the video installation in the northern region of our project and gave regular support during the whole project.

* The Dutch College of General Practitioners (NHG) provided guidelines for medical performance, supported the study financially and offered me time to finish this thesis implicitly by offering me a job as a member of staff. Therefore, Hans van der Voort, Ron Helsloot, Arno Timmermans, Kees in 't Veld and others: thank you for being real colleagues. 
* All the vocational training staff members of the Department of General Practice at the University of Maastricht contributed to this thesis by exempting me from all "over-head tasks". Paul Hoppener and all colleagues: thank you for that!

* The Dutch Association of General Practitioners (LHV) supported the study by buying our comprehensive assessment products. Moreover, their districts in the south of the Netherlands recruited the participating general practitioners.

* The Skillslab at the University of Maastricht offered me well trained standardized patients, written cases and materials for the simulated surgeries: Jules Been, Marleen van Zandwoort and Pie Bartholomeus, thank you!

* Ger van Wunnik's "Science Vision", i.e. the "Gedragslab" at the University of Maastricht contributed to the simulated surgery by videotaping over more than 800 consultations. Ger, the technical quality of your work has been assessed as well and proved to be excellent.

* Bob Wilkinson, Jan van Dalen, Mrs. L. Teunisse and Marij Hamers corrected my "pit-coal English".

* Arnold Kester from the Department of Methodology and Statistics supported our basic statistics. Last but not least, the members of the "PIT-project team", which has been a perfect team!

* Richard Grol and Cees van der Vleuten, the promoters, Jan Joost Rethans, co-promotor, I highly appreciated the atmosphere of "being equal professionals" in our discussions. You were the study experts and I, being an experienced GP, was an "inexperienced young researcher". You teached me the scientific principles and how to write an article. You have suffered from my first attempts to write a "story". I hope this thesis, being a product of your efforts, may compensate the pain! Thank you for being my marvelous sparring partners and teachers.

* Karin Aretz, Marleen van den Boogaart, Berna Schouten and Karin Vaessen were more than research-assistants and secretaries. You organized the whole project in detail and you showed endless patience with me in analyzing all sort of data and in creating tables. In this way, we together wrote this thesis. Drearn team, thank you for working with you during the last five years.

* Dear Hanneke and dear Koen, invisible members of this perfect team, thanks for al!! 


\section{Introduction}

Past twenty years, quality of care has evolved into a new important field of work including quality management, which involves both quality assessment, i.e. the process of evaluating the current level of performance, and a process of change and improvement. ${ }^{3}$ The assurance that good quality is maintained requires continuously repeating the process of assessment and improvement. ${ }^{2}$ Ideally, quality improvement in general practice means continuous and systematic activities integrated in normal practice care, visible for all other parties in health care (insurance companies, health authorities and the public) as a firm demonstration that general practice is taking quality seriously. ${ }^{3}$ In the Netherlands, legislation will change in order to guarantee the quality of care. "Therefore, implementation of systematic quality assessment is a priority for many professional organizations and policymakers in general practice. In addition, assessment of practising General Practitioners (GPs) enables doctors to plan medical education on actual needs and deficiencies rather than on personal preference. The subjective needs of doctors tend to match personal interests and specific experiences. ${ }^{5}$ Therefore, objectively collected information should increase knowledge of strengths and weaknesses in general practice care, which can subsequently be used for educational, certification and recertification purposes ${ }^{6}$ Only such an assessment can provide a minimum guarantee to the public and policymakers that physicians are competent and can serve as a velhicle for quality improvement. ${ }^{7}$ Although the idea of formal assessment and reassessment of practising GPs is becoming an accepted fact, a formal assessment procedure which enables a systernatic, valid, reliable and feasible assessment procedure for practising GPs is yet lacking in most countries in Europe. ${ }^{8-12}$ Isolated non-comprehensive assessment activities may fail to cover the extensive domain of general practice care. Moreover, the implementation of different assessment methods, which are not linked to each other, may hamper the integration of results and effective feedback. In this way, assessment may not lead to a systematic quality improvement.

This thesis focuses on the development and integration of different methods to be used in a comprehensive assessment procedure for practising GPs. Priority will be given to comprehensive assessment and its basic psychometric characteristics, such as validity, reliability, feasibility and the predictive value of methods used for actual performance. The educational impact, i.e. the influence of the assessment on GPs" educational activities, will be taken into account as well. It this educational study, aspects of health services research or, for example, epidemiological issues or other research concerning quality of care, have been left out of consideration.

Important assessment issues in medical education and their implications will be discussed in this introduction, followed by other chapters presenting results of research on psychometric characteristics, conclusions and recommendations for research. 


\section{Issues to be followed in the implementation of assessment procedures}

The development and implementation of valid, reliable and feasible assessment can be operationalixed as a series of steps to be followed.:

1. definition and selection of the clinical problems and clinical tasks to be addressed

2. development and selection of assessment methods, such as written tests, orals or direct observation tests and concurrent scoring issues, such as checklists, scoming keys, and scales

3. logistics of test administration as regards number of candidates, resources and time available

4. feedback to the participants, the levels of score details and their interpretation

These prerequisites for implementation of assessment procedures will be discussed in some detail.

1. Definition and selection of the clinical problems and tasks to be tested

An important phase in developing an assessment procedure is the definition of what has to be tested, assuming that the purpose of the assessment has been determined. This definition forms the basis for evaluating the content validity. ${ }^{14,45}$ The approach to determining what needs to be tested consists of three activities. First, the aspects of care the GP should be able to handle must be identified. Second, for each problem the clinical tasks in which the GP is expected to be competent should be defined. In different countries these activities have resulted in job descriptions, consisting of analyses of the functions and tasks most critical for health care in the setting of general family practice. ${ }^{16-18}$ The third activity consists of the development of a framework to be used as a blueprint for the selection of problems to be included. ${ }^{19}$

In relation to practising GPs, the question arises whether any model can represent the "state of the art" in general practice care as well as can cover the extensive and complex domain of general practice care, including "process" and "structure" aspects leading to desired patient outcomes. ${ }^{20}$ Such a blueprint should represent recent developments in clinical management of patients and recent insights in communication and problem-solving strategies, and should include all dimensions of practice management organization. It is obvious that no single assessment method can cover all these aspects: therefore, a blueprint for a comprehensive assessment approach is needed. ${ }^{21.22}$

\section{The development and selection of test methods}

A wide variety of assessment methods is available, resulting in the need to select appropriate methods for each aspect of general practice care to be assessed. ${ }^{23}$ Methods should be suitable for use in regular continuing medical education and quality improvement strategies in order to make the procedure as effective as possible. ${ }^{24,25}$ Defining the conditions under which the assessment will be conducted is required. Will the assessment take place in the clinical practice, in a simulated situation, or by means of indirect tests, such as written papers?

Assessment methods can be divided in competence-based and performance-based tests. ${ }^{23}$ Competence concerns doctor's knowledge (knows) and capability of doing (shows), whereas performance has been defined as what a doctor is doing in his day-to-day practice (does). ${ }^{26,27}$ Written tests, i.e. 
self-assessment tests and knowledge tests, and direct observation of doctors in a simulated test condition using standardized patients represent competence-based tests. ${ }^{28.29}$ Observation of doctors' regular surgeries, practice organization and assessment of data gathered from daily practice, such as data on referrals and prescriptions, are performance-based tests. ${ }^{30-32}$

Since considerable experience has been gathered with competence-based assessment methods in undergraduate curricula and vocational training, it is tempting to use these methods for assessment of practising GPs. However, practising GPs are different from medical students and GP trainees: experienced GPs have developed their own working style, they take care of relatively stable patient populations and they usually "manage" their own practices. ${ }^{33}$ In addition, recent insights into medical expertise show a distinction between novices and experienced GPs. Medical students have to acquire knowledge and skills, whereas experienced doctors include facts related to the context, e.g. the medical and individual history of the patient. ${ }^{34}$ Recognition and interpretation of these contextual factors determine the diagnostic accuracy of practising GPs. ${ }^{35}$ These aspects should be taken into account in the process of defining and selecting clinical tasks to be addressed, and in selecting concurrent assessment methods as well. Therefore, undergraduate assessment methods are not always suitable for assessment of practising GPs and the development of alternative methods is required.

Both the process between GPs and their patients (performance) and structure (practice management) contribute to patient outcome. Authentic assessment by direct observation of a GP's clinical performance in daily practice, including observation of his practice organization, is a very valid approach and may therefore be preferred over other methods in quality assessment. ${ }^{36}$ However, observation of a GP's performance seems to be difficult to standardize and requires considerable resources. Tests using simulated clinical situations, on the other hand, can be standardized, but involve high cost as well. ${ }^{37-39}$ Written knowledge tests pose less logistical and financial problems, but the predictive value of these tests for GPs' actual daily performance is questionable. ${ }^{10,40}$ Moreover, research aimed at determining whether competence-based observation methods using standardized patients do predict actual performance has resulted in conflicting evidence.11 The tenuous relationship between competence-based and performance-based methods as well as the need to cover a broad domain of patient care in general practice require the inclusion of different methods within an assessment procedure for practising GPs. Knowledge tests, competenceassessment using standardized patients at the medical school and assessment of actual performance by observation, using peer-observers and (standardized) patients to score performance may all have their place in such a "comprehensive assessment". The relationship between competence-based and performance-based methods within such an assessment should be analysed, in order to enable one to select the most valid, reliable and feasible methods using sound psychometric criteria for final assessment and reassessment procedures.

As mentioned above, the domain of general practice care is extensive and complex, including "process", "structure" and "outcome" aspects. "Process" refers to the GP's medical performance and communication with patients, concerning an infinite number of complaints and diseases of 
patients. This is embedded in a practice management organization, i.e. the structure. ${ }^{43}$ Process and structure ideally produce desired patient outcomes. However, the relation between process and structure, including the way in which these aspects attribute to a good patient outcome, is unclear, requiring further research ${ }^{4}$ Therefore, both actual performance and practice management should be assessed separately in a maximally comprehensive way. The problem in general practice is that good measures of outcome of care, i.e. the effects of care on patients, are difficult to devise. Many presenting symptoms never crystallize into recognizable clinical entities. Chronic conditions run their own course over long periods of time and many diseases are self-limiting, making it difficult to attribute a charige in a patient's condition to single health care interventions.

Finally, technical issues such as making choices between checklists and rating scales, observation and (video) recording, and calculating case scores, should be taken into account. In relation to comprehensiveness and integration of different methods, the use of similar scoring lists and systems within different methods is preferred in order to allow these methods to be compared on validity and reliability. For example, regular consultations in daily practice and consultations in a simulated station examination should best be observed by using preferably the same scoring lists and scoring systems. Also for different knowledge tests similar answer formats are preferred. This will improve the power of the feedback to the candidates as well.

\section{Logistics of test administration and procedures}

Administrative problems, such as the need to test large numbers of candidates or limitations of time and resources, may lead to the adoption of test methods based on feasibility arguments rather than on validity aspects. Written tests, such as self-assessment tests and knowledge tests, may be preferred to performance tests. This may strengthen the risk that knowledge, skills and behaviours may be assessed in isolation rather than as an integrated performance construct, by which the GP has to handle complex problems as usually presented in general practice care. ${ }^{45}$ On the other hand, if an assessment procedure focuses on validity and reliability only; without evaluating the logistics, i.e. the feasibility, the final assessment procedure cannot be implemented. Therefore, cost should be registered by keping accounts and should be reported in detail in order to evaluate what resource investments will be required for the implementation of vallid and reliable procedures.

\section{Feedback to the participants}

Assessment should lead to improved care for patients. So, appropriate and understandable feedback to the physicians assessed should provide an insight into necessary improvements and forms an important part of each assessment procedure. The interpretation of scores by the participants should be carefully guided by objective feedback. Special attention should be paid to the educational impact of both the assessment method and corresponding feedback. Feedback, on the other hand, may induce an order effect in comprehensive assessment: GPs" performance in one method may be influenced by prewious assessment experiences within the same procedure. Analysis of the relationship between those methods may be biased by this order effect. 


\section{Research questions}

In summary, this thesis focuses on the development and integration of different assessment methods to be used in a comprehensive assessment procedure for practising GPs, while taking into account the aspects mentioned above.

More specifically the following research questions are addressed:

1. What would be an appropriate model for comprehensive assessment of practising GPs, which covers the domain of general practice care as completely as possible?

2. To what extent do competence-based tests predict actual clinical performance?

3. What is the relationship between management in general practice (structure) and actual clinical performance of GPs in that practice (process)?

\section{Methods and design}

To address the research questions a study was conducted in three phases.

In the first phase, a literature search was carried out into models and blueprints for the comprehensive assessment of GPs. The desired blueprint was meant to cover the extensive domain of general practice care. Moreover, it had to take into account the difference between competence and performance and recent insights in medical expertise, recent developments in continuing medical education, quality improvement and assessment procedures in order to be as effective as possible. In addition, existing assessment instruments and methods were screened on their psychometric qualities (validity, reliability and feasibility) in order to select the optimal combination of instruments for the main study.

Consecutively, in the second phase, a new model for comprehensive assessment of GPs was constructed. Based on this blueprint competence-based and performance-based assessment methods and instruments were included in the main study: knowledge tests, direct observation of regular and standardized consultations as well as a practice visit to assess practice management. In the third phase, the main study, a cross-sectional study was performed (see figure $\mathbb{1}$ ). 
FIGURE 1. DESTON OI THE MAN STUDY

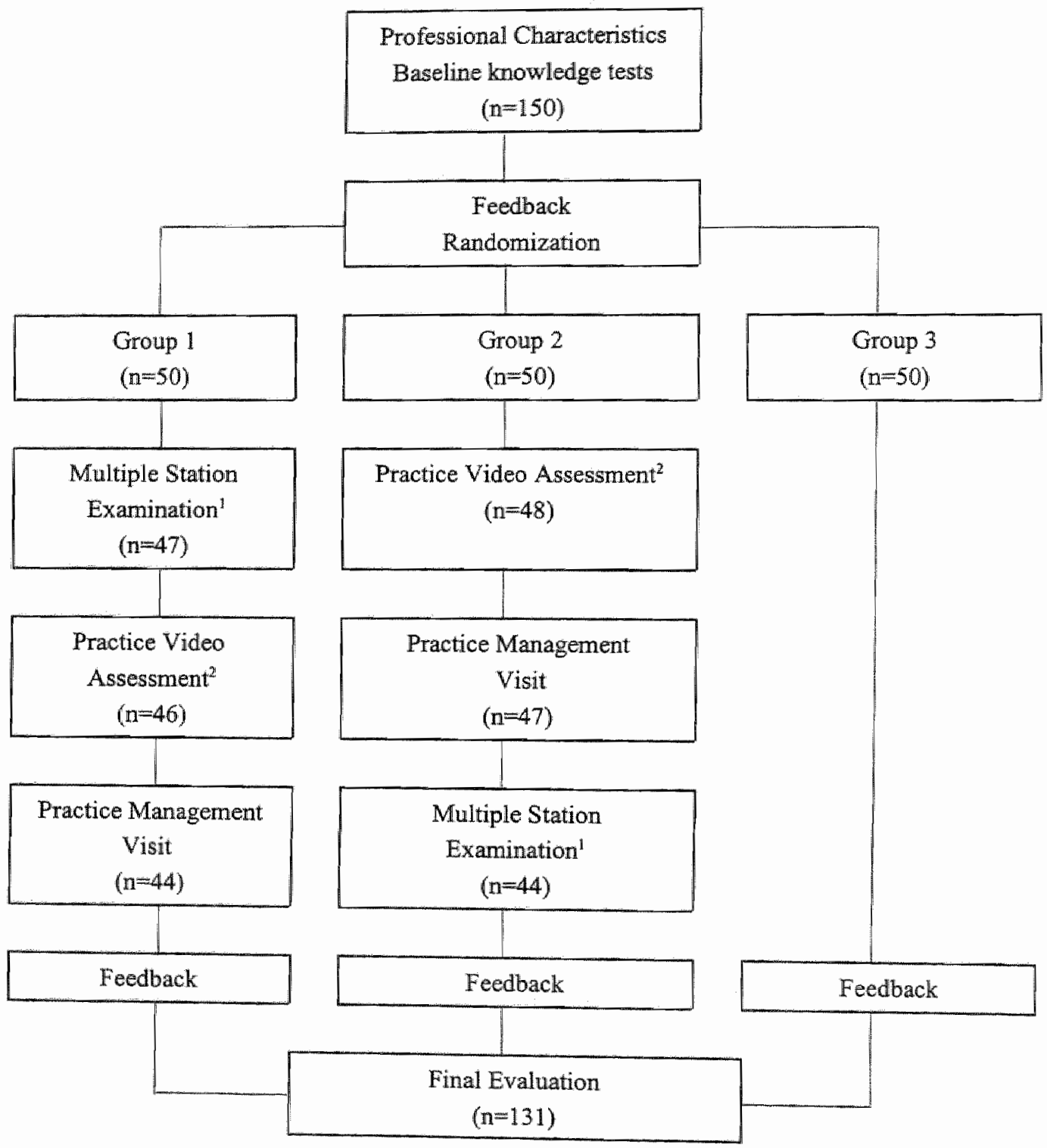

Observers: pwers and standardized patients

${ }^{2}$ Obserwers: peers and real patients 
First, GPs in the south of the Netherlands were invited by letter to participatte, 100 to be assessed comprehensively, 50 to serve as a control group and 35 to participate as peer-observers. GPs were sent a questionnaire, to be completed at home, conceming their personal and professional characteristics.

Second, two knowledge tests (paper-and-pencil tests) were completed by the participants at home: a General Medical Knowledge test and a Knowledge test on Technical Skills.

Third, after the written tests had been completed, a randomization was carried out in order to control for order effects caused by the design: three groups of 50 GPs each, two groups of participants and one control group, comparable on personal and professional characteristics and on results on the knowledge tests, were formed. In the following steps groups 1 and 2 were observed directly. Group 1 went first through the Multiple Station Examination, a real life-like surgery at the medical school, using eight cases presented by standardized patients. A few months later they went through the Practice Video Assessment. GPs of group 2 did the same but in reverse order: they started with the Practice Video Assessment and were then given the Multiple Station Examination. Consultations were scored by peer-observers, on both medical performance and communication with (standardized) patients. These patients participated as evaluators of the communication component as well.

In the final step (group 1) and in the one but final step (group 2), the practice management of GPparticipants was assessed by trained non-physician observers using a practice visit. In this method, practice management is defined as "all aspects of the GP's task necessary to realize good operation of care, excluding clinical care or treatment of patients". GPs, practice assistants, patients and observers completed questionnaires and observation sheets before and during the practice visit.

At the end, participants were sent a questionnaire asking about the degree of their acceptance of each method and the educational impact of the methods including feedback, i.e. their plans and actual changes in performance and practice management induced by their participation in this study.

\section{Structure of this dissertation}

Chapter 1 (Comprehensive assessment of general practitioners: a theoretical and practical model) presents a new model for comprehensive assessment of practising GPs, taking into account the difference between competence and performance, current insights in medical expertise and tecent developments in continuing medical education, quality improvement and assessment procedures, addressed in the literature.

Chapter 2 (Assessment of General Practitioners by video observation of medical and communica. tive performance in daily practice: issues of validity, reliability and feasibility) describes a method of direct observation of GPs' communication with patients and actual medical performance. Approximating the real professional performance as closely as possible, this video assessment in daily practice was considered as the criterion for all other assessment methods used in this study. 
Chapter 3 (Assessment of practising family physicians: comparison of observation in a station examination using standardized patients with observation of real surgery in daily practice) compares the psychometric characteristics, i.e. validity, reliability and feasibility, including acceptance by GPs, of the video assessment procedure in daily practice and an assessment in a simulated situation at the medical school using standardized patients.

Chapter 4 (Assessment in General Practice: the predictive value of Written Knowledge Tests and a Multiple Station Examination for actual performance in daily practice) investigates the predictive value of medical knowledge tests for actual medical performance in daily practice and the predictive value of the Multiple Station Examination for actual medical performance.

In Chapter 5 (Structure and process: the relationship between practice management and actual clinical performance in general practice) the relation between clinical performance (process) and practice organization (structure) is analysed.

Chapter 6 (General practitioners' communication with patients: assessment by peers, patients or standardized patients?) presents the results of the relationship between evaluation by peers and (standardized) patients' evaluation of GPs' communication with patients.

Chapter 7 (General discussion) summaries the main conclusions including GPs' evaluation of the whole assessment procedure and discusses the points raised by this study on comprehensive assessment.

\section{Aid for the reader}

For those who do not wish to read the entire dissertation, it is possible to read chapters separately, since each chapter presents a complete study description in an article format. Because of the article format some repetitive information is inevitable.

\section{References}

1. Orol R. Research and development in quality of care: establishing the research agenda. Quality in Health Care $1996 ; 5: 1 \times 8$.

2. Lawrence M, Schofield T eds. Medical audit in primary health care. Oxford University Press, Oxford 1993.

3. Grol R. Quality of care in general practice: into the next century. Huissarts Wet 1993;36:467-72.

4. de Jong EIC. BIG-registratie anisen nadert. [BIG registration is coming]. Medisch Contact 1997;52:1237.

5. Sibley JC, sacket DL, Neufeld W al. A randomized trial of continuing medical educarion. New England Journal of Medicine 1982;306:51:1-5.

6. Caulford $\mathrm{PG}_{\mathrm{s}}$ Lamb $\mathrm{SB}$, Kaigas TB, Hanna $\mathrm{E}$, Nomam GR, Dawis DA. Physician incompetence: speciffic problems and predictors. Acad Med 1994;69 suppl(10):16-20.

7. Mc Auley, Paul WM, Morrison GH. Five years results of the peer assessment program of the College of Physicians and Surgeons of Ontario. Can Med Assoc J 1990;143:1193-99.

8. Gellhom A. Periodic physician recredentialing. JAMA 1991;265:752-55.

9. Hays RB, Bridges-Webb C, Booth B. Quality assurance in genteral practice. Med Educ 1993;27:175*180.

10. Noman $\mathrm{G}$. Can an examination predict competence? The role of recertification in maintenance of competence. Annals RCPSC 1991;24:121-4. 
11. Sylvester SH. General practitioners atritudes to professional reacteditation. BMO $1993,307912.14$.

12. Windak A. A survey of current reaccreditation and recertification procedures in Europe Cambridge: BURACT Council, 1995.

13. Newble $D$, Jolly $B$, Wakeford $R$. The certification and recertification of doctors issues in assessment of chimical competence. Cambridge University Press, 1994.

14. Kane MT. The validity of licensure examinations. Americam Pychologist 1982;39.911-18.

15. Ebel RL. The practical validation of tests of ability. Educational Measurement: Issues and Practice 1983,27\%-10

16. Royal Australian College of General Practitioners. The scope of General Family Practice. Melboume: RACop, 1981:3-78.

17. Royal College of General Practitioners. What sort of doctor? Jounal of the Royal College of General Practitioners $1981 ; 31: 698-702$

18. Springer MP, ed. Basic job description for the general practitioner. Utrecht: Dutch National Association of General Practitioners, 1983 .

19. Fabb WE, Marshall JR. The assessment of clinical competence in general family practice. MTP Press Limited. Lancaster, England and Hingham, USA 1983.

20. Donabedian A. Explorations in quality assessment and monitoring 1. The definition of qualty and approaches to its assessment. Ann Arbor: Health Administration Press, 1980.

21. Neufeld VR, Nomam GR, eds. Assessing clinical competence. New Hork: Springer Publishing Company, $1985: 51.71$.

22. Kane MT. The assessmemt of professional competence. Evaluation the Health Professions 1992;15:163-82.

23. Rethans JI, Westin S, Hays R. Methods for quality assessment in general practice. Fam Pract 1996;5:468-76.

24. Formest JM, McKenna M, Stanley DM et al. Contimuing education: a survey among general practitioners. Fam Pract $1989 ; 6: 98-107$.

25. Savage R. Continuing education for general practice: a life long journey [editorial]. Br J Gen Pract 1991;41:31 1-14.

26. Rethans $\mathrm{JJ}_{\text {, Leeuwen }} \mathrm{Y} \operatorname{van}_{\text {, Drop }} \mathrm{R}$, Vleuten $\mathrm{C}$ van der et al. Competence and performance: two different concepts in the assessment of quality of medical care. Farm Pract $1990 ; 7: 168-74$.

27. Miller GE. The assessment of clinical skills/competence/performance. Acad Med 1990; $1:$ S63-567.

28. Pollemans M. Kennistoetsing bij huisartsen. [Dissertation]. [Assessment of knowledge of general practitioners]. Maastricht: Rijksuniversiteit Limburg, 1994.

29. Harden $R$, Gleeson F. Assessment of clinical competence using abjective structured clinical examination (OSCE). Med Educ 1979; $13: 41-54$.

30. Campbell LM, Murray TS. Assessment of competence. Br J Gen Pract 1996;46,619-22.

31. Stanley $I$, Al-Shehri $A_{n}$ Thomas $P$. Continuing education for general practice. 1. Experience, competence and the medin of self-directed learning for establighed general" practitioners. Br II Gen Pract 1993:43:210 14.

32. Jankowski RF. Performance indicators in general practice [letter]. BMJ 1993; 307:1356.

33. Jones RVH, Bolden KJ, Perreira Gray DJ, Hall MS. Running a practice, manutal of practice management. 3rd Eudition. London: Capman and Hall, 1990

34. Schmidt $\mathrm{H}$, Noman $\mathrm{G}$, Boshuizen HA. Cognitive perspective on medical expertise: theory and implications. Acad Med $1990 ; 65: 611-21$.

35. Hobus P. Expentise van huisartsen [Dissertation]. [Expertise of general practitioners. Maastricht: Rujksuniversiteil Limburg, 1994.

36. van der Vleuter CPM. The assessment of professional competence develupments, research and practical implications Advances in Health Sciences Education. Theory and practice 1996;1:41-67,

37. van der Vleuten CPM, Swanson DB. Assessment of clincal skills with standardized patients: state of the art. Teaching and Learning in Medicine 1990;2:58-76.

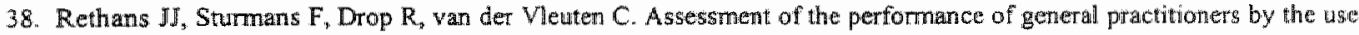
of standardized (simulated) patients. Br J Gen Pract 1991; 47:97-99.

39. Reznick RK, Smee $\mathrm{S}$, Bamber IS et al. Gudelines for estinating real cost of an objective structured clinical examination. Acad Med 1993;68:513-17.

40. Ramsey $\mathrm{PG}_{\mathrm{s}}$ Carline JD, Inui YS et al. Predictive walidity of certification by the American Board of lnternal Medicite: Annals of Internal Medicine 1989:110:719-26. 
41. Rethams JI. Does competence predict performance? Standardized patients as a means to inwestigate the relationship berween conpetence and performance of general practitioners [Thesis]. Maastricht, the Netherlands 1991.

42. Rethans JJ, Sturmans $F$, Drop $R$ et al. Does conpetence of general practitioners predict their perfomance? Comparison between exarrination setting and actual practice. BMJ 1991; 303: 1377-80.

43. Irwine D \& Irwine S. The practice of quality. Radeliffe Medical Press Ltd, 1996. Oxford and New York.

A4. Southgate L. Freedom and discipline: clinical practice and the assessment of clinical competence (James Mackenzie lecture 1993). Br I Gen Pract 1994;44:87.92.

45. Hager P, Conczi A, Athanassou J. General issues about assessment of competence. Assessment \& Evaluation in Higher Education 1994;1:3-16. 
Chapter 1.

\section{Comprehensive assessment of general practitioners: a theoretical and practical pyramid model.}

Submitted as: Comprehensive assessement of general practitioners: an up-to-date pyramid model. Paul Ram, Jan-Joost Rethans, Cees van der Vleuten, Sjoerd Hobma and Richard Grol 


\section{Summary}

Objectives. Assessment of General Practitioners (GPs) for reaccreditation and educational purposes requires a blueprint to guide the selection of problems to be included. Such a model should cover the extensive and complex domain of general practice care, including medical performance, communication with patients, and practice management. The aim of this study is to develop a blueprint for comprehensive assessment of GPs, taking into account recent views on medical expertise, the distinction between competence and performance, the state of the art in continuing medical education (CME), quality improvement and assessment methods.

Methods. Computerized and hands-on literature searches were performed, focused on collecting models, data and ideas, useful for the construction of an assessment model for practising GPs. A systematic review was not sought.

Results. Existing frameworks were transformed into a new three-dimensional pyramid. One axis represents the domain of general practice care: medical performance, communication with patients and practice management. On the second axis there is a clear distinction between competence on the lower levels, i.e. knowledge and skills, and performance at the top: actual communication and medical performance (both process) and practice management (structure) finally produce patient outcomes. Diseases and complaints, ordered according to chapters of the Intemational Classification of Primary Care (ICPC), including contextual factors as important features, are represented on the third axis.

Conclusion. This model allows test developers to define precisely their objective for testing, i.e. what should be assessed, and where and how. For each of the domains and for each level different assessment instruments can be chosen. This model may facilitate an uniform and generally accepted blueprint for comprehensive assessment of GPS in Europe.

\section{Introduction}

There is consensus among licensing bodies that the assessment of general practitioners (GPs) at the end of vocational training requires regular follow-up assessments for reaccreditation and educational purposes during their professional career. ${ }^{1.2}$ Such assessments need not only to be valued as a minimum gurantee to the public that physicians are competent, but also as a major contribution to reaching higher quality of care for patients., For the assessment of practising physicians the same prerequisites hold as for assessment at undergraduate level: the methods should be valid, reliable, feasible and acceptable. "Validity" refers to the proposed content of the assessment: it should measure what it is supposed to measure. An important phase in developing an assessment procedure is the definition of what is to be tested, assuming that the purpose of the assessment has been determined. This definition forms the basis for evaluating the content validity." The approach to determining what is to be tested consists of three steps. First, the clinical problems the GP should 
be able to handle must be identified. Second, for each problem the clinical tasks in which the GP is expected to be competent should be defined, and finally a blueprint to guide the selection of problems to be included has to be prepared. ${ }^{6}$ In different countries the first two steps have resulted in a job description, consisting of an analysis of the functions and tasks most critical for health care in the setting of general family practice. 7.89 The development of a generally accepted blueprint is the next step. Such a blueprint should cover the extensive and complex domain of general practice, including recent developments in medical management of patients, e.g. new medical techniques, recent insights in communication and problem-solving strategies, and dimensions of practice organization. No single assessment method will cover all these aspects. A blueprint for a comprehensive assessment approach may therefore be more suitable. ${ }^{10}$

Moreover, it is necessary to define under what conditions the assessment will take place. Will the clinical practice be observed or a simulated situation, or will written papers or other indirect tests be used?" Since there is considerable experience with competence-based assessment methods in undergraduate curricula and vocational training, it is tempting to use these methods for assessment of practising GPs as well. However, practising GPs are different from medical students and GP trainees: experienced GPs have developed their own working style, they take care of a relatively stable patient population, and they usually manage their own practices. ${ }^{1 ., 14}$ Some of these aspects are not addressed in undergraduate assessment methods, rendering these unsuitable for assessment of practising GPs.

In addition, GP assessment may be more effective when it is embedded in Continuing Medical Education (CME) and quality assessment..,15 A model for the assessment of GPs might be more useful if it is in line with CME programmes.

Finally, after preparing a blueprint, test methods should be chosen and implemented. ${ }^{6}$ An insight in recent methods used in the health professions education is therefore required. ${ }^{16}$

The objective of this paper is to present an overview of these issues in order to present an up-to-date model for the comprehensive assessment for practising GPs. First, relevant frameworks used in general practice care and medical education are described. Second, a view is given of the competence, performance, and medical expertise of experienced GPs. Third, some important aspects of CME and quality improvement are highlighted. Fourth, recent developments of assessment methods are addressed. Finally, a new model is presented which reflects these issues. This model is proposed as a tool for further validity studies and for implementation of assessment in general practice. An example of application of this model in daily practice is presented.

\section{Methods}

Computerized searches were conducted of the relevant English-language literature on conprehen sive assessment in general practice published between 1983 and 1997 with the help of Medline and Eric databases using the following keywords: performance, competence, assessment, biueprint, 
model, family physicians, general practitioners, general practice and medical education.

A.most all articles retrieved describe the assessment of patients by doctors as regards patients" health state in relation to different diseases. Therefore, another strategy was added. Proceedings, ${ }^{17223^{3}}$ books and articles about assessment of clinical competence, CME and quality improvement were consulted. These methods focused on data useful for the construction of an assessment model for practising GPs. A systematic review was not the objective. Findings conceming existing frame-

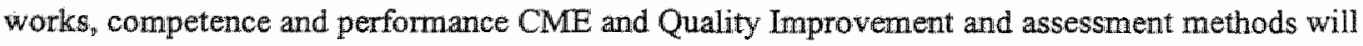
be presented and discussed to some extent.

\section{Existing frameworks and models for assessment}

Although much has been written about the competence of medical students, GP-trainees and GPs, recent attempts to systematically describe a model or blueprint for the comprehensive assessment of practising physicians seem to be lacking.

A classic framework for measuring quality has been described by Donabedian: the triad of structure, process and outcome. ${ }^{\text {Is }}$ In this triad, structure describes the physical features of health care, emphasizing surgery premises, equipment, medical records and other aspects of practice management, whereas process refers to clinical interactions and communication between doctors and patients. The synonym for process is actual performance, defined as what a doctor is doing in daily practice in medical care and in communication with patients. ${ }^{24}$ Outcome is defined as the changes in a patient's current and future health status that can be attributed to past health care. Good measures of outcome are difficult to devise, since many presenting symptoms in general practice never crystallize into recognizable clinical entities. Self-limiting and chronic multifactorial diseases may run their own course, making it difficult to attribute change in a patient's condition to single interventions by GPs and/or specialists. Therefore, assessment mainly focuses on structure and process. Fabb presented a three-dimensional cube with the axes: 1 . clinical competencies, 2 . intellectual skills, attitudes and manual skills and 3. skills in managing health problems in all age groups ${ }^{25}$ Each axis consists of 5 to 9 categories, so that over 200 atomistic aspects of general practice are distinguished. Using this model, the comprehensive assessment of GPs' competence may consist of a series of 15 different test formats, each test assumed to address (parts of) a specific "domain". In addition, Fabb decided to weight different tests in order to reflect the relative importance of the components of the assessment procedure.

This model is mainly competence-based. It does not reflect the distinction between competence and performance. For example, the domain of practice management has been described on the level of doctor's skills (capability, competence), not on the actual structure or organization of the practice. The third model is the "pyramid" of Miller. ${ }^{26}$ In contrast to the aspect-dimensions of Fabb, Miller presented a concept-oriented approach. At the base of the pyramid there is the concept knowledge: a student or a physician "knows" what is required in order to carry out professional tasks effectively. To fulfill that broader objective, he or she must know how to use the knowledge in applied 
situations ("knows how"), subsequently followed by "shows how": the demonstration of their competence when faced with a patient. Finally, after certification, a doctor works independently in a clinical practice ("does"). Miller pays considerable attention to standardized patients, the instrument of choice for the "knows" and "shows" levels. However, this model lacks the incorporation of general practice domains such as commumication, medical performance and practice management. No descriptions are given how the "does" should be assessed.

Finally in literature many different terms have been used for similar concepts: domains and dimensions, skills and competence, practice organization and practice management. The development of a generally accepted blueprint for assessment of GPs is likely to be hampered by this language profusion. An international accepted glossary is needed.

We suggest dividing the domain of general practice care in three sub-domains: medical performance, communication with patients including GP's attitude, and practice management. The first two sub-domains together represent "process", the third represents "structure".

\section{Competence, performance and medical expertise}

The different ways of thinking about knowledge, competence, performance and expertise also need to be addressed when developing a blueprint. ${ }^{11}$ Competence can be defined as the GP's capability to successfully perform series of discrete observable tasks in isolation from actual work and performance as what a GP is doing in his day-to-day practice while integrating these tasks. ${ }^{12}$ Thus, competence can be defined as the capability of an individual to act at the required level in a given situation, whereas performance describes the actions of the individual when, in reality, confronted by this situation. This distinction is critical for general practice. The competent, however defined, does not always perform competently. ${ }^{24,27}$ Competence and performance should therefore both be included as different constructs in a blueprint for the assessment of GPs.

Descriptions of clinical competence of practising GPs have graduated from a traditional view, addressing competence as an accumulation of knowledge, skills and attitudes, relatively stable and distinct from each other ${ }^{28}$ to the current view today based on cognitive psychological literature, how and when physicians act professionally. ${ }^{29.30}$ In the development of professional expertise isolated facts are increasingly encapsulated into knowledge networks, to become condensed into patterns of signs and symptoms. This process is mostly the result of individual experience and clinical exposure, known as "illness scripts" ${ }^{31}$ Reasoning then is no longer needed to arrive at the right conclusion: in many cases the doctor compares new problems with those encountered before. ${ }^{32}$ The doctor includes facts related to the context, e.g. the medical and individual history of the patient. ${ }^{33}$ Recognition and interpretation of these contextual factors determine the diagnostic accuracy of general practitioners. ${ }^{34}$ These findings clarify that the process of acquisition and use of expertise is closely linked to actually seeing patients and their context. Any assessment of practising GPs, either written tests or direct observations, should include this view on medical expertise. 


\section{Continuing Medical Education and Quality Improvement}

Continuing Medical Education (CME), such as reading, audit, research, teaching and discussion with colleagues, is essential to maintain up-to-date competence i.e. knowledge, attitudes and skills, in order to ensure the quality of health care. ${ }^{35,36,37}$ However, it has not been demonstrated that those methods influence doctors' actual performance, i.e. behaviour in practice. ${ }^{38.39 .40}$ After reviewing 777 papers, Davis and his colleagues found 50 satisfactory randomized trials, of which only 18 studies showed any positive effect of CME on patient outcomes. ${ }^{41}$ No evidence of the magnitude of reported changes in doctors' performance was presented. The practical sigmificance of these results is therefore questionable. ${ }^{42}$ However, the review also shows that CME is more effective when it incorporates practice-based enabling and reinforcing strategies (practice guidelines, feedback) and that adequate assessment of physicians' needs leads to increased potential for change. ${ }^{41}$ Further research is needed to ascertain which types of CME actually influence doctors' behaviour and improve the outcome for patients, ${ }^{43}$ but practice-based strategies seem to be a fundamental requirement.

Quality Improvement is a complex of systematic and contimuous activities including guidelines and goals for good performance, the assessment of actual performance and actions aimed at changing performance, when necessary. ${ }^{44,45,46}$ Real improvement in quality depends on evaluating and revising the production processes on the basis of data about the actual processes themselves. ${ }^{3}$

Both CME and Quality Improvement activities must have their focus on evaluation, i.e. assessment, of actual performance and data obtained from actual practice. A blueprint for the assessment of GPs should therefore be practice-oriented.

\section{Assessment of professional competence and performance}

Traditionally, medical assessment was based on the unstandardized apprenticeship model, accompanied in the 1960 s by the widespread introduction of multiple choice questions (MCQs). However, according to the critics, selecting alternatives from a list of options is considered to be rather trivial and a poor reflection of clinical competence. ${ }^{47}$ Therefore specific attempts were made to measure clinical reasoning ability or problem solving using written simulations of patient problems like the Patient Management Problem (PMP). ${ }^{48}$ However, disappointing outcomes such as case specificity (a score derived from one problem was not very predictive for a score on another problem), and low construct validity (experienced clinicians scored hardly better than students; high correlations with MCQs were found) presented major practical and theoretical problems. New methods were introduced which assessed examinees in standardized live simulations of clinical situations using standardized patients, such as the Objective Structured Clinical Examinations $(\mathrm{OSCE}){ }^{49}$ Aspects of problem solving, patient management, communication and attitude were measured as integral parts of clinical performance. However, case specificity, inherent in any assessment method, necessitated long testing time, a sampling of many stations and hence requiring considerable resources. Moreover, the predictive value of those methods for actual performance 
remained questionable. ${ }^{12}$ Finally, procedures for direct observation of $\mathrm{GP}$-trainees and $\mathrm{GPS} b y$ video assessment in daily practice have recently been developed. ${ }^{50.51}$

A common denominator in all assessment developments is the progressive approximation of the real practice situation in the test situation, while maintaining standardized test-iaking conditionts Although it is perhaps administratively more easy to test, for example, knowledge and shlis separately and unrelated to practice context, it seems more useful to tailor assessment to practice situations, paying attention to the patient's contextual factors (risks factors, age, gender, medical and personal history) as important determinants of the GP's diagnostic accuracy.

We conclude that a model for GPs' assessment should cover the broad domain of general practice care, i.e. practice management (structure), communication with patients and medical performance (process). Assessment of patient outcomes needs further research. Secondly, we conclude that such a model should reflect the distinction between competence and performance, and the present view on medical expertise, focusing on the important role of contextual factors in actual practice. Finally, assessment procedures have developed from knowledge tests through written and live simulations to observation of actual performance and to analysis of data obtained in actual practice. $\mathrm{CME}$ and Quality Improvement are practice-oriented as well. Any assessment procedure of GPs should reflect these developments if it is to be comprehensive and effective.

\section{A new model for comprehensive assessment of GPs}

Although mainly focused on competence, Fabb's model has most systematically approached comprehensive assessment in general practice. In contrast to Fabb, Miller's pyramid reflects the processes of clinical reasoning and the distinction between competence and actual performance. However, domains to be assessed are not mentioned nor are assessment procedures.

We suggest combining both models in a new pyramid model in order to profit from their complementary benefits. The new model reflects: contextual factors as the general feature in medical expertise, the difference between competence and performance; the practice-orientedl approach of $\mathrm{CME}$, Quality Improvement and assessment procedures of the health professions.

This new three-dimensional model is presented in figure 1. As can be seen, the model builds strongly on Miller's pyramid, but there is clear distinction between competence (the three bottom lines) and performance (the top) on the vertical axis. Three sub-domains in general practice are represented on one axis: medical performance, communication with patients and practice management. Finally, diseases and complaints of patients, including contextual factors as important features of general practice, are represented on one axis as well, ordered according to chapters of the International Classification of Primary Care (ICPC). ${ }^{53}$ Aspects of Fabb's approach such as patient categories have thus been included. Using this model, tasks related to the three sub-domains can be connected with different diseases and complaints of patients and 
FIOURE 1. THE PYRAMD ASSESSMENT MODER

Performance

\section{Competence}

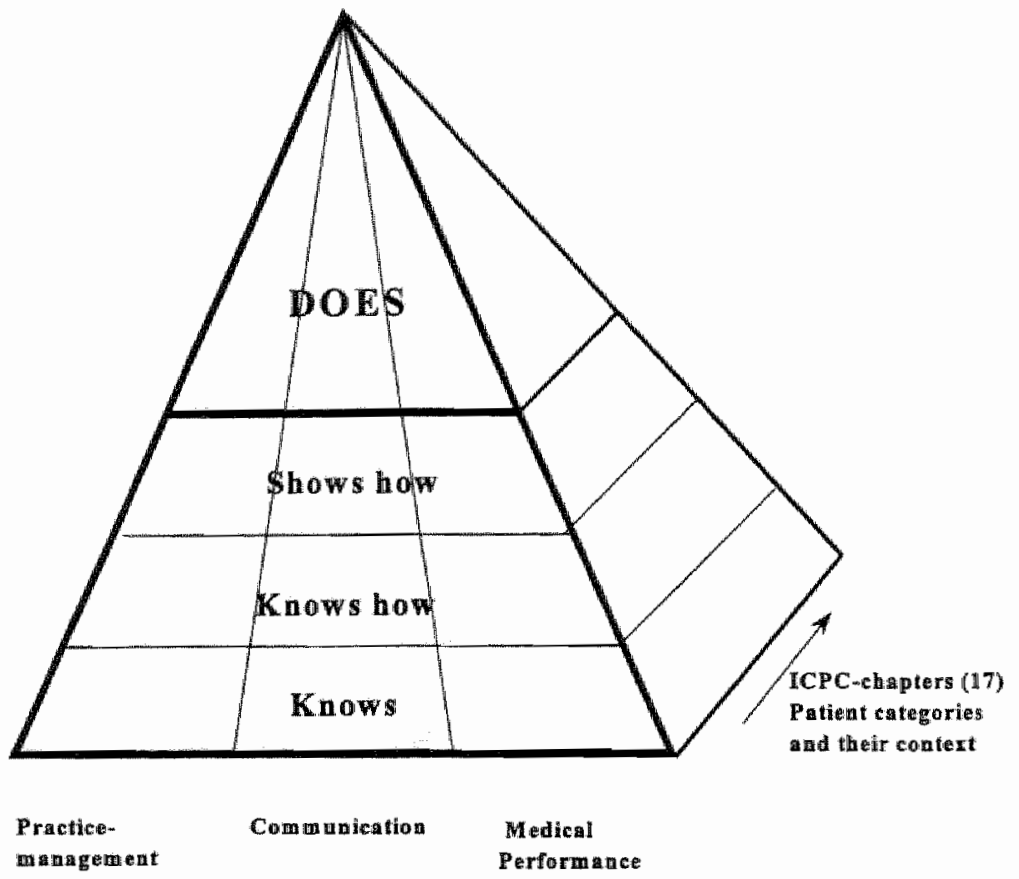

their contexts, whereas the assessment level, i.e. competence or performance, cam be indicated. The top has a symbolic intention too: actual communication and medical performance (both process) and practice management (structure) finally produce patient outcomes, the ultimate target for quality of care. ${ }^{15}$

\section{Practical and theoretical use of the new comprehensive assessment model}

In contrast to former models, this model allows test developers to define in advance precisely their objective for testing, i.e. what should be assessed, and where and how. For each of the domains and for each level the optimal assessment instrument can be chosen. The purpose of this model is to guide test developers in choosing very carefully the design of a comprehensive assessment.

A practical approach in using this blueprint is suggested in figure 2. The levels "knows" and "knows how" could be assessed by written tests and the "shows how" level by standlardized tests in a laboratory such as an OSCE or a multiple station examination. Actual performance and practice management ("does") could be assessed by direct observation in daily practice and by practice visits. For each sub-domain, dimensions and sub-dimensions related to required tasks can be described. In this example, practice management is not assessed on the "shows how" level, as can be seen. 


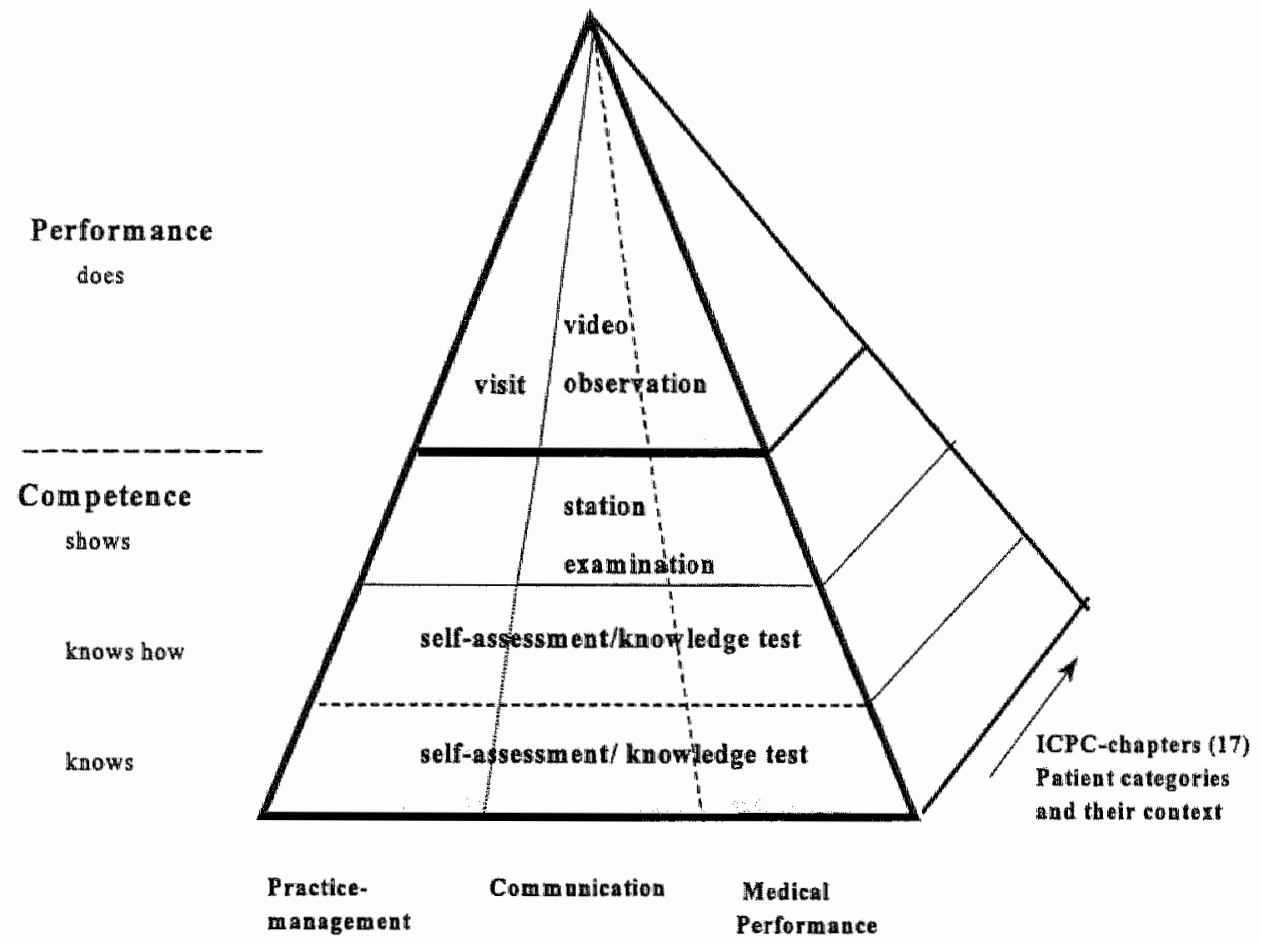

This model was presented and, to our opinion, well accepted at the 8th Ottawa Conference in Maastricht, the Netherlands (1996) ${ }_{x}^{23}$ and at the seminar on the state of the art in "Educational assessment in generall practice", organized by the European Academy of Teachers in General Practice (EURACT) in Bled (1997), Slovenia. Using this model, effective communication on this subject between representatives was supported.

\section{Conclusion}

Our model can be helpful in the systematic analysis of the relation between "structure and process". In this horizontal approach, the relation between different structural aspects as well as the relation between process aspects, i.e. communjcation and medical performance, can also be analysed. In the verticall approach the relation between knowledge, competence and performance can be studied systematically for each sub-domain. An analysis of the relationship between process and structure and between competence and performance may ultimately provide insight into the way these 
factors contribute to outcome. Factors which contribute to outcome fallures may be identified and localized more precisely. Finally, this model allows further analysis of the predictive value of knowledge tests, station examinations and aspects of practice management, such as data on medical records, presence and use of equipment, for actual performance. These issues are imporiant in order to select adequate, valid, reliable and feasible assessment procedures in general practice.

\section{References}

1. Campbell LM, Murray TS. The assesment of competence. BT J Gen Pract 1996; 46:619-22.

2. Windak A. A survey of curent reacceditation and recertification procedures in Europe. Cambridge: EURACT Council 1995.

3. Berwick DM. Continuous improvement as an idea in health care. New Engl Joum of Med 1989; 320:53-50.

4. Rethans JJ, Westin S, Hays R. Methods for quality assessment in general practice. Fam Pract 1996; 5: 468-76.

5. Ebel RL, Frisbie DA. Essentials of educational measurement. Englewood Ciff, New Jersey: Prentice Hall, 1986.

6. Newble $\mathrm{D}$, Jolly $B$, Wakeford $\mathrm{R}$. The certificanion and recertification of dociors: issues in assessment of clinical competence. Cambridge University Press, 1994

7. Royal Australian College of General Practitioners. The scope of General Family Practice. Melboume: RACGP, 1981:378.

8. Royal College of General Practioners. What sort of doctor? Joumal of the Royal College of General Practitioners $1981 ; 31: 698-702$

9. Springer MP, ed. Basic job description for the general practitioner. Utrecht: Dutch National Association of General Practitioners, 1983.

10. Neufeld VR, Normar GR, eds. Assessing chinical competence. New Youk: Springer Publishing Company, 1985:51-71.

11. Rane MT. The assessment of professional competence. Evaluation \& the Health Professions 1992; 15:163-82.

12. Rethens JI, Stumanis $F$. Drop MJ et al. Does competence of general practitioners predict their performance? Br Med $\sharp$ 1991: $303: 1377-80$.

13. Baker R. General practice in Gloucestershire, Avon and Somerset: explaining variations in standards. Br J Gen Pract $1992 ; 42: 415-8$

14. Hobus PPM, Schmidt HG, Boshuizen HPA, Patel VC. Contextual factors in the activation of first hypothesis expertnovice differences. Med Educ 1987; 13:175-81.

15. Donabedian A. Explorations in quality assessment and monitoring. 1. The definition of qually and approaches to its assessment. Amm Arbor: Health Administration Press, 1980.

16. Pendleton $D_{k}$ Schofield $T$, Marinker $M$, eds. In pursuit of quality. Approaches to performance review in general practice. Royal College of General Practitioners, 1986. The Devonishire Press, Devon.

17. Hart IR, Harden RM, Walton HI, eds. Newer developments in assessing clinical competence. Montreal: Heal Publicathons Liti, 1986.

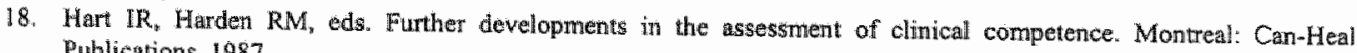
Publications, 1987.

19. Bender W, Hemstra RJ, Scherpbier AJJA, Zwierstra RP eds. Teaching and assessing clinical competence. Groningen: Bookwerk Publications, 1990.

20. Hart IR, Harden $R$ M, Des Marchais $J$, eds. Cursent developments in assessing clinical competence. Monmeal: Can-Heal Publictations ine, 1992

21. Harden RM, Hart IR, Mulholland $\mathbb{H}_{\text {a }}$ eds. Approaches to assessment of clinical competence. Pant I and Part M. Norwich:
Page Brothers, 1992 .

22. Rothman AJ, Cohen $\mathrm{R}$, eds. Proceedings of the sixth Ottawa conference on medical education. Toronto: Universiny of Toronto Bookstore Custom Publishing, 1995.

23. Seherpbier AJA, Vlenten van der CPM, Rethans JJ, Steeg van der AFW, eds, Advances in Medical Educalion. Kluwer Acacternic Publishers, Dordrecht 1997. The Netherlands. 24. Rethans JJ, van Leeuwen $Y$, Drop R. at al. Performance and competence: two different constructs in the assessment of
quallity of medical care. Fam Pract $1990 ; 7: 168-74$.

25. Fabo WE, Marshilh IR. The assessment of climical competence in gemeral family practice. MTP Press Limited. Lancaster, Fingland and Hingham, USA 1983.

26. Miller GE. The assessment of clinichl skills/competence/perfomance. Acad Med 1990; 65:S63-\$67. 
27. Stanley $I$, Al-Shehri A, Thomas P. Continuing education for general practice. 1. Experience, competence and the media of self-directed learning for established general practitioners. Br J Gen Pract 1993; $43: 210-14$.

28. Sackett DL, Haynes RB, Tugwell P. Clinical epidemiology. A basic science for medicine. Boston/Toronto: Little, Brown and Company, 1985.

29. Patel VL, Groen GJ. Knowledge based solution strategies in medical reasoning. Cognit Sei 1986; 10:91-116.

30. Schmidt $H$, Norman G, Boshuizen HA. Cognitive perspective on medical expertise: theory and implications. Acad Med 1990;65:611-21.

31. Feltowich PJ, Barrows HS. Issues of generality in medical problem solving. In: Schmidt HG, De Volder ML, eds. Tutorials in problem based learning; a new direction in teaching the health professions. Assen: wan Gorcum, 1984: 12842.

32. Grant I, Marsden $P$. The structure of memonized knowledge in students and clinicians: an explanation for diagnostic expertise. Med Educ 1987; 21:92-8.

33. Boshuizen HPA. De ontwikkeling van medische expertise. Een cognitief-psychologische benadering [Dissertation]. [The development of medical expertise. A cognitive psychological approach]] Masstricht: Rijkssumiversiteit Limburg. 1989.

34. Hobus P. Expertise van huisartsen [Dissertation]. [Expertise of general practitioners.] Maastricht: Rijksumiversiteit Limburg, 1994.

35. Forrest JM, McKenne M, Stanley IM et al. Continuing education: a survey among general practitioners. Fam Pract $1989 ; 6: 98-107$.

36. Savage R. Continuing education for general practice: a life long joumey [editorial]. Br I Gen Pract 1991; 41:311-14.

37. Anonymous. Continuing medical education [editorial]. Lancet 1993; 342: 1497-98.

38. Mamning PR, Petit DW. The past, present and future of continuing medical education. Achievement and apportunities, computers and recertification. JAMA $1987 ; 258: 3542-6$.

39. Al-Shehri $\mathbb{A}$. The market and educational principles in continuing medical education for general practice. Med Educ $1992 ; 26: 3.84-88$.

40. O'Dowd TC; Sprackling PD. Continuing medlical education in general practice. Br Med I 1989; 298: 1472.

41. Davis D, Thomson MA, Oxman AD, Haymes B. Evidence for the effectiveness of continuing medical education. JAMA 1992; $268: 1111-17$.

42. Hayes TM. Continuing medical education: a personal view. Br Med J 1995; 310: 994w6.

43. Nicol F. Making reacereditation meaningful. Br J Gen Pract 1995; 45: 321 4.

44. Grol $R$, Wensing $M$, Jacobs $A$, Baker $R$. Quality assurance in general practice. The state of the art in Europe. NHG and EQuiP, 1993. Utrecht, the Netherlands.

45. Berwick D. Heal thyself or heal the system: can doctors help to improve medical care? Quality Health Care 1992; I(Suppl):S2-\$8.

46. Grol R. Quality of care in general practice: into the next century. Huisarts Wet 1993; 36: 467-72.

47. Newble DI, Baxter A, Elmslie $G$. A comparison of multiple choice and free response tests in examination of clinical competence. Med Educ 1979; 13: 263-8.

48. Mc Guire $\mathrm{CH}$, Babnot D. Simulation technique in the measurement of problem solving skills. Joumal of Educational Measurement 1967; 4:1-10.

49. Harcen R, Gleeson F. Assessment of climical competence using an objective structured clinical examination (OSCE). Med Educ 1979; 13:41-54

50. Campbell LM, Howie JGR, Murray TS. Use of videotaped consultations in sumrotative assessment of trainees in general practice. Bi J Gen Pract 1995; 45: 137-141.

51. Ram PM, Grol RPTM, Rethans J, Schouten B, Van der Vleuten CPM, Kester A. Assessment of General Practitioners by video observation of medical and communicative performance in dally practice: issues of validity, reliability and feasibility. Accepted by Medical Education.

52. Van der Vleuten CPM. The assessment of professional competence: developments, research and practical implications. Advances in Health Siciences Education. Theory and practice 1996;1:41-67.

53. Lamberts $\mathrm{H}$, Wood M, eds. ICPC. International Classification of Primary Care. Ox ford: Oxford University Press, 1987. 
Chapter 2.

\section{Assessment of general practitioners by video observation of communicative and medical performance in daily practice: issues of validity, reliability and feasibility.}

Accepted by Medical Education as: Assessment of general practitioners by video observation of communicative and medical performance in daily practice: issues of validity, reliability and feasibility. Paul Ram, Richard Grol, Jan Joost Rethans, Berna Schouten, Cees van der Vleuten \& Amold Kester. 


\section{Summary}

Objectives: To develop a video assessment method for General Practitioners (GPs) by analysing issues of validity, reliability and feasibility of observation of videotaped regular consultations.

Methods: In a cross-sectional study consultations of 93 GPs were video recorded in the practice during one week. The GPs registered consultation and patient data in a logbook; 16 consultations per GP were selected using preset criteria. The quality of communicative and medical performance of these consultations was assessed by GP observers with a validated instrument. The validity of the procedure was evaluated by checking the content of each GP's sample using specific sample criteria. Selection bias was estimated by multiple regression analysis, with sample characteristics as independent variables and scores on communication and medical performance as dependent variables. The influence of observation on GPs and patients was assessed by a questionnaire. Generalizability theory was used to estimate reliability. Feasibility was assessed by conducting a questionnaire, by keeping accounts, and by checking the technical quality of the videotaped consultations.

Results: The domain of general practice was well covered in the samples; content validity was satisfactory. As regards the sample characteristics, only the total duration of consultations appeared to correlate significantly with both the score on communication and the score on medical performance. A majority (71\%) of GPs reported not being influenced by the observation, except in the first cases, and recognizing their usual daily performance in the videotaped consultations. An acceptable level of reliability was reached after 2.5 hours observation, i.e. 12 cases by a single observer. The method was well accepted by both GPs and patients. The costs were $£ 250$ per GP.

Conclusion: Video assessment of GPs in daily practice according to the procedures described is a valid and reliable method, one which is useful for education and quality improvement. There is a trade off between feasibility on the one hand and validity, reliability and credibility on the other. Compared to investments in observation methods in standardized settings, the costs of video observation of GPs' actual performance are acceptable.

Keywords: video observation, assessment, performance, general practice. 


\section{Introduction}

Assessment of the performance of general practitioners (GPs) in daily practice can play an essential role in improving the quality of care GPs provide to patients. It has been shown that self-ratings of performance usually produce overestimation of service delivery, and that self-selected postgraduate education has little effect on changing practice behavior of doctors, objective assessment is preferred. ${ }^{1,2}$ If deficiencies in practice performance could be identified objectively, postgraduate medical education and quality improvement activities could be focused on GPs' insight into their deficiences and real educational needs in order to make them as effective as possible, ${ }^{3,4}$

It is uncertain which assessment method(s) should be used. Which have the highest validity and reliability, and which are feasible on a broad scale? One can distinguish between direct and indirect methods of quality assessment. ${ }^{5}$ With the former, clinical activities are observed directly. Indirect methods, on the other hand, infer clinical competencies from written or oral exams, from chart review, from assessment of referral letters or from data from insurance agencies. A direct method can be applied both in the day-to-day practice and in a laboratory setting. Direct observation of actual performance in daily practice has the highest validity, since this method approximates the real professional world as closely as possible. ${ }^{6}$ Direct observation is possible by thaving standardized patients (SPS) or peer observers visit the practice or by placing video-equipment in the practice. Although used in daily practice, SPs present logistic difficulties. ${ }^{7}$ It is demanding for SPs to observe the complex processes involved in medical care and communication. Practice visitation by peer observers may disrupt real practice and requires considerable resource investments. On the contrary, video recordings of consultations can be judged by different trained observers without consultations being disrupted; there are, however, problems conceming validity, reliability and feasibility.

Validity might be reduced by the "audience effect": both GPS and patients could be influenced by the video recording. ${ }^{8}$ Moreover, the logistics of performance testing often restrict the sellection of consultations to be included into the assessment, thus incurring the risk that the sample may not be representative of actual patient care."

Reliability might be influenced by the content specificity problem: for example, the predictive value of a mark, acquired with a case concerning cystitis to one dealing with angina pectoris turns out to be very low. ${ }^{10}$ Moreover, reliability could suffer from the unstandardized and complex. problems as they are presented in day-to-day practice. The optimal management of a complex problem in a specific daily context may not be immediately apparent and experts may disagree in grading the quality of performance. A key issue yet to be determined is the duration of observation and the number and range of cases that need to be observed to give a reliable judgement of performance. Even under standardized conditions the testing time required to achieve an acceptable level of reliability appears to be a limitation of such an assessment method." 
As for feasibility, both ethical, practical and technical aspects may limit the use of video asssessment. Wideotaping all aspects of the complex care process, including physical examination, may be difficult, while acceptance by the target group may be hampered by fear of abuse of tapes." Also, there are no reports on the cost of video assessment. While various problems can thus be expected in applying video assessment in the practice of GPs, videotapes of daily consultations are already being used succesfully, for example in the United Kingdom in the selective assessment of GP-trainees and in the Fellowship by Assessment of the Royal College of GPs. ${ }^{13.14}$ The latter has been revised recently to be more objective. However, issues concerning validity, reliability and feasibility need further investigation in order to support this method for both selective and educative purposes.

In order to investigate the problems mentioned above, a study was conducted focused on video assessment of both GPs" communication with patients and medical performance. The following questions were posed: how might consultations be identified and selected for a valid assessment; how reliable is video assessment considering the number of consultations and observers; how feasible is this method conceming technical aspects, logistics, costs and acceptance by GPs and patients?

\section{Methods}

\section{Subjects and procedure}

In a cross-sectional study, consultations of general practitioners were videotaped during one week in their own practice. All general practitioners in the south of the Netherlands were invited by letter to participate in this study; $220(25 \%)$ were willing to do so. For budgetary reasons 135 GPs were selected randomly, 100 of them to be videotaped, the other 35 to act as peer observers to score performance. Personal and professional characteristics of the participants (see Table 1) were collected and compared to the national population of GPS to determine representativeness (T-test and Chi-Square tesit) and confounding. ${ }^{\text {is }}$

A videowobservation system, consisting of two cameras with built-in microphone, a monitor and a recorder, was unstalled by trained electricians in each practice. All consultations were recorded both in the consulting room and the examination room. The GP was responsible for switching from one camera to the other when necessary, and for recording patient and consultation data, such as the patient's age and gender, (number of) complaints and duration of consultation (see table 2), into a logbook directly after the consultation. The receptionist informed patients about the video recording and asked permission. Consent was registered by giving the patient a coloured card (green = consent, red $=$ no consent) to be handed to the GP at the start of the consultation. Video registrations were erased if patients revoked their permission. 


\section{Evaluation of walidity}

To achieve a satisfactory content validity, a blueprint for the practice video assessment was designed, based on prevalence of complaints and diseases in general practice and on a nationally accepted job description. ${ }^{16,17,18,19}$. With this blueprint ten specific criteria were formulated for selecting a representative sample of consultations per doctor for the final assessment (see Table 2).

TABLE 1. CHARACTERISTICS STUDY POPULATHON (N=93) AND POPULATION DUTCH GENERAL PRACTTIONERS (N=6549) IN PERCENTAGES, EXCEPT FOR, AGE

\begin{tabular}{lcc} 
& study-populatior & Dutch GPs \\
\hline gender : male & 88 & 85 \\
solle practice & 44 & 51 \\
college member & 71 & 69 \\
urban area & 54 & 59 \\
GP trainer/postgraduate trainer & 55 & n.a.* $^{*}$ \\
age (mean, yrs) & 43.1 & 44.3 \\
\hline
\end{tabular}

*n.at. $=$ not applicaple

TABLE 2. SAMPLE CRTTERIA FOR SELECTING CONSULTATIONS TO BE INCLUDED IN DATA ANALYSIS WTTH PERCENTAGE OF SAMPLES WHICH MET THE CRITERION FULLY

sample criteria

representativeness of a 8 different ICPC chapters

2. the first 5 videotaped consultations not included

3. at least 8 cases with accepted guidelines

4. representativeness of $5 \mathrm{ICPC}$ chapters with highest prevalence: $D, K, L, R$ and $S$

5. at least 14 cases with duration $\geq 5$ and $\leq 15$ minutes / case

6. age distribution: youngest patient $<18$ years and oldest patient $>65$ years

7. gender heterogeneity: 26 and $\leq 10$ female patients

8. at least 8 initial consultations, at least 4 follow-up consultations

9. maximum 2 cases with $>2$ reasons for encounter

10. samples in which criterion was fully met (\%) 100.0 94.6 86.2 $7 ! .3$ 86.2 84.0 72.3 70.2

The first criterion, the selection of sufficient different cases, received highest priority in order to solve the case-specificity problem. Using logbook data 20 consultations per GP, 16 for direct observation and 4 as reserve, were selected per GP. This number was expected to offer sufficient content validity and observation time for analysis. Since it is known that scores from the first cases to be assessed are less reliable than later ones, the first five cases were not included ${ }^{20}$ Validity was evaluated by checking each GP's sample with the specific sample criteria. Furthernore, the influence of differences in sample characteristics of each GP on the performance scores was measured by a multiple regression analysis, with performance scores as dependent variable and sample charac- 
teristics as independent variables. In this way the contribution of GPs personal and professional characteristics to performance scores was also analysed. Influence of the observation on GPs and patients and feasibility aspects were assessed by a questionnaire for GPs, containing 20 structured questions (five-point Likert scale). GPs were asked to score questions about recognition of their "usual working style", after they had viewed the selected consultations.

\section{Evaluation of reliability}

Consultations were assessed for communication and medical performance by using the MAAS-Global scoring list. ${ }^{21}$ This instrument, containing 12 items on the quality of communication with patients and 4 items on the quality of medical performance, is based on literature related to effective communication between GPs and patients and on guidelines for medical performance. Items are case-independent and global, but anchored with detailed criteria. They are scored on a 7 point Likert scale (Figure 1 and appendix). An extensive list of criteria is available. ${ }^{22}$

FIGURE 1. MAAS-GLOBAL: ITEM 8: PROVDING NNFORMATION

\section{GENERAL COMMUNICATION SKILLS}

PROWIDING INFORMATION

announcement, categorizing

in small amounts, concrete explanation

comprehensible language

asks about reaction and comprehension

$0=$ absent $1=$ bad $2=$ insufficient $3=$ doubtual $4=$ sufficient $5=$ good $6=$ excellent

Case scores were calculated by summing the item responses on the MAAS-Global for each case expressed as a percentage score. The mean score for the 16 cases, i.e. the sample, determined the total score of the participant GP. Scores were calculated for the two components: communication and medical performance, and for the overall consultation performance (communication score + medical performance score / 2). To estimate reliability, generalizability theory was used. This theory uses ANOVA procedures and variance component estimation to estimate "generalizability coefficients" ${ }^{23,24}$ For part of the data set - 25 GPs and 15 cases - cases were scored by pairs of independent peer-observers (raters). To avoid a Halo-effect, i.e. the tendency to rate a GP high (or low) in all areas being evaluated in a session if he or she scores high (or low) in one area, a maximum of 6 consultations per GP was assessed by the same rater. Because different raters were used for different daily practice cases, a "raters-nested-within-cases-within-persons" design was used, followed by variance component estimation. ${ }^{25}$ This design allows a concurrent estimation of the reliability of raters and cases.

From the variance components generalizability coefficients were estimated; this enables projection of the reliability from the actual number of cases used to other hypothetical test conditions with different sample sizes (see table 4). 


\section{Evaluation of feasibility}

Problems experienced by GPs and receptionists with the video installation, operating of the video equipment and the informed consent procedure were assessed by the "feasibility and influence on GPs" questionnaire. Furthermore, feasibility was measured by checking the technical quality of the videotaped consultations and particularly by checking the number of re-installations and spare consultations needed to complete the sample. Costs were calculated on the basis of accounts kept by all participants.

\section{Results}

\section{Subjects and drop-out}

Of 100 GPs seven (7\%) dropped out before video observation on the grounds that "participation is too threatening" (1\%) or that they were "too busy to participate" (6\%). As regards professional and personal characteristics the study population $(\mathrm{N}=93)$ was representative for Dutch GPs in all respects, except for average age (Mean is 43.1, SD 5.5 respectively Mean is 44.3 years, SD 7.4; $t=2.03 ; \mathrm{df}=92 ; \mathrm{p}<0.05$, Table 1).

\section{Validity}

A minimum of 40 and a maximum of 95 consultations were recorded and registered in the logbooks by the participants. The number of videotaped consultations was related to the number of (patients per) surgeries during video recording. In the selection of 16 cases it was possible to meet criterion 1: in all samples (100\%) eight cases from eight different chapters of the International Classification of Primary Care (ICPC) ${ }^{1 \%}$ were included (Table 2). Thus, at least eight of all 17 ICPC chapters were represented in each sample. A majority of samples also met the remaining criteria. In a multiple regression analysis, with GPs" characteristics as independent variables and performance scores as dependent variables, only the characteristic "sole practice" appeared to be a significant (negative) factor of influence on communication scores $(\mathrm{p}<0.05)$. GPs" characteristics had no predictive value for scores on medical performance $(p<0.05)$.

Multiple regression analysis indicated a significant association between the total duration of the 16 consultations of each sample (Mean 156.62, SD 19.62, Minimum 100, Maximum 200 minutes) with GPs' scores, on both communication and medical performance $(\mathrm{p}<0.001)$. The longer the duration of 16 consultations, i.e. the sample, the higher the total score.

In the questionnaire, $29 \%$ of physicians reported they were influenced constantly by the video observation: $12 \%$ considered the effect positive (i.e better consultations), while $1.7 \%$ believed the effect to be negative. Conversely, $42 \%$ of GPs thought they were not influenced at all while $29 \%$ considered that they were only influenced during the first cases. Since the first five cases have not been included in $95 \%$ of the samples, one may conclude that the majority of GPs felt they were not 
influenced by the observation. Moreover, $92 \%$ of the GPs recognized their usual style of performance, when they wiewed the consultations after the analysis.

\section{Reliability}

The range in scores and the standard deviation in Table 3 indicate a broad distribution of scores, on both communication and medical performance.

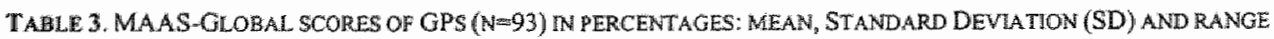

\begin{tabular}{lcc} 
& mean (SD) & \\
\hline commulitication & $41.7(7.4)$ & 25.8 .63 .9 \\
medical performance & $62.0(6.9)$ & $47.1-84.1$ \\
averall performance & $51.9(6.6)$ & $36.5-73.3$
\end{tabular}

Table 4 shows generalizability coefficients as a function of the number of cases, the corresponding estimated testing time, and number of raters. Each entry represents a reliability estimate for the given sample sizes of cases and raters. An arbitrary "benchmark" of 0.80 is usually considered as a minimal acceptable value. This means that when an infinite number of similar tests is applied randomly to the same GPs with different cases in each test and different raters for each case, the average correlation expected between the scores of these tests would be $>0.80$. Using 2 raters, this value is found after 8 cases (i.e. 96 minutes) on the overall score, and on both communication and medical performance after 12 cases (i.e. 144 minutes). For one rater this level was reached after 12 and 16 cases respectively.

TALLE 4. RELIALITY: GENHERALIZABLLTY COEFICIENTS AS A FUNCTION OF THE NUMBER OF CASES AND RATERS

\begin{tabular}{|c|c|c|c|c|c|c|c|}
\hline \multicolumn{2}{|c|}{ sample sizo } & \multicolumn{6}{|c|}{ performance } \\
\hline \multirow[b]{2}{*}{ calses } & \multirow[b]{2}{*}{ minutes } & \multicolumn{2}{|c|}{ overall } & \multicolumn{2}{|c|}{ communication } & \multicolumn{2}{|c|}{ medical } \\
\hline & & 1 tater & 2 raters & 1 rater & 2 raters & I rater & 2 raters \\
\hline 4 & 48 & 0.58 & 0.68 & 0.55 & 0.65 & 0.52 & 0.63 \\
\hline 8 & 96 & 0.74 & 0.81 & 0.71 & 0.79 & 0.68 & 0.78 \\
\hline 12 & 144 & 0.81 & 0.87 & 0.79 & 0.85 & 0.76 & 0.84 \\
\hline $16^{*}$ & 192 & 0.95 & 0.90 & $0: 83$ & 0.88 & 0.81 & 0.87 \\
\hline 20 & 240 & 0.87 & 0.91 & 0.86 & 0.90 & 0,84 & 0.90 \\
\hline
\end{tabular}

*actual sample size used 


\section{Feasibility}

In $3 \%$ of the installations, the video equipment had to be re-installed due to an erroneous operation by GPs; a further $5 \%$ of selected consultations had to be replaced by "spare" consultations on account of inadequate sound or vision quality. Thus $92 \%$ of consultations were recorded adequately in first instance, in both consulting rooms and examination rooms. Questionnaire data (response level $91 \%$ ) showed that $82 \%$ of GPs considered the informed consent procedure clear; $85 \%$ of patients gave their permission to record. A minority of GPs (10\%) considered video recording a burden for patients. Completion of the logbook took $92 \%$ of GPs less than 1 minute per case. Selection of consultations from the logbook by the researcher took 1 hour per participant. Peerobservers compared the logbook data with the content of video recordings and in $5 \%$ of cases logbookdata appeared to be incomplete.

Table 5 provides an estimate of costs for two different sample sizes of consultations. One video set ( $\& 800$, to be depreciated within 4 years) was used by 14 GPs, which reduced costs to $£ 15$ per GP. Peer-observers were paid $£ 15$ per hour and the electrician was paid $£ 10$ per hour.

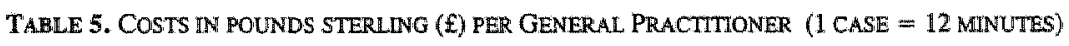

\begin{tabular}{lcc}
\hline & 12 cases & 16 cases \\
equipmeat & $15^{*}$ & $15^{*}$ \\
videotapes & $15^{*}$ & $15^{*}$ \\
instaillation & $50^{*}$ & $50^{*}$ \\
one observer & 75 & 100 \\
adrninistration & 45 & 60 \\
review logbook & 20 & 25 \\
raters training & $30^{*}$ & $30^{*}$ \\
notal & \pm 250 & $£ 295$ \\
\hline
\end{tabular}

* g.tible rosts

\section{Discussion}

To our knowledge this is the first study which systematicly addresses issues of validity, reliability, and feasibility of a video procedure for assessing both communicative and medical performance of general practitioners (GPs) in daily practice. A blueprint including a procedure for sampling of consultations by using selection criteria has been developed. Generalizability, i.c. relliability considering number of cases and observers, and aspects of feasibility, especially costs, were taken into account. In this way, a valid and reliable assessment procedure has been established. Results on acceptance should be interpreted with care since our study population participated voluntarily and the assessment was educative, not summative. 
Concerning validity, the results show clearly that the domain of general practice was covered extensively by the procedures followed and a satisfactory content validity was obtained. Eight different ICPC chapters were represented in each sample. Concerning this classification system, it is estimated that the use of other classification systems will lead to the same conclusions. In addition, sufficient initial and follow-up consultations with both elderly patients and children were included, which support the representativeness of daily practice care. Our sample criteria, formulated for the selection of 16 cases, were well met. The lack of control over the case selection process, one of the major disadvantages of an observation in practice, ${ }^{26}$ was prevented by this procedure. Strict sample uniformity does not seem desirable anyway, since a sample has to be representative for an individual GP. It should reflect differences between GPs as regards characteristics of their patient population, workload, working style and their perception of tasks. ${ }^{27,28}$ The variation in total duration of consultations of each sample may reflect these differences. The positive relationship between the total duration of the samples and GPs' scores on communicative and medical performance is in line with previous research. ${ }^{29,30}$ The negative relation between working single handed and high score of communication with patients may be explained by the contrasting difference with more partner practices, where collaboration must rely on communication and delegation of tasks within a team. Compared with selection of cases by candidates, case selection from the logbook by an external reviewer using preset criteria, prevents sampling bias. The logistics of producing 90 consultations should not be underestimated. However, provided that the videoequipment has been installed and the informed consent procedure has been handled at the desk, GPs spend on average one minute per case to fill in the logbook and patient care can be continued normally. Moreover, continuous videotaping regular consultations during several days increases the chance to observe what a doctor is doing in his day-to- day practice; this might be different from what a doctor is capable of doing. ${ }^{3 .}$

Finally, as regards validity, with two cameras actual performance was followed as closely as possible. Physical examination and concurrent communication are essential aspects of performance. Therefore, validity of video assessment in daily practice increases if equipment is able to record consultations in both consulting and examination rooms. Switching cameras by the GP intrudes on normal surgery routine, on the other hand, having others to operate equipment may entail high costs $^{32}$ An automatic switching system could solve this problem, which may decrease the audience effect.

We may conclude that the validity of this video assessment of GPs in daily practice is high.

The reliability results are encouraging, particularly considering the limitations in standardization of practice assessment. This is actually comparable or even better to test conditions using highly trained standardized patients in multiple station examinations at a "skills laboratory" ${ }^{33.34,35}$ These results may be explained by a consistency of GPs" usual performance during video recording, confirmed by GPs recognizing their usual working style in the consultations. In addition, peerobservers were trained in four sessions in scoring videotaped regular consultations with the explicit criteria. Adding another observer to each case substantially improves reliability, suggesting 
considerable "rater bias". Therefore, efforts to improve reliability should be focused on rater training in scoring complex daily cases and on further development of nationally accepted guidelines for both communication and medical performance..$^{36}$

Finally, reliability (and validity) of this video assessment procedure could be enhanced by combining video observations with an inspection of medical records. However, clinical data are often incomplete and inconsistent, which may raise other problems. ${ }^{37.38,39}$

Organization of our video assessment in daily practice proved to be feasible. Although $92 \%$ of all consultations were usable for data handling in first instance, this figure could even be higher with still better instructions to operators and GPs. Fandling the informed consent procedure at the counter by the receptionists seems fair for the patients. Our figures of acceptability, similar to former studies, ${ }^{40.41}$ support this view, taking into account that physical examination was videotaped integrally. Our detailed informed consent procedure, the use of peer-observers and the transport of the tapes by registered mail or couriers may have decreased patients' and GPs" fear of abuse of tapes. For ethical reasons, in video assessment one should always demand from both GP-participants and peer-observers to handle the tapes as "medical secret" and to erase the video registrations after reviewing, as we did. No copies should be made. Concerning ethical aspects, these videotapes should be considered as a part of patients' medical files just like medical journals.

Concerning costs, compared with investments of resources in observation methods in medical education, ${ }^{42}$ the costs were acceptable, and could even be reduced by frequent use of the same video equipment and by integrating rater-training in regular quality improvement activities or in GPtrainer activities. Acceptance of both participant GPs and peer-observers was high due to the educative impact of a video assessment method, but participation was voluntary.

We conclude that we have developed a procedure for educative assessment of GPs by means of video observation in daily practice, taking into account issues of validity, reliability, feasibility and acceptability, which enables GPS to evaluate and to improve professional quality. There is a trade off between content validity and feasibility. Futher research to increase feasibility and acceptability by reducing the number of consultations to be observed, while maintaining content validity and reliability, is needed. A decision about pass-fail level should be made if our procedure is used in selective assessment. Especially in high stakes assessments, credibility of the method is of major importance. In our opinion credibility and acceptability increases if the assessment method measures what it is supposed to measure in a reliable way. 


\section{References}

1. Wchee SJ, Bird JA, Fordhan D, Rodnck JE, Osbom EH. Promotimg cancer preventing activities by primary care physicians. JAMA $1991 ; 266: 393-401$

2. Sibley JC, Spitzer WO, Rudnick KW, et al, Quality of care appraisial in primary care: A quantative method. Arn Intern Med $1975 ; 83: 46-52$.

3. Grel R, Wersing M, Jacobs A, Baker R, editors. Quality assurance in general practice. The state of the art in Europe. Uirech: Nederlands Huisartsen Genootschap, 1993.

4. Davis DA, Thomson MA, Oxman AD, Haynes RB. Evidence for the effectiveness of CME. A review of 50 randornitged controlled trials. JAMA $1992 ; 268: 1111-7$

5. Rethans J, Westin $\mathrm{S}$, Hays R. Methods for quality assessment meneral practiec. Fam Pract 1996; 13:468476.

6. Vleuten van der CPM. The assesment of profiessional cormpetence: developments, researchand practical implications. Advances in Health Sciences Education. Theory and practice 1996; 1:41-67,

7. Rethans JJ, Stumans $F$, Drop MJ, Van der Weutem CPM. Assessment of perfomance in actual practice of general practitionets by use of standardized patients. Br J Gen Pract 1991:41:97-99.

8. Wakefield J. Direct Obstrwation. In: Neufeld VR, Norman GR, edrors. Assessing Clinical Competence. New York: Springter Publishing Company, 1985: 51-71.

9. Kane MT. The assessment of professional competence. Evaluation \& the Health Professions 1992; 15:163-82.

10. Elstein A, Shuman LS, Sprafka SA. Medical problem solwing: An analysis of clinical reasoring. Cambridge Massachusetta: Harvard University Press, 1978.

11. Newble DI, Swanson DB. Psychometric characteristics of the objective structured clinical examination. Med Educ $1988 ; 22: 325-34$.

12. Bain JE, Mackay NSD. Videotaping general practice consultations (letter to the editor). Brit Med J 1993; $307: 504$.

13. Campbell LM, Howje JGR, Murtay TS. Use of videotaped consultations m sumumative assessment of trainees in generall practice. Br It Gen Pract 1995; $45: 13744$.

14. Anomymus, Fellowhip by assessment-Criteria FBA8. Wale of Trent faculty. Royal College of General Practioners. Ist October 1996-30th September 1997.

15. Caulford $\mathrm{PG}$, Lamb SB, Kaigas TB, Hanma E, Norman GR, Davis DA (1994) Physician incompetence: specific problems and predictors. Acad Med 69 sippl(10), 16-20.

16. Metsemakers JFM, Höppenter $P$, Knottnerus JA. The Registration Network Family Practices: a computerized health information system in the Netherlands. Br J Ger Pract 1992; 42: 102-6.

17. Lamberts $\mathrm{H}$, Wood M, editors. ICPC. International Classification of Primary Care. Oxford: Oxford University Press, 1987.

18. Lisdonk EH wan de, Bosch WJMM van den, Huygen FJA, Lagro-Jansen ALM. Ziekten in de huisartspraktijk. Utrecht, the Netherlands: Bunge, 1994.

19. Springer MP, editor. Basic job descripion for the general practitioner. Utrecht: Dutch National Association of General Practitioners, 1983 .

20. Stilliman FL, Regan MB, Swanson DB, Haley HLA. Sequence effect in multiple station examination using stundardzed patients. In: Hart IR, Harden RM, Des Marchais $J$ (eds). Current developments in assessing clinical competerice Mortureal, Cañadi: Can Heal Publications, 1992.

21. Van Thid J, Von der Vieuter CPM, Kram H. Assessment of medical interviewing skills: generalizability of scores using whecssive MAAs-versions. In, Harden RM, Hart IR, Mullholland H. editors. Approtehes to the Assessment of Cinicial Competence. Dumdee: Cetre for Medical Edacation, 1992.

22. Thiel I wat, Dalen I van, Ram P. MAAS-globaal Criterialijst. Interne publicatie. Uniwersiteit Maastricht the Netherlainds 1995

23. Cronbach Li, Gleser GC, Nanda H, Rajaratnam N. The Dependability of Behaviorial Measurements: Theory of Gencralizability for Seores and Profiles. New York: Wiby, 1972.

24. Grenmin RL. Elements of Generalizability Theory. lowa City, llowa: Amencan College Testing Publications, 1983.

25. Suen HK. Principles of Test Theories. Hillsdale, New Jersey: Lawrence Erlbaum Associates, 1990.

26. Hays RB, Jones BF, Adkins PB, McKan PJ. Analysis of videotaped consultations to certify competence. The Medical Jourat of Australia 1990; 152:609-11.

27. Mokkink HGA, Schellekens CMAM, Tielens VCL. Consultdur in de huisantspraktik. Huisarts Wet 1993; 36" 28590.

28. Bensing I. Doctor-patient communication and the quality of care [Dissentation]. Rotterdam, the Netherlands: Erasmus University, 1991 
29. Howrie JGR, Porter AMD, Heaney DJ, Hopton IL. Long to short consultation rario; a proxy measure of aquality of care for general practice. Br I Gen Pract 1991; $41: 48-54$.

30. Howie JGR, Heaney DJ, Maxwell M. Measuring quality in general practice. Occasional paper 75. London, Royal College of General Practitioners, 1997.

31. Rethans JJ, Leeuwen van $Y$, Drop $R$, Sturmans F, Vleuten van der $C$. Performance and competence: two different constructs in the assessment of quality of medical care. Fam Pract 1990; 7: 168-74.

32. Pringle $M_{s}$ Stewart-Evans $C$. Does awareness of being video recorded affect doctor's consultation behaviour'? Br I Gen Pract 1990; $40: 45-8$.

33. Fraser $\mathrm{RC}$, McKinley $\mathrm{RK}$, Multholland $\mathrm{H}$. Consultation competence in general practice: testing the reliability of the Leicester assessment package. Br I Gen Pract 1994; 44: $293-6$.

34. Newble $D_{1}$, Swanson D. Psychornetric characteristics of the objective structured clinical examination. Med Educ $1988 ; 22: 325-34$

35. Norcini $J$, Swanson D. Factors influencing testing time, requirenents for simulation-based measurements: do simulations ever yield reliable scores? Teaching and Learning in Medicine 1989; 1: 85-91.

36. Rutten GEH, Thomas $\mathrm{S}$ (eds). NHG standaarden voor de huisarts. Utrecht: Bunge/NHG, 1993.

37. Rethans $\mathrm{JJ}$, Martin $\mathrm{E}$, Metsenakers J. To what extent do clinical notes by general practitioners reffect aetual performance? A study using simulated patients. Br J Gen Pract 1994; 44: 153-6.

38. Johnson $N$, Mant $D$, Jones $L$, Randall $T$. Use of computerised gemeral practice data for population surweillance: comparative study of influenza data. BMJ $1991 ; 302: 766$.

39. Houghton, G. General practitioner reaccreditation: use of performance indicators. Br J Gen Pract 1995; 45:677-81.

40. Shafir MS. Patient consent to obserwation. Can Farn Phy 1995; 41: 1367-72.

41. Campbell LM, Sullivan F, Murray TS. Videotaping of general practice consultations: effeet on patient satisfaction. Brit Med I 1995; $311: 236$.

42. Reznick RK, Smee S, Baumber JS, Cohen R. Rothman A, Blackmore D, Berard M. Guidelines for estimating the real cost of an Objective Structured Clinical Examination. Acad Med 1993;68: 513-7. 
Chapter 3.

Assessment of practising family physicians: comparison of observation in a station examination using standardized patients with observation of real surgery in daily practice.

Accepted for publication by Academic Medicin: Assessment of practicing family physicians:

comparison of observation in a station examination using standardized patients with observation of real surgery in daily practice. Paul Ram, Cees van der Vleuten, Jan-Joost Rethans, Richard Grol, \& Karin Aretz. 


\section{Summary}

Purpose. To compare the measurement characteristics of a Multiple Station Examination in a skills laboratory, using standardized patients, with video assessment of regular consultations in daily practice in order to make an informed choice for a valid, reliable and feasible method to collect data on the performance of practicing family physicians on sound methodological criteria.

Methods. In a cross-sectional study, consultations of 90 family physicians were video taped both in a Multiple Station Examination at the medical school using standardized patients and their daily practice surgery with regular patients. Peer-observers assessed communication with patients and medical performance with a validated instrument (MAAS-Global). Participants were randomly divided into two groups, comparable for demographic characteristics, in order to check for timeorder effects. Both groups passed through both assessments, but in reverse order. Content validity, criterion validity, reliability, i.e. generallizability, and feasibility of both methods were compared. Time-order effects were taken into account.

Results. Content validity of Practice Video Assessment was superior to the Multiple Station Examination, since the domain of general family practice care was better covered. Participants judged the video taped practice consultations as "natural", whereas hardly any family physician recognized his usual working style in the Multiple Station Examination, after reviewing the video taped consultations. Using specific criteria it proved to be possible to standardize real practice. Concerning concurrent validity, only the medical performance component of both methods correlated. Also real practice performance proved to be less influenced, thus more stable, than behavior during the station examination.

Reliability of both methods, expected to be better in the controlled Multiple Station Examination, was comparable. The organization of Practice Video Assessment was more flexible, less costly and better accepted by family physicians than the Multiple Station Examination.

Conclusion. Assessment for quality improvement of family physicians by video observation in daily practice is superior to video assessment in a simulated setting using standardized patients. Keywords: family physician, general family practice, quality assessment, competence, performance, multiple station examination, direct observation, video.

\section{Introduction}

Improving quality of care of medical professionals, such as familly physicians, demands regular collection and evaluation of data on competence and actual performance in practice. Such assessments should address whether care given to patients meets quality criteria in order to tailor educational activities to family physicians real needs and deficiencies., ${ }^{1,2}$ Since it has been shown that selfratings of performance usually produce overestimation of service delivery, and that self-selected postgraduate education has little effect on changing practice behavior of doctors, objective assess- 
ment is preferred. ${ }^{3,4}$ Competence, defined as what a doctor is capable of doing, and performance, defined as what a doctor does in his day-to-day practice, should be assessed by valid, reliable and feasible methods. ${ }^{5}$ In addition, assessment should approximate the real professional practice as closely as possible, while maintaining standardized test-taking conditions. ${ }^{6}$ Assessment of doctors performance by direct observation in the surgery is assumed to have a high validity. ${ }^{7,8}$ However, even modest levels of standardization of this "in vivo" assessment are difficult to acquire. The selection of consultations for assessment will be restrained by logistics of the organization, patients may not consent and family physicians may be influenced by the observation. This may decrease the representativeness of the sample and hamper generalizations. ${ }^{10}$ An alternative is "in vitro" assessment in a fully standardized lab using standardized patients (SPs). Well-developed methodologies of assessment using direct observation in a simulated situation have been proposed in recent decades, including the Objective Structured Clinical Examination (OSCE) and the Standardized Patient(SP)-based test. ${ }^{1112}$ These methods involve simulation of clinical situations in so-called stations. The OSCE usually focuses on parts of an encounter, whereas an SP-based test typically uses standardized patients to simulate an encounter, each station focusing on an integrated approach of different reasons for encounter..$^{13}$ These "multiple station examinations" offer the advantage of standardization by using uniform and standardized cases which can be directly observed and rated with objective checklists and rating scales. The question whether such a method relates to actual performance has resulted in conflicting evidence. ${ }^{14,15}$

Performance assessment so far commonly relies on indirect measurements such as chart audits, chart review, assessment of referral letters or prescription data. ${ }^{10,16,87}$ These indirect methods too show limitations in predicting the quality of family physicians' actual performance. ${ }^{18,19}$ In order to further investigate the strengths and weaknesses of competence and performance assessment, in this study "in vitro" video-observation of family physicians in a station examination using standardized patients is compared with video-observation of their regular consultations in daily practice. This experimental study focuses on validity, reliability, and feasibility in order to select the most efficient method to be used in quality assessment of family physicians.

\section{Methods}

\section{Subjects}

All family physicians in the south of the Netherlands were invited by letter to participate in this study, of whom $220(25 \%)$ reacted positively. For budgetary reasons 135 family physicians were randomly selected, 100 of them to be observed, 35 to serve as peer-observers. Personal and professional characteristics of the participants were collected and compared to the national population of family physicians to determine representativeness ( $T$-test and Chi-Square test). 
FIGURE 1. DESIGN

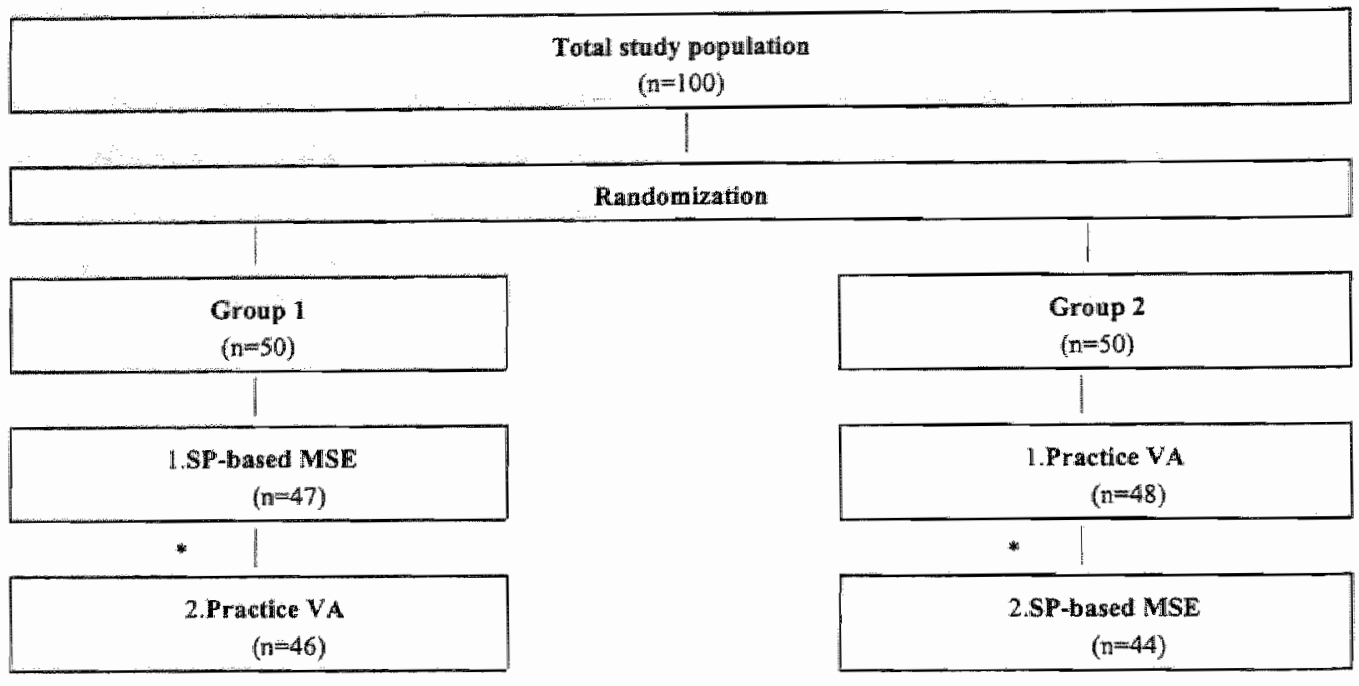

*period between both test-settings: \pm 4 months

\section{Procedure and Instruments}

To check for aryy time-order effect, participants $(\mathrm{N}=100)$ were randomly divided into two groups of 50 each, comparable on personal and professional characteristics. Both groups went through two test settings, a Multiple Station Examination (MSE) and a Practice Video Assessment (PVA), but in a reverse order (Figure 1). In order to make the MSE and the PVA comparable, it was necessary to design the MSE as similar to real practice as possible and to standardize the PVA.

Eight standardized cases, to be used in the Multiple Station Examination, were written by a panel of seven family physicians. A blueprint was developed, reflecting complaints with high prevalence in general practice. ${ }^{20.21}$ The content of the cases was based on this blueprint. Cases represented both acute and chronic diseases as well as multiple problems within the same case (Figure 2 ). Checklists were derived from national guidelines for appropriate clinical performance. ${ }^{22}$ Rooms were equipped as real surgeries and participants were allowed to bring in their doctor's bag. Doctors remained in their rooms while eight well-trained standardized patients rotated from one doctor to another, schematically following a "time pressure design" of 12 minutes per doctor (96 minutes in total). Participants were instructed to perform as naturally as possible. All encounters were video taped. 


\section{ICPC}

1. Aspecific stomach pain

2. Headache by refractive disease (presbyopia)

D

3. Angina pectoris and peripheral. vascular disease

F

4. Shoulder conplaints (painfull arc) by surmenage

$\mathrm{K}$

5. Disturbances of sleep and fatigue

L

6. Sore throat + partial deafness (eustacian salpingitis)

7. Exercised induced astma

$\mathrm{R}+\mathrm{H}$

8. Check-up non-insulin dependent diabetes mellitus

R

$\mathrm{T}$

For the Practice Video Assessment, during one week the participants' regular practice-site surgery consultations were video taped. Since a Practice Video Assessment is less standardized by nature than a Multiple Station Examination, more cases (16) were considered to be necessary for analysis. The cases were selected from a logbook completed by the participants on each patient seen.

Selection of these 16 cases was done by following a blueprint similar to the MSE, based on prevalence of diseases in general practice and on the national family physician task descriptions. ${ }^{20,21,23}$ On basis of this blueprint 10 sample criteria were formulated for the final selection of consultations. This process is described elsewhere. ${ }^{24}$

For both MSE and PVA all consultations were assessed by peer observers, trained in four sessions, on quality of communication and medical performance using the MAAS-Global (Maastricht Anamnestic and Advice Scoring list-Global). ${ }^{25}$ This validated rating scale contains 12 items on communication and 4 items on medical performance. Items are case-independent, to be scored on at 7-point Likert scale and anchored on an extensive list of detailed criteria. ${ }^{26}$ To avoid a "halo effect ${ }^{t \prime},{ }^{8}$ one observer scored only four MSE and six PVA consultations of the same doctor. In order to study generalizability for reliability analysis, $25 \%$ of all cases were observed by 2 observers independently.

Content validity, based on the blueprints described above, was assessed on the following aspects (see table 1): time-order effects (MSE and PVA), representativeness of the selected practice cases and influence of differences of sample characteristics on the practice performance scores, such as number and content of complaints, age and gender of patients, duration and type of consultations, i.e. follow-up or initial consultation (PVA). Furthermore, authenticity of MSE cases, influence of observation on the performance of the participants (the audience effect) and recognition of usual working style by the participants (MSE and PVA) were assessed by a questionnaire (13 items, 5point Likert scale). Criterion validity was defined as the predictive value of the Multiple Station Examination for the Practice Video Assessment. Reliability was operationalized as generalizability. Acceptance of both procedures by familly physicians was assessed with a questionnaire "feasibility and preference", with 15 items concerning the impact of the assessment procedures on practice 
organization (5-point Likert scale) and one question about family physicians" preference to methods, on both communication and medical performance.

Analysis

Overall case scores were calculated by summing the scores on each item for each case. These were expressed as a percentage score (maximum 100\%). The test score was the mean score across cases. These scores were also caloulated for communication and medical performance separately.

TABLE 1. METHODS USED TO COMPARE THE PSYCHOMETRC CHARACTERSTICS OF MULTIPLE STATION EXAMINATION (MSE) AND PRACTCE YMDEO ASSESSMEVT (PVA)

\begin{tabular}{|c|c|c|}
\hline Characteristicsi & MSE & PVA \\
\hline \multicolumn{3}{|l|}{ Vallidity". } \\
\hline \multicolumn{3}{|l|}{ Content validity: } \\
\hline Content of cases selected & selection criteria prevalence/gutdelines & selection criternastevallencerguidelines \\
\hline Timelorder effect & t-Testi & t-Test \\
\hline Representativenuess cases & by defunition & statistics: \% samples criterion fully met \\
\hline Inifluence sample differences on scores & T.a (equal samples) & regression analysis \\
\hline A whenticity cases & questionnatre & n.a. (implicit) \\
\hline Audience effert & questionnaite & questionnaine \\
\hline Recognition of working style & questionnaite & questionnaire \\
\hline Criteriom validity & Pearson cortelations & Pearson correlafions \\
\hline Reliability & generalizability anulysis & generalizability analysis \\
\hline \multicolumn{3}{|l|}{ Feasibility: } \\
\hline Acceptance & questionnaire & questionnaire \\
\hline Cost & keeping accounts & keeping accounts \\
\hline
\end{tabular}

*na. $=$ not applicable

To study validity (table 1), time-order effects of the design were analyzed by calculating the significance of differences between the Multiple Station Examination scores and the Practice Video Assessment scores, within and between both groups (paired and unpaired t-Tests). Representativeness of selected cases in the PVA was assessed by calculating the percentages of samples which met the predetermined criteria. Influence of differences in PVA sample characteristics on performance scores was analyzed by a multiple regression analysis with the practice scores as dependent and the sample characteristics as independent variables. Authenticity of MSE cases was assessed by calculating the percentages of family physicians agreeing. The "audience effect" and recognition of usual working style in both methods were assessed by calculating the percentage of family physicians agreeing. Finally, concurrent validity between MSE and PVA (on communication and medical performance) was analyzed by calculating the observed correlations (Pearson), which were corrected for attenuation, i.e. for unreliability of the instruments.

Generalizability theory was used to estimate reliability, calculated on the data set which had multiple ratings per consultation. ${ }^{27.28}$ In the MSE different observers (raters) were used for each 
case, and each case was similar for each doctor; therefore a "raters-nested-within-cases-crossedwith-persons" ANOVA was used. In the PVA different raters were used for each case and since each case, being a regular consultation, was different for each doctor, a "raters-nested-within-caseswithin-persons" ANOVA was used. These designs allow for concurrent estimation of reliability of raters and cases and allow for estimated projections of reliability from the actual number of cases and raters used in the study to other hypothetical test conditions with different sumple sizes.

To judge feasibility descriptive statistics of the questionnaire "feasibility and preference" were calculated. Cost of both tests was registered by keeping accounts.

\section{Results}

In totall ten participants $(10 \%)$ dropped out arguing that "participation is too threatening" (1\%), "on boliday" (4\%) and "too busy to participate" (5\%). On demographic variables the study population $(N=90)$ was representative for Dutch family physicians, except for age (Dutch family physicians: Mean 44.3 years, SD 5.5 against Mean: 43.1 , SD 7.4. Unpaired T-test: $=2.03$; $d f=89 ; p<0.05$ ). Falidity

Scores on communication, medical performance and overall scores on the Multiple Station Examination (MSE) and Practice Video Assessment (PVA) are reported in table 2.

TABLE 2. MAAS-GLOBAL SCORES OF GPS (N=90) IN PERCENTAGES: MEAN AND STANDALD DEVIATION (SD)

\begin{tabular}{|c|c|c|c|c|}
\hline & \multicolumn{2}{|c|}{ group $1(N=46)$} & \multicolumn{2}{|c|}{ group $2(\mathrm{~N}=44)$} \\
\hline & $\begin{array}{c}\text { MSE } \\
\text { mean (SD) }\end{array}$ & $\begin{array}{c}\text { PVA } \\
\text { mean (SD) }\end{array}$ & $\begin{array}{c}M S E \\
\text { mean }(S D)\end{array}$ & $\begin{array}{c}\text { PVA } \\
\text { mean (SD) }\end{array}$ \\
\hline communication & $44.4(10.3)$ & $41.3(7.7)$ & $52.4(8.6)$ & $42.1 \cdot(7.1)$ \\
\hline medical performarice & $64.9(8.5)$ & $62.8(7.6)$ & $70.7(6.4)$ & $61.3(6.2)$ \\
\hline overall score & $54.7(8.4)$ & $52.1(7.1)$ & $62.0(6.6)$ & $51.7(6.1)$ \\
\hline
\end{tabular}

As regards time-order effects, within group 1 no significant differences were found between MSE and PVA scores. Within group 2 scores between MSE and PVA differed significantly, on both communication and medical performance $(p<0.001)$. Comparing MSE scores of both groups, group 2 scored significantly higher than group 1 on both communication and medical performance $(p<0.001)$. No significant difference was found between both groups for the PVA scores. Apparently scores on the Multiple Station Examination increased significantly when the Practice Video Assessment had been done previously (group 2), whereas PVA scores appeared to be consistent, irrespective of whether MSE had been done before or not (see figure 1).

In both groups, the scores on communication were significantly lower than the scores on medical 
performance, in both MSE and PVA (all comparisons p< 0.001).

The eight MSE cases were judged as authentic by $94 \%$, not authentic by $3 \%$ and neutral by $3 \%$ of the participants. In PVA the domain of general practice care was covered extensively since at least eight different ICPC chapters (criterion 1) were represented in every sample of all participants and other criteria such as heterogeneity in age and gender of patients were met in the majority $(>70 \%)$ of all samples. ${ }^{24}$ The sample characteristic "total duration of 16 consultations" (Mean: 156.62, SD: 19.62 minutes) showed a significant relationship with PVA scores: the longer the duration, the higher the performance, on both communication $(B=0.351 ; p<0.001)$ and medical performance $(B=0.356 ; \mathrm{p}<0.001)$.

Table 3 reports data of the influence of observation on perceived performance and on recognition of usual working style, judged by participants after wiewing the video tapes. Comparing both tests, significantly more family physicians judged they were influenced by observation in the MSE, in both groups 1 and 2. This difference was significantly higher in group 1 (MSE first, PVA later) than in group 2 ( $40 \%$ and $28 \%$ respectively; $p<0.001)$.

TABLE 3. RECOGMITION OF WORKNAG STYLE FOR COMMUNICATION AND MEDICAL PERFORMANCE ALDO WNLUENCE OF OBSERYATION ON PERFORMANCE, EXPRESSED AS THE PEECENTAGE OF GPS AGREETNG

\begin{tabular}{llllll}
\hline & \multicolumn{2}{c}{ group 1 } & & \multicolumn{2}{c}{ group 2 } \\
\cline { 2 - 3 } \cline { 5 - 6 } & MSE & PVA & & MSE & PVA \\
\hline recogmition communication & 6.3 & 93.7 & & 16.7 & 83.3 \\
recognition medical performance & 6.3 & 93.7 & & 12.2 & 87.8 \\
\hline permanent influence & 75.0 & 35.5 & & 50.0 & 22.0 \\
no permanent influence & 25.0 & 64.5 & & 50.0 & 78.0 \\
\hline
\end{tabular}

In table 4, observed and true Pearson correlations between the MSE and PVA scores are given, on communication, on medical performance and on owerall scores separately for group 1 and 2 . On medical performance a significant comrelation between the scores of the MSE and PVA was found in both groups. No significant correlation was found between the scores of both tests on communication, either in group 1 or in group 2 . 
TABLE 4. OBSER VED AND DISATTENUATED CORRELATIONS BETWEEN MSE AND PVA

\begin{tabular}{llllll}
\hline & \multicolumn{2}{c}{ group 1} & & \multicolumn{2}{c}{ group 2} \\
\cline { 2 - 3 } & obserwed & disattenuated & & observed & disattenuated \\
\cline { 2 - 3 } & Pearson $(\mathrm{p})$ & Pearson $(\mathrm{p})$ & & Pearson $(\mathrm{p})$ & Pearson $(\mathrm{p})$ \\
\hline commumication & $.14^{1}$ & $.17^{1}$ & $.20^{1}$ & $.25^{1}$ \\
medical performance & $.41(<0.01)$ & $.59(<0.01)$ & & $.23^{1}$ & $.33(<0.05)$ \\
\hline
\end{tabular}

not significant

\section{Reliability}

In table 5, generalizability coefficients are reported as a function of the number of cases, their corresponding estimated testing time, and number of raters, i.e. peer-observers, for both the Multiple Station Examination and the Practice Video Assessment. Each entry represents a reliability estimate for the given sample size of cases and raters. For example, using two raters a value of 0.81 (PVA) and 0.84 (MSE) on the total score was found for 8 cases, i.e. 96 minutes of testing time. An arbitrary "benchmark" of 0.80 is usually considered as an acceptable value, which is reached for all scores within two and a half hours of testing time, using two raters.

TABLE 5. RELIABILITY: GENERALLZZABILITY COEFFICIENTS AS A FUNCTION OF THE NUMBER OF CABES AND RATERS

\begin{tabular}{|c|c|c|c|c|c|c|c|c|c|c|c|c|c|}
\hline \multirow[t]{4}{*}{ cases } & \multirow{4}{*}{$\begin{array}{l}\text { time } \\
\text { min. }\end{array}$} & \multicolumn{4}{|c|}{ Overall } & \multicolumn{4}{|c|}{ Communication } & \multicolumn{4}{|c|}{ Medical performance } \\
\hline & & \multirow{2}{*}{\multicolumn{2}{|c|}{$\frac{\text { MSE }}{\text { raters }}$}} & \multirow{2}{*}{\multicolumn{2}{|c|}{$\frac{\text { PVA }}{\text { raters }}$}} & \multirow{2}{*}{\multicolumn{2}{|c|}{$\frac{\text { MSE }}{\text { taters }}$}} & \multirow{2}{*}{\multicolumn{2}{|c|}{$\frac{\text { PVA }}{\text { raters }}$}} & \multirow{2}{*}{\multicolumn{2}{|c|}{$\frac{\text { MSE }}{\text { raters }}$}} & \multirow{2}{*}{\multicolumn{2}{|c|}{$\frac{\text { PVA }}{\text { raters }}$}} \\
\hline & & & & & & & & & & & & & \\
\hline & & 1. & 2 & 1 & 2 & 1 & 2 & 1 & 2 & 1 & 2 & 1 & 2 \\
\hline 4 & 48 & 0.57 & 0.72 & 0.58 & 0.68 & 0.60 & 0.75 & 0.55 & 0.65 & 0.42 & 0.59 & 0.52 & 0.63 \\
\hline 8 & 96 & 0.72 & 0.84 & 0.74 & 0.81 & 0.75 & 0.86 & 0.71 & 0.79 & 0.59 & 0.74 & 0.68 & 0.78 \\
\hline 12 & 144 & 0.80 & 0.89 & 0.81 & 0.87 & 0.82 & 0.90 & 0.79 & 0.85 & 0.68 & 0.81 & 0.76 & 0.84 \\
\hline 16 & 192 & 0.84 & 0.91 & 0.85 & 0.90 & 0.86 & 0.92 & 0.83 & 0.88 & 0.74 & 0.85 & 0.81 & 0.87 \\
\hline 20 & 240 & 0.87 & 0.93 & 0.87 & 0.91 & 0.88 & 0.94 & 0.86 & 0.90 & 0.78 & 0.88 & 0.84 & 0.90 \\
\hline
\end{tabular}

bold italics=real sample-sizes

\section{Feastibility}

Fixed and variable costs were estimated for two different sample sizes of consultations of both methods. For a 12-case sample the cost for the MSE was $\$ 530$ and for the PVA $\$ 375$ and for 16 cases $\$ 680$ and $\$ 440$ respectively (see Table 6 ).

Participants' preferences to methods favored the PVA to MSE, on both communication (73\% versus $27 \%$ ) and medical performance (66\% versus $34 \%)$. 
T.ALE 6. COSTS (S) WN BOTH SETTNGS PER GP WITH I RATHR (N=90)

\begin{tabular}{|c|c|c|c|c|}
\hline & \multicolumn{2}{|c|}{12 cages } & \multicolumn{2}{|c|}{16 cases } \\
\hline & MSE & PVA & MSE & PVA \\
\hline Administration & 60 & 54 & 75 & 67 \\
\hline Equipment/rooms & 52 & 22 & 70 & 22 \\
\hline Videotapes & 7 & 22 & 7 & 22 \\
\hline Rater training & 45 & 45 & 45 & 45 \\
\hline Observation & 112 & 112 & 150 & 150 \\
\hline Feedback & 15 & 15 & 22 & 22 \\
\hline Standardised patients & 75 & - & 100 & - \\
\hline Seript cases: & 7 & - & 10 & - \\
\hline Travelling costs (GP/SP) & 45 & - & 51 & - \\
\hline Locum tenens costs & 112 & - & 150 & - \\
\hline Insitallation video & - & 75 & - & 75 \\
\hline Review logbook & - & 30 & - & 37 \\
\hline Total & 530 & 375 & 680 & 440 \\
\hline
\end{tabular}

stable costs

\section{Discussion}

In this study a Multiple Station Examination (MSE) at the medical school, using standardized patients, was compared with a Practice Video Assessment (PVA) in family physicians' practice, using regular consultations, on aspects of validity, reliability and feasibility. Results showed superiority of the Practice Video Assessment on all aspects. We realize that our study population is not representative, since the family physicians participated voluntarily, showing their readiness to be assessed. However, since our study is a methodological study and the psychometric characteristics of both methods were studied within the same study population, we think this nonrepresentativeness is not a major bias.

Since scores of group 2 in the MSE (administered after PVA) were significantly higher than MSE scores of group 1 and no significant difference between both PVAs was found, one may conclude that a time-order effect only shows in one direction: from actual performance assessment to "in vitro" assessment, resulting in better scores for competence. Apparently, only" "in vitro" assessment is influenced by previous assessment experiences. This stability in scores in the Practice Video Assessment may be explained by the entity of common interaction between family physicians and their patients in daily practice.

In both settings satisfactory content validity was achieved: authenticity of standardized station cases was confimed by family physicians and in the Practice Video Assessment the domain of general 
practice care was well covered as was evident from the attained sample criteria. However, PVA consultations were more authentic than MSE cases since initial and follow-up consultations with children and older patients in the natural daily context were included. ${ }^{24}$ Moreover, almost all family physicians judged the video taped practice consultations as "natural", whereas hardly any family physician recognized his or her working style in the standardized station cases, since they met unknown standardized patients in an artificial setting. The influence of variation in total duration of the 16 PVA consultations on performance scores reflects differences between family physicians in their perception of tasks, work load and working style. Therefore, our selection criterion $\geq 5$ and $\leq 15$ minutes/consultation) contributes to the representativeness of the samples. Finally, concurrent validity between MSE and PVA is ambiguous, since only a moderate correlation was found for medical performance. Overall, validity of the PVA is superior to MSE.

Reliability results of both methods are encouraging, compared with other studies..$^{20,30,31}$ We expected results to be superior for the controlled Multiple Station Examination, but after 16 cases a "benchmark" of 0.80 was met for all scores, except for medical performance in the MSE. This finding favors the Practice Video Assessment. Family physicians may perform more consistently in their authentic daily practice, whereas they show more variability from case to case in an unfamiliar competence test. Adding another rater to each case substantially improves the reliability in both test formats, suggesting considerable rater bias. Therefore, efforts to improve reliability should be focused on rater training. Overall, the expected loss of reliability of the PVA as compared to MSE was not confirmed.

Finally, the Multiple Station Examination is more expensive than the Practice Video Assessment, through the use of standlardized patients, laboratory facilities and travelling cost for participants and standardized patients. Furthermore, the MSE was more burdensome for participants because of travelling time, disruption of patient care by being out of their practice and the fixed period of organization. In contrast, in the PVA patient care was continued normally and the planning of the period of video recordings was more flexible without increasing cost. Again, the Practice Video Assessment appeared to be superior to the Multiple Station Examination.

We conclude that results on validity, reliability and feasibility favor the Practice Video Assessment over the Multiple Station Examination. In quality assessment of communication and medical performance of practicing family physicians, video observation in daily practice is therefore to be preferred to assessment by observation in a controlled simulated situation. 


\section{References}

1. Grol $R$, Wensing $M_{n}$ Jacobs $A$, Baket $R$, editors. Quality Assurance in General Practice. The state of the art in Europe. NHG and EQuiP, 1993. Utrecht, the Netherlands.

2. New perspectives and opportunities in quality assurance: our role. Federation of State Medical Boards of the United States Annual Meteting, San Diego, 1988.

3. McPhee SI, Bird JA, Fordham $D_{n}$ Rodnick. JE, Osbom EH. Promoting cancer preventing activities by primary care physicians, JAMA. 1991; 266: 393-401.

4. Sibley $J_{\text {, }}$, Spitzer WO, Rudnick $K V$, et al. Quality of care apporaisal in primary sare: A quantative method. Ann Intem Med. $1975,83: 46-52$.

5. Rethans IJ, Sturmans F, Drop MJ, Van der Vleuten CPM, Hobus P. Does competence of general practitioners predict their perionance? Br Med J. 1991; 303:1377.80.

6. Van der Veuten CPM. The assersment of Professional Competence: Developments, Research and Practical Imphcations. In: Advances in health Sciences Education. Theory and Pracrice. Schmidt H, Noman G, Editors. Volume 1, 1996. Kluwer Academic Publishers. Dordrecht/Boston/London.

7. Rethans JJ, Westin S, Hays R. Methods for quality assessment in general practice. Fam Pract. 1996; 13:468-76.

8. Wakefield J. Direct Observation. Irs: Neufeld VR, Norman GR, editors. Assessing clinical competence. New York: Springer Publishing Company, 1985: $51=71$.

9. Kane MT. The assessment of professional competence. Evaluation \& The Health Professions 1992; 15: 163-82.

10. Elstein A, Shulman LS, Sprafka SA. Medical problem solving: An analysis of clinical reasoning. Cambridge Massachusetts: Harward University Press, 1978.

11. Harden RM, Stevenson M, Downie WW, Wilson GM. Assessment of clinical competence using objective structured examination. Br Med J. 1975; 1: 447.51.

12. Stillman P, Swanson D. Ensuring the clinical competence of medical school graduates through standardized patiemts. Archives of Interral Medicine 1987; 147: 1049-52.

13. Van der Vleuten, Swanson DB. Assessment of clinical skills with standardized patients: state of the art. Teaching and Learning in Medicin 1990; 2: 58-76.

14. Rethans JJ, Wan Leeuwen $Y$, Drop $R_{a}$ Van der Vleuten $C$ (1990) Competence and performance: two different concepts in the assessment of quality of medical care. Family Practice 7, 1.68-74.

15. Campbeli LM, Murray TS. Assessment of competence. Br J Gen Pract. 1996; 46: 619-22.

16. Norman GR, Davis DA, Painvin A, Rath D, Ragbeer M. Comprehensive assessment of clinical competence of familygeneral physicians using multiple measures. Proceedings 28th Conference on medicall eduction, Washington, DC, 1989.

17. Ramsey $\mathrm{PG}$, Carime JD, Innui TS, Larson. EB, LoGerfo JP, Wenrich MD . Predictive validity of certification by the American Board of Internal Medicine. Ann Int Med. 1989; 110: 719-26.

18. Rethans JJ, Martin $E_{n}$ Metsemakers I. To what extent do clinical notes by geteral practitioners reflect actual performance? A study using simulated patients. Br J Gen Pract. 1994: 44: 153-6.

19. Johnson $N_{\text {, Mant }} \mathrm{D}$, Jones $\mathrm{L}_{*}$ Randall $T$. Use of computerised general practice data for population surveillance: comparative study of influenza data. Br Med J. 1991; 302:766-8.

20. Metsemakers JFM, Hoppener P, Knotnerus JA, et al. The Registration Network Fumily Practices: a computerized health information system in the Netherlands. Br J Gen Pract. 1992; 42: 102-6.

21. Lamberts $\mathrm{H}$, Woad $\mathrm{M}$, editors. ICPC. International Classification of Primary Care. OxPord: Oxford University Press, 1987.

22. Rutten GEH, Thomas $S_{\text {n }}$ eds. NHG-standlaarden voor de huisarts. [Guidelines for the general practitioner] Utrecht: Bunge/NHO, the Netherlarnds, 1993.

23. Springer MP, editor. Basic job description for the general practitioner. Utrecht: Dutch National Assaciation of General Practitioners, 1983.

24. Ram PM, Grol RPTM, Rethans JI, Schouteru B, Van der Vleuten CPM, Kester A. Assessment of General Practitioners by video observation of medical and communicative performance in daily practice: issues of validity, relliability and feasibility. Submitted for publication.

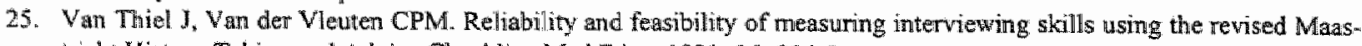
tricht History Taking and Advice Checklist. Med Educ. 1991; 25; $224-9$.

26. Van Thiel J, Van Dalen J, Ram P. MAAS-globaal criteriajijst. Internal publication. Maastricht University, the Netherlands, 1995.

27. Cronbach $L_{y}$ Gleser GC, Nanda $H$, Rajaratnam $N$. The dependability of behaviorial measurements: theory of gerzeralizability for scores and profiles. New York: Willey, 1972. 
28. Brennan RL. Elements of generalizability theory. Iowa City, Iowa: American College Testing Publications, 1983.

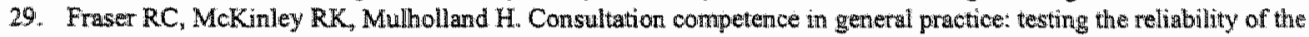
Leicester assessment package. Br J Gen Pract 1994; 44: $293-6$.

30. Newble D, Swanson D. Psychometric characteristics of the objective structured clinical examination. Med Educ. $1988 ; 22: 325-34$.

31. Norcini $J$, Swanson $D$. Factors influencing testing time, requirements for simulation-based measurements: do simulations ever yield rellable scores? Teaching and Learning in Medicine 1989; 1: 85-91. 
Chapter 4.

\section{Assessment in General Practice: the predictive value of Written Knowledge Tests and a Multiple Station Examination for actual medical performance in daily practice.}

In press by Medical Education: Assessment in General Practice: the predictive value of Written Knowledge Tests and a Multiple Station Examination for actual medical performance in daily practice. Paul Ram, Cees van der Vleuten, Jan-Joost Rethans, Berna Schouten, Sjoerd Hobma \& Richard Grol 


\section{Summary}

This study compares the predictive values of written knowledge tests and a standardized Multiple Station Examination for actual medical performance of General Practitioners (GPs) in order to select effective assessment methods to be used in continuing medical education and quality improvement.

First, 100 GPs from the southern part of the Netherlands were assessed by a general medical knowledge test and by a knowledge test on technical skills. Second, in order to check for time-order effects, participants were randomly divided into two groups of 50 each, comparable on scores of both knowledge tests and on professional characteristics. Finally, both groups went through a Multiple Station Examination using standardized patients and a Practice Video Assessment of real surgery, but in opposite orders. All consultations were videotaped and assessed by well trained peer observers. Drop-out was 10\%.

In both groups the predictive value of medical knowledge tests, ranging from $0.43-0.56$ (Pearson correlation disattenuated), proved to be comparable with the predictive value of the Multiple Station Examination for actual performance (0.33-0.59). The overall explained variance of scores of the Practice Video Assessment, measured by multiple regression analysis with performance scores as dependent variables and scores on the knowledge tests and professional characteristics as independent variables was moderate (35\%). A time-order effect showed in only one direction: from Practice Video Assessment to the Multiple Station Examination. GPs' professional characteristics did not contribute to the explanation of variation in performance scores.

Medical knowledge tests can predict actual clinical performance to the same extent as a Multiple Station Examination. Compared with a station examination, a knowledge test may be a good alternative method for assessment procedures of a large number of practising GPs.

\section{Keywords}

General practice, competence, performance, knowledge tests, multiple station examination, video observation, assessment, general practitioners.

\section{Introduction}

After completing a vocational training scheme, a general practitioner (GP) is supposed to have reached a level of competence which should reflect the demands of diagnostic, patient management and communication skills in daily practice. There is growing consensus that this level of competence does not imply the same level of actual performance in day-to-day practice during the rest of the GP's professional life. ${ }^{1.2}$ Performance may change due to severall interrelated factors such as changes in medical knowledge, practice organization or age. ${ }^{3-6}$ To sustain an acceptable level of performance GPs should attend postgraduate courses. Although time investment for these courses 
may be set, the choice of topics usually depends on the individual GP and his or her subjective needs. Subjective selection of topics in continuing medical education (CME) is hardly effective in changing the practice behaviour of doctors. If deficiencies in practice perfornance could be objectively identified, CME and quality improvement could be matched better to real needs in order to maximize effectiveness. ${ }^{8}$ Therefore, an assessment procedure is needed that is both valid and reliable in revealing deficiencies in performance of GPs and appropriate for use on a large scale. Knowledge tests such as Multiple Choice Questions (MCQs) are efficient in handling large numbers of GPs and can easily cover a wide content domain. ${ }^{9}$ On the other hand, critics raise doubts about the validity and acceptability of MCQs, claiming that selecting options from a list of alternitives is quite distant from clinical reality. ${ }^{10,11}$ Moreover, these methods mainly assess aspects of competence, i.e. what a doctor is capable of doing, and this may not be the same as what a doctor does do in his day-to-day practice (performance), the ultimate focus of quality improvement. ${ }^{12}$ In this perspective the question arises whether results on written tests do predict actual performance in practice. Different studies have shown a moderate positive relationship between written tests and performance measurements. ${ }^{13-15}$ Performance in these studies was assessed either indirectly by chart review and chart stimulated recall, or directly by peer rating by colleagues who worked with the observed colleague. Assessment by using medical records has its limitations, since clinical data are often incomplete and inconsistent. ${ }^{16}$ Observation by cooperating colleagues may be quite subjective and is not useful in single-handed practices. Direct observation using trained (peer) observers, not cooperating with the observed physician, may be more valid and reliable. However, assessment in daily practice is difficult to standardize. Better controlled competence-based tests closely limked to professional reality, called Multiple Station Examination or Objective Structured Clinical Examination (OSCE), could be alternatives. ${ }^{17,18}$ In these methods clinical skills must be demonstrated in standardized simulated clinical situations using direct (video) observation to score performance. These tests have more authenticity than knowledge tests and include aspects of problem solving, patient management and attitude. Therefore, these are assumed to have better predictive value for actual performance than written tests. However, implementation on a large scale may be more difficult, because of the high resource requirements and its organizational complexity." Moreover, research on the predictive value of these methods has resulted in conflicting evidence. ${ }^{20}$ In all, more insight is needed into the value of both knowledge testing and station examinations to predict performance in regular clinical practice.

The study presented here compares the predictive value of written knowledge tests (less vilid, feasible) with the predictive value of direct observation in a Multiple Station Examination (more valid, less feasible) for medical performance in daily practice. 


\section{Methods}

\section{Subjects}

All general practitioners in the south of the Netherlands were invited by letter to participate in this intensive study and $220(25 \%)$ reacted positively. For budgetary reasons 135 were randomly selected, 100 to be assessed, 35 to participate as peer observers. Data on personal and professional characteristics (age, gender, working single-handed, being medical teacher, working full-time or part-time, urbanization area) were collected.

\section{Instruments and procedure}

Knowledge tests and observation instruments were screened on their psychometric qualities. Two instruments with established validity and reliability were included. These were a general medical knowledge test and a scoring list for direct observation of medical performance and communication with patients, the MAAS-Global. ${ }^{21,22}$ The general medical knowledge test consists of 60 short cases with 131 items about complaints and diseases, stratified according to chapters of International Classification of Primary Care (Cronbach's alpha $=.64$ ). ${ }^{23}$ Using the blueprint of the general medical knowledge test, a knowledge test on medical technical skills was constructed (124 items, Cronbach's alpha $=.60$ ) in order to cover the broad cognitive domain of general practice as completely as possible. ${ }^{24}$ This knowledge test on skills is focused on knowledge pertaining to why and how a certain skill should be performed, the skills being used in daily practice and selected from nationally accepted job description and guidelines for general practice. ${ }^{25}$ Answers on both knowledge tests were given in a true/false/? format. Item-examples of both the general medical knowledge test and the knowledge test on technical skills are shown in figure 1 and 2 respectively.

FICURE 1. EXAMPLE OF CASE WITH SUBSEQUENT QUESTHONS FROM THE GENERAL MEDICAL KNOWLEDGE TEST

Mrs: Cleveland, 75 years old, is known with aridvanced arthrosis of her lef knee. She enters the room, walking slowly and leaning to the right on her stick. The left knee is swollen and warn.

There is a hydjops.

Anong the therapeutical measures, adequate at this moment, is/are:

- application of icepacks

- massage and exercises

- intra-articular injection of corticosteriods

- holding the stick in the other band (left) true/false/?

truelfalseh?

true/false/?

truelfalse/?

Literature: Linden AJ van der, Claessens I. Lerboek orthopaedie, 1995. 
The GP decides to resuscitate an infant (less than 1 year old), who has no signs of spontaneous breathing nor arterial pulsations. The head of the infant is hyperextended.

- The correct extent of hyperextension of the head is LESS with an infant compared to an aduit.

tritadfalsed?

The GP places his mouth ower the nose and mouth of the infant.

- This is a correct procedure for insufflation of an infant.

truthalser?

During the resuscitation the GP gives thorax compression at a rate of about 90 per minute.

- This is a correct rate for infants. true/talsel?

- During resuscitation of an adult the adequate rate of compressions is closer to 80 per minute than to 60 per minute.

true/false/?

- During resuscitation with one resuscitator the recommended schedule is: 15 compressions followed by 1 insufflation.

mue/falsel?

Literature: Leerboek elememtaire reanimatie. Den Haag: Nederlandse Hartstichting 1996

Participants were assessed in three sequential steps (see figure 3). First, the two knowledge tests, both paper-and-pencil tests, were sent to the participants. After the knowledge tests had been completed, a randomization was done in order to check for order effects caused by the design. Two groups of 50 GPs each, comparable on demographic characteristics and on scores of the knowledge tests, were formed. In steps two and three both groups were observed directly. Group 1 went first through a Multiple Station Examination, a real life-like surgery at a skills laboratory of the medical school, using eight stations with cases presented by standardized patients. All consultations wert videotaped. A few months later these GPs went through the Practice Video Assessment of regular surgeries in dally practice. Group 2 started with the Practice Video Assesment and followed by the station examination some months later. In the Practice Video Assessment, nedical performance including physical examination (and communication with patients) was recorded during one week with patient's consent using two cameras. By means of 10 preset criteria a representative sample of 16 consultations was selected from a logbook completed by the GPs. ${ }^{27}$

In both tests medical performance was assessed by trained peer observers using the MA.AS-Global scoring list. ${ }^{26}$

Validity of both tests proved to be adequate in previous research. ${ }^{27}$ Reliability, i.e. generalizability coefficients, ${ }^{28}$ of the scores in the Multiple Station Examination was 0.59 ( 8 cases) and of the scores in the Practice Video Assessment 0.83 ( 16 cases). 
FIGURE 3. STUDY-DESIGM

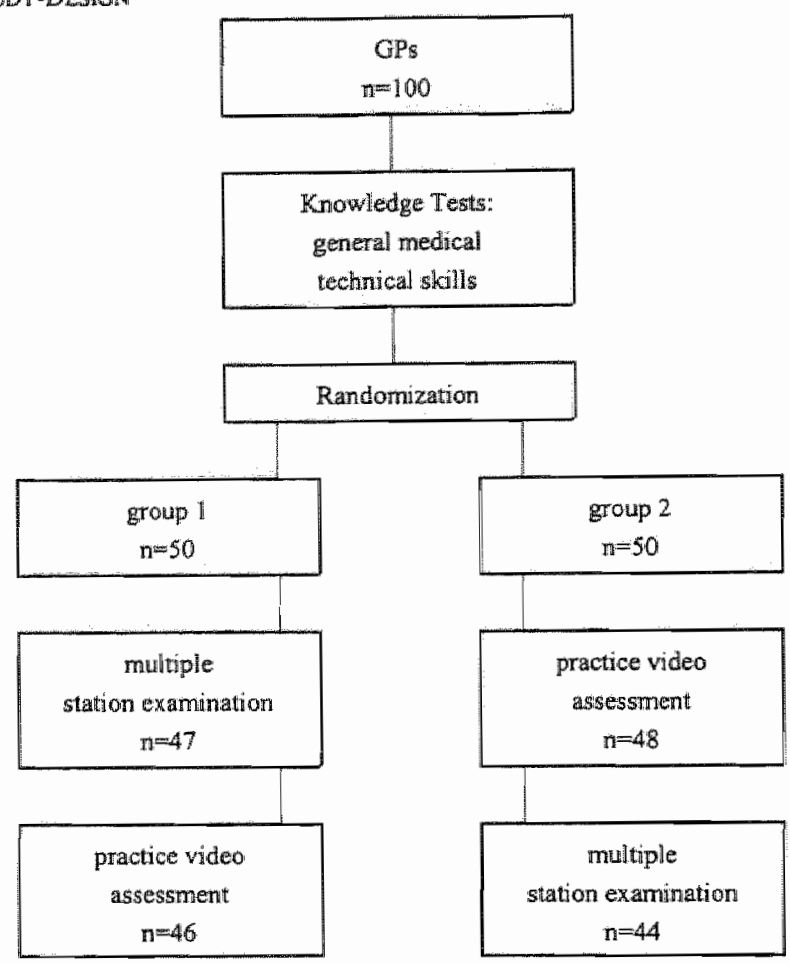

\section{Analysis}

Scores on knowledge tests were calculated as the sum of correct minus incorrect scores (correction for guessing). Case scores in the Multiple Station Examination and Practice Video Assessment were calculated by summing the number of item responses for each case. All scores were expressed as percentages of the maximum score. The test score was the mean score across cases. The predic tive value of both written knowledge tests and the Multiple Station Examination for actual performance in the Practice Video Assessment was assessed by calculating the bivariate comelations (Pearson, observed and corrected for attenuation) between these methods. Confounding of the predictive values by GPst characteristics and by a time-order effect was assessed by using a multiple regression andysis with Practice Video Assessment scores as dependent variables and scores on the knowledge tests, scores on the Multiple Station Examination, professional characteristics and possible time-order effects as independent variables. In this way the percentages of explained variance in the practice scores were calculated ( $\mathrm{R}$ and $\mathrm{R}$-squared). Time-order effects were assessed by calculating the significance level of differences between scores of the Multiple Station Examina tion and scores of the Practice Video Assessment, between and within both groups (paired and umpaired T-tests). 


\section{Results}

\section{Drop out}

In total ten participants ( $10 \%$ ) dropped out arguing that "video observation is too threatening" (1\%), "on holiday" (4\%) and "too busy to participate" $(5 \%)$. The study population $(\mathrm{N}=90)$ was representative of Dutch GPS for professional and personal variables, except for age (Mean 43.1, SD 5.5 ; Dutch GPs Mean 44.3, SD 7.4. T-test: $t=2.03$; $\mathrm{df}=89$; $\mathrm{p}<0.05$ ).

\section{Scores and differences in scores, within and between both groups}

Table 1 shows descriptive statistics for scores of the knowledge tests and Multiple Station Examination on medical competence and for scores of Practice Video Assessment on medical performance, for groups 1 and 2 . Scores of the general medical knowledge test were significantly higher than the scores of the knowledge test on technical skills ( $t=21.5 ; \mathrm{df}=89 ; \mathrm{p}<0.01$; paired T-test). Time-order effects are revealed within group 2 where scores between the Multiple Station Examivation and Practice Video Assessment differed significantly ( $t=8.2 ; \mathrm{df}=43 ; \mathrm{p}<0.01$; paired T-test). In the Multiple Station Examination group 2 scored significantly higher than group 1 ( $t=3.7 ; \mathrm{df}=89$; $\mathrm{p}<0.05$; unpaired T-test). No significant difference was found between groups for scores of the Practice Video Assessment ( $\mathrm{p}<0.05$ ). Apparently the scores of the Multiple Station Examination increased significantly when a Practice Video Assessment was done beforehand (group 2), whereas practice scores appeared to be unaffected by previous assessment experiences. This time-order effect was therefore taken into account as an independent variable in regression analysis.

TABLE 1. SCORES KNOWLEDGE TESTS, MULTIPLE SIATION EXAMNATION AND PRACTICE WIDEO ASSESSMENT NNERCENTAGES AND DIFFERENCES OF SCORES BETWEEN AND WTTHIN BOTH GROUPS

\begin{tabular}{|c|c|c|c|c|c|}
\hline & \multirow[b]{2}{*}{$\begin{array}{l}\text { iumber of } \\
\text { items }\end{array}$} & \multicolumn{2}{|c|}{ group $1(n=46)$} & \multicolumn{2}{|c|}{ group $2(n-44)$} \\
\hline & & mean (SD) & range & $\operatorname{meun}(\mathrm{SD})$ & range \\
\hline $\begin{array}{l}\text { Knowledge tests: } \\
\text { general medical } \\
\text { technical skills }\end{array}$ & $\begin{array}{l}131 \\
124\end{array}$ & $\begin{array}{l}52.7(1.5) \\
31.1(10.9)\end{array}$ & $\begin{array}{r}24.4-80.9 \\
6.5-54.0\end{array}$ & $\begin{array}{l}50.8(11.0) \\
31.4(12.5)\end{array}$ & $\begin{array}{r}31.3-72.5 \\
6.5-54.8\end{array}$ \\
\hline $\begin{array}{l}\text { Multiple Station } \\
\text { Examination }\end{array}$ & 8 cases & $64.4(8.6)^{\prime}$ & $49.1-83.0$ & $70.1(5.9)^{1.2}$ & $55.7-84.4$ \\
\hline $\begin{array}{l}\text { Pactice Video } \\
\text { Assessment }\end{array}$ & 16 cases & $62.8(7.6)$ & $47.1-84.1$ & $61.3(6.2)^{3}$ & $47.6-75.8$ \\
\hline
\end{tabular}

significant difference ( $p<0.001$ ) between groups on same measure (Multiple Station Examination)

2 significant difference $(p<0,001)$ within group 2 between different measures (station-practice) 


\section{Predictive values}

Table 2 shows the correlations (observed and disattenuated with their significance levels) of scores of knowledge tests and scores of the Multiple Station Examination with scores of the Practice Video Assessment. In both groups the two medical knowledge tests correlate significantly with medical performance in practice. These correlations are comparable with the correlation between scores of the Multiple Station Examination and scores of the Practice Video Assessment.

Table 3 shows the results of multiple regression analysis with Practice Video Assessment scores as. deperident variables and the scores of both knowledge tests and Multiple Station Examination, time-order effect (group 2) and professional characteristics as independent variables. The multiple $R$ and $R$-squared are given, representing percentages of variance explained by the variables in equation. Overall, the explained variance is moderate. The general medical knowledge test contributes to the explained variance more than the Multiple Station Examination does. Personal and professional characteristics of the GPs did not contribute to explained variance.

TABLE 2. OBSERVED AND DISATIENUAATED PEARSON CORRELATIONS BETWEEN KNOWLEDGE TESTS AND PRACTICE VDEO ASSESSMENT (PWA), AND BETWEEN MULTIPLE STATION EXAMNATION AND PRACTICE VIDEO ASSESSMENT

\begin{tabular}{|c|c|c|c|c|}
\hline & \multicolumn{2}{|c|}{ PVA group $1(n=46)$} & \multicolumn{2}{|c|}{ PVA group $2(n=44)$} \\
\hline & observed & disattenuated & observed & disattenuated \\
\hline Knowledge tests & & & & \\
\hline general medical & $0.41^{\prime}$ & $0.57^{1}$ & $0.33^{2}$ & $0.46^{!}$ \\
\hline technical skctls & $0.41^{\prime}$ & $0.59^{\circ}$ & $0.32^{2}$ & $0.46^{\prime}$ \\
\hline Multiple Station Examination & $0.41^{\prime}$ & $0.59^{1}$ & 0.23 & $0.33^{*}$ \\
\hline
\end{tabular}

${ }^{1} \mathrm{p}<0.01$

$2 p 0.05$

TABLE 3. MUITTPLE REGRESSION ANALYSES: PRACTICE VTDEO ASSESSMENT (PVA) SCORES AS DEPENDENT WARIABLES, RESPECTIVE TEST SCORES AND SCORIS ON PROFESSIONAL CHARACTERISTICS AS INDEPENDENT WARLABLES

\begin{tabular}{lcccc}
\hline & Beta & t & $\mathbb{R}$ & $\begin{array}{c}\text { R-squared } \\
\text { (adjusted) }\end{array}$ \\
\hline $\begin{array}{l}\text { general medical knowledge test } \\
\text { station examination }\end{array}$ & 0.26 & $2.61^{\prime}$ & 0.37 & $0.13(0.12)$ \\
time-order effect & 0.33 & $3.10^{\prime}$ & 0.43 & $0.19(0.17)$ \\
& -0.23 & $-2.19^{2}$ & 0.48 & $0.23(0.20)$ \\
\hline
\end{tabular}

"p<0.01

ip<0.05 


\section{Discussion}

The aim of this study was to compare the predictive value of knowledge tests with the predictive value of a Multiple Station Examination for actual medical performance, assessed by video observation in GPs" day-to-day practice. We realize that our study population is not representative, since GPs participated voluntarily. However, since our study is a methodological study this nonrepresentativeness is not a major problem. In addition, the predictive values of the different instruments for actual performance were studied within the same study population.

Both the general medical knowledge test and the knowledge test on skills proved to predict actual medical performance to the same extent as the Multiple Station Examination. These findings contrast with the hypothesis that competence-based tests using direct observation, such as multiple station examinations and OSCEs, will have a stronger relationship with actual performance than knowledge tests. These findings may be explained by the reported "audience-effect", i.e. influence of observation on performance, in the Multiple Station Examination. ${ }^{27}$ In a questionnaire, taken after the study, a majority of GPs reported they felt inhibited by the observation throughout the entire station examination, judged as an artificial and unfamiliar setting, whereas a minority said they were influenced in the Practice Video Assessment. As a consequence, a majority of GPs judged the videotaped consultations of daily surgery as "natural". In the videotaped consultations of daily surgeries they recognized their normal "working style" better than in the standardized station consultations. This audience effect may lead to special variation in GPs' performance in each case of the Multiple Station Examination, which may disturb the correlation with actual performance in daily practice. Compared to these effects in multiple station examinations, written tests and observation in daily practice may be less intrusive.

The knowledge tests were sent to the participants, which could be a scope for cheating. However, the assessment was purely educative and looking up things would minimize the educational value, as the participants was told. Moreover, cheating would have had a decreasing effect on the relationship between knowledge and performance. Cheating GPs probably would have a high knowledge test score and lower performance score, having less ready knowledge available.

At variance with knowledge tests, GPs (professional) characteristics did not contribute to the explanation of variation in performance scores. This suggests that knowledge tests are much better predictors for strengths and weaknesses in actual performance for groups of GPs than GPs' characteristics such as age, gender, working single-handed or being a GP-trainer. Since welldeveloped knowledge tests are available for screening purposes, the current system of postgraduate medical education, allowing GPs to choose on subjective needs, is highly questionable and should become a serious matter of debate.

Finally, we conclude that medical knowledge tests should be developed for use in assessment of practising GPs. Compared with multiple station examinations and OSCEs, knowledge tests can be used on a broad scale with fewer logistical problems. In addition, these predict actual performance 
relatively well. Nevertheless, the explained variance in actual performance by knowledge tests and station examination reported here, is too low to bridge the gap between competence and actual performance assessment. In assessment of practising GPs a combination of different methods, including observation in daily practice, is probably the most walid and reliable approach.

\section{References}

1. Norman G (1991) Can an examination predict competence? The role of recertification in maintenance of competence. Annalig RCPSC $24,121-4$

2. Rethans J, Van Lecuwen $Y$, Drop $R$, Vaw der Meuten $C$ (1990) Competence and performance: two different concepts in the aissessment of quality of medical care. Family Practice 7, 168.74.

3. Day $\mathrm{SC}$, Norcin $\mathrm{dJ}$, Webster GD (1988) The effect of changes in medical knowledge on examination performance at the time of recertification. In Proceedings of the 27 th Annual Conference on Research in Medical Education. Chicago Association of American Medical Colleges, 139-44.

4. Lockyer JM (1992) Physician performance: the roles of knowledge, skill, and environment. Teaching and Learning in Medicine 4, 86-96.

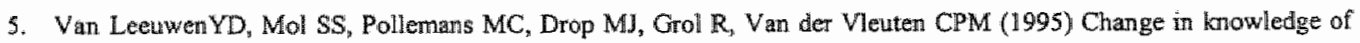
general practitioners during their professional careers. Family Practice 12, 313-7.

6. Caulford PG, Lamb SB, Kaigas TB, Hanna E, Norman GR, Davis DA (1994) Physician incompetence specifie problemis and predictors. Academie Medicine 69 suppl(10), 16-20.

7. Sibley JC, Sacket DL, Neufeld W, Gerrard B, Rudrick KV, Fraser W (1982) A randomized trial of continumg medical education. New England Journal of Medicine $306,511-5$.

8. Grol R (1996) Research and development in quality of care: establishing the research agenda. Quality in Health Care 5 , $1-8$.

9. Van Leeuwen YD, Pollemans MC, Mol SS, Eekhof JAH, Grol R, Drop MJ (1995) The Dutch iknowledge test for general practice: issue of validity. The European Joumal of General Practice 1, 13-7.

10. Newble DI, Baxuer A, Elmslie $G$ (1979) A comparison of multiple choice and free response tests un examinations af cinical competence. Medical Education 13,263-8.

11. McGure C (1993) Perspectives in assessment. Academic Medicine 68(Supp), S3-B.

12. Rethans JJ, Sturmans F. Drop MJ, Van der Vletten CPM, Hobus P (1991) Does competence of general practitioners predict their performance? Eritish Medical Journal 303, $1377-80$.

13. Woman GR, Davis DA, Painvin A, Rath D, Ragbeer M (1989) Comprehensive assessment of clinical competence of family general physicians using multiple measures. Procedings 28 th Conferemce on Research in Medical Education. Washington: American Association of Medical Colleges.

14. Page OG, Fielding DW (1980) Petformance on PMP's and performance in practice. are they related? Joural of Medical Education 55, 529-37.

15. Ramsey PO. Carline JD, Inui YS, Larsom EB, LoGerfo JP, werrich MD (1989) Predictive validiry of certification by the American Board of Intemal Medicine. Anmals of Intemal Medicine 110, 719-26.

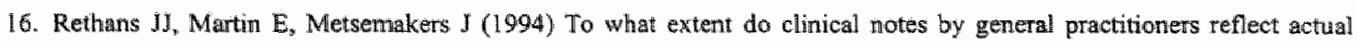
performance? A study using simulated patients. British Journal of General Practice 44, $153-156$.

17. Harden $R$, Gleseson $F(1979$ ) Assessment of clinical competence using an objective structured clinical examination (OSCE). Medical Education 13,41-54.

18. Anderson MB \& Kassebaum DG (1993) Proceedings of the AAMC s consensus conference of the use of stundardized patients in the treaching and evaluation of chinical skills. Acadernc Medicine $68,437-83$. 
19. Reznick RK, Sme S, Baumber JS (1993) Guidelines for estimating real cost of an objective structured slinical examination. Academic Medicine 68, 513-17.

20. Campbell LM, Murray TS. Assessment of competence (1996) British Joumal of General Practice 46, 619-22.

21. Pollemans M (1994) Kennistoetsing bij huisartsen. [Thesis]. [Assessment of knowledge of general practitioners]. Maastricht: Rijksuniversiteit Limburg-

22. Van Thiel $J$, Van der Vleuten $C_{n}$ Kraan $H$. Assessment of medical interviewing skills: Generalizability of seores using successive MAAS-wersions. Im: Harden RM, Hart IR, Mulholland $H$, ed. Approaches to assessment of clinical competence-Part 2. Norwich: Page brothers, 1992; 536-540.

23. Lamberts $\mathrm{H}_{3}$ Wood $\mathrm{M}$, editors (1987) Intemational Classification of Primary Care. Oxford: Oxford University Press.

24. Van Leeuwen $Y(1995)$ Growth in knowledge of tranees in general practice. Figures on facts. [Thesis] Masstricht: Universitaire Pers.

25. Jansen JM, Tan LHC Var der Vleuten CPM, Luijk van SJ, Rethans J, Grol RPTM (1995) Assessment of conapetence in technical clinical skills of general practitioners. Medical Education 29, 247-53.

26. Ram P, Grol R, Rethans JJ, Van der Vleuten C, Kester A. Assessment of General Practitioners by video observation of medical and communicative in daily practice: issues of validity, reliability and feasibility. Acepted by Medical Education. In press.

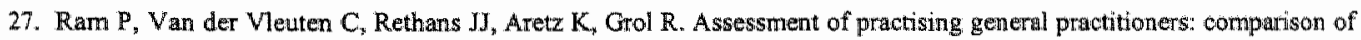
observation in a station exam using standardized patients with observation of real surgery in daily practice. In press.

28. Brennan RL (1983) Elements of generalizability theory. Iowa City, Iowa: American College Testing Publications. 


\section{Chapter 5}

\section{Structure and process: the relationship between practice management and actual clinical performance in general practice.}

In press by Family Practice: Structure and process: the relationship between practice management and actual clinical performance in general practice: Paul Ram, Richard Grol, Pieter van den Hombergh, Jan-Joost Rethans, Cees van der Vleuten and Karin Aretz. 


\section{Summary}

Objectives. The precise relationship between practice management (structure) and the doctor"s actual performance (process) in general practice is tenuous. Analysis of their mutual relationship may yield insight into the way they contribute to outcome and into corresponding assessment procedures.

Method. In a cross sectional study consultations of 93 General Practitioners (GPs) were videotaped in their own practice and assessed by peer-observers on medical performance and on communication with patients, followed by a practice visit by a non-physician observer using a validated Visit Instrument to assess Practice management (VIP).

Pearson correlations (observed and disattenuated for unreliability of the instruments) between scores on 22 practice management dimensions and scores of 16 selected cases on medical periormaince and communication were calculated. The predictive value of specific practice management aspects for actual performance was detemined by multiple regression analysis, with performance scores as dependent variables and scores on the 22 management dimensions and GPs' professional characteristics as independent variables.

Results. Nine practice management dimensions correlated significantly with medical performance and so did five dimensions with actual communication with patients. Overall, most associations were weak.

Combined with demographic variables (age for medical performance and working single-handedly for communication), 26 percent of variance in medical performance scores could be explained by only three practice management dimensions. The practice management dimension "delegation of medical technical tasks to the practice assistant" explained 11 percent of variance in communication with patients. Organization of quality assessment activities explained most of the variation in medical performance.

Conclusions. Practice management (structure) and actual performance (process) seem largely autonomous constructs. Quality improvement and assessment activities should emphasize that practice management is different from actual performance. Structure and process may contribute to patient outcome independently from each other.

Keywords: general practice, practice management, structure, clinical perfomance, process, assessment.

\section{Introduction}

Maintaining and improving quality in all aspects of patient care is of paramount importance and a challenge for all General Practitioners (GPs). It requires setting targets for good clinical practice and a continuous process of collection and evaluation of data on clinical performance, on communication with patients as well as on practice management. 1,2 A framework for measuring quality is 
available: the classic triad of structure, process and outcome. ${ }^{3}$ In this triad, structure describes the physical features of health care, emphasizing surgery premises, equipment, medical records and other aspects of practice management, whereas process refers to clinical interactions and communcation between doctors and patients. The synonym for process is actual clinical performance, defined as what a doctor is doing in daily practice in medical care and in communication with patients. ${ }^{4}$ Outcome is defined as the changes in a patient's current and future health status that can be attributed to past health care and is the ultimate target of quality of care. The precise relation between structure and process is still tenuous. ${ }^{5}$ More structure tended to be equated simplistically with better care and poor management was supposed to result in a lower standard of clinical care. ${ }^{6}$ One has assumed that for the average doctor quality fails when the system or structure fails. "This presumed self-evidence and lack of valid and reliable methods for assessment of actual clinical performance and of practice management may be responsible for the indistinctness of this relationship to the present day. Previous studies analysed clinical performance extensively, but usually in competence-based tests using standardized patients or in daily practice isolated from practice management. ${ }^{810}$ In conclusion, there is still no evidence that structure and process are two inter-related constructs, ending in patient outcome via an imaginary contimuous line."

Insight in the precise relationship between structure and process will influence quality improvement activities of an individual GP, the profession and assessors in general practice. For example, improving performance (process) may depend on specific practice management aspects (structure) which are directly related to that specific performance, for example:" "is my performance hampered because of the presence of an uncalibrated blood pressure device?" On the other hand, performanice and practice management aspects can be analysed separately if there is no mutual relationship. In addition, guidelines and standards for clinical performance set by the profession should include indicators for specific practice management aspects if these are "conditional" for good performance. ${ }^{12}$ Finally, the possible use of practice management aspects as "performance indicators" in assessment procedures, less complex and less expensive than direct assessment of performance, depends on the predictive value of those aspects for actual performance: ${ }^{13}$ Therefore, transparency in the relation between structure and process will benefit effectiveness, efficiency and other core components of quality. ${ }^{14}$

Recently, valid and reliable methods to assess practice management and actual performance have become available. ${ }^{15-17}$ The focus of this study was to investigate the relation between different aspects of practice management on the one hand with actual medical perfornance and actual communication with patients on the other. We especially focused on the predictive value of practice management for actual performance. 


\section{Method}

\section{Procedure and subjects}

In cross-sectional study actual performance and practice management of 93 GPs were assessed, by using videotaped regular consultations and by visiting GPs ${ }^{*}$ practices. GPs in the south of the Netherlands were invited by letter to participate in this study and 220 (25\%) reacted positively. For budgetary reasons 135 GPs were randomly selected for the study, 100 of them to be video taped and assessed in daily surgery and to be visited by trained non-physician observers, the other 35 to serve ass peer observers to assess the video taped consultations.

Personal or professional characteristics such as age, gender, working full time or part time, working single-handedly, or having a training practice were taken into account since these characteristics may influence actual performance. ${ }^{18}$

Assessment of actual clinical performance (process).

A video-observation system, two cameras with built-in microphone, a monitor and a recorder, was installed by trained electricians in each practice. All consultations were recorded both in the consultation room and the examination room. The GP was responsible for switching from one camera to the other, and for recording patient and consultation data into a logbook directly after the consultation. The practice-assistant informed patients about the video recording and asked their permission. Consent was registered and video recordings were erased if patients revoked their permission. In order to select a representative sample of consultations, a "blueprint" for this video assessment of actual performance was designed based on the prevalence of complaints and diseases in general practice and on a nationally accepted job description. ${ }^{19,20}$ By means of this blueprint ten specific selection criteria were formulated. Using logbook data 20 consultations per GP, 16 for direct observation and 4 as reserve, were selected. After selection, the percentages of samples which met each criterion fully were calculated. In this way content validity of the sample of consultations was obtained (table 1 ). The consultations were assessed by peer observers using the MAAS-global scoring list. This is a validated instrument for measuring both communication with patients and taedical performance. This instrument consists of 12 items on communication, such as exploring patients" reason for encounter, organizing the consultation systematicly, summarizing, and reflecting emotions, and four items on medical performance: history-taking, physical examination, evaluation/diagnosis and patient management. ${ }^{21,22}$

Reliability of the video assessment of actual performance was calculated using generalizability theory. ${ }^{23}$ Acceptable generalizability coefficients $(>0.80)$ were reached after 16 consultations for scores both on communication with patients and medical performance using a single rater. ${ }^{24}$

Assessment of pracrice management (structure)

After video observation of actual clinical performance, practice management of participants was assessed by a trained non-physician observer using the "Visit Instrument to assess Practice management (VIP)" in a practice visit. ${ }^{25}$ In this method, practice management is defined as "all aspects of 
the GP"s task necessary to realize good operation of care, excluding clinical care or treatment of patients", and it concerns premises and equipment, delegation to the assistants and collaboration with health professionals, service and organization of the practice, administration, organization of quality improvement, workload and job stress. This method is based on a framework comprising six chapters and twenty-two dimensions covering the complete domain of practice management, validated by means of consecutive studies in three groups with 59,110 and 90 GPs respectively. ${ }^{16}$ The number of indicators for each dimension of practice management are represented in table 2. GPs, practice assistants, patients and observers completed questionnaires and observation sheets before and during the practice visit. The response category was "yes or no" for most indicators, except for time spent on collaboration, waiting time for patients and workload (minutes and hours) and for job stress (5-point Likert scale).

TABLE 1. SAMPLE CRTERLA FOR SELECTING WDEO TAPED CONSULTATIONS TO BE INCLUDED IN DATA ANALYSIS AND PERCENTAGE OF SAMPLES WHICH MET THE CRITERION FULLY

sample criteria

representativeness of $2 \&$ different ICPC chapters

the first 5 video taped consultations not included

at least 8 cases with accepted guidelines

representativeness of 5 ICPC chapters with highest prevalence: $D, K, L, R$ and $S$

at least 14 cases with duration $\geq 5$ and $s 15$ minutes $/$ case

age distribution: youngest patient $<18$ years and oldest patient $>65$ years

gender heterogeneity: $\geq 6$ and $s 10$ female patients

at least 8 initial consultations, at least 4 follow-up consultations

maximum 2 cases with $>2$ reasons for encounter

maximum 2 cases with only psychosocial problems samples (\%) in which

criterion was fully met

100.0

94.6

86.2

71.3

86.2

84.0

72.3

70.2

92.6

93.6 
I. Lquipment of the Practice

Indicators (n)

1. Hygiene

8

2. Presence of equipment 14

3. Use of equipment 12

4. Conkent of the doctors bag 11

II. Delegation and Collaboration:

5. Delegathion of chinical and techrical tasks 9

6. Delegated laboratory rests (in service) 4

7. Collaboration with colleagues (local CP-group) $\quad 12$

8. Collaboration with direct staff (primary level) 5

9. Collaboriation with other careproviders 8

III. Service and Organization

10. Accessibility

11. Organdzation of surgery/availability

12. GP's usage of information materials (in surgery)

13. Organzation of information

14. Organization of preventive activities

IV. Medicall Record Keeping

15. Summary health problembackground 5

16. Recording using SOAP system 4

17. Recording of prescription 4

18. Level of computerized records 4

19. Actual usage of records 3

V. Organization of Quality Improvement

20. Quality assessment activities

(year report, assessment on outcome data)

VI. Workload and Job Stress

21. a. Primary activitics (direct patient care) *

b. Secondary activities (indrect patient care) 7

c. Tertiary activities (medical education) 3

d. Quarternary activities (jofessionall meetings) I

e. Total workload 15

22. a. Job satisfaction, commitment 4

b. Inappropriate derinands 4

c. Satisfied with avallable time

d. Costs versus bentifis 3

e. Experienced workload $\$ 6$ 


\section{Analysis}

For the Practice Video Assessment consultation scores were calculated by summing the item responses on the MAAS-Global for each consultation expressed as a percentage score. The mean score across the 16 consultations (i.e the sample) determined the total score of the participant. These scores were calculated for the communication with patients and medical performance separately. Similarly summing the item responses of indicators resulted in scores on each practice management dimension of the VIP.

Pearson correlations, observed and disattenuated for unreliability of the instruments, between scores on the 22 dimensions of practice management and the MAAS-Global scores on both medical performance and communication with patients were calculated. To detemine predictive value of practice management aspects for actual clinical performance a multiple regression analysis was used with both medical performance scores and commumication scores as dependent variables and. scores on the 22 practice management dimensions and the GP's (professional) characteristics as independent variables. $R$-squared was calculated to measure the extent of explained variance in the performance scores.

\section{Results}

In total seven participants (7\%) dropped out arguing that "participation is too threatening" $(1 \%)$, "on holiday" ( $2 \%$ ) and "too busy to participate" (4\%), leaving 93 GPs for whom complete data could be collected. On demographic variables the study population $(N=93)$ was representative for Dutch GPs, except for age (Dutch GPs' Mean: 44.3 years, SD: 5.5 against Mean: 43.1 years, SD 7.4. T-test: $t=2.03 ; \mathrm{df}=92 ; p<0.05$ ).

Table 3 shows disattenuated Pearson correlations between practice mamagement dimemsions of the VIP on the one hand and scores on medical performance and communication with patients of the Practice Video Assessment on the other. 
TARLE 3. PEAFSOW CORRELATIONS BETWEEN SCORES ON PRACTICE VIDEO ASESSMENT (PVA) AND SCORES ON PRACTICE MAASAGEMENT DUMENSIONS OF THE VTP

\begin{tabular}{|c|c|c|c|c|}
\hline \multirow[b]{2}{*}{ Dimension } & \multicolumn{2}{|c|}{$\begin{array}{c}\text { PVA } \\
\text { medical perfionnance }\end{array}$} & \multicolumn{2}{|c|}{$\begin{array}{c}\text { PVA } \\
\text { cornmunication }\end{array}$} \\
\hline & \multicolumn{2}{|c|}{ trae eorrelation (p) } & \multicolumn{2}{|c|}{ true comelation $(p)$} \\
\hline \multicolumn{5}{|l|}{ 1. Equip ment of Practice: } \\
\hline $\begin{array}{l}\text { 1. Hygriene } \\
\text { 2. Presence equaprnent }\end{array}$ & .30 & $(0.0)$ & 31 & $(.01)$ \\
\hline $\begin{array}{l}\text { 2. Presence equipment } \\
\text { 3. Usse equipment }\end{array}$ & .32 & $(00)$ & 21 & $(.05)$ \\
\hline $\begin{array}{l}\text { 3. Uste equipmient } \\
\text { 4. Doctor"s bags }\end{array}$ & .28 & (01) & 03 & * \\
\hline \multirow{2}{*}{\multicolumn{5}{|c|}{ II. Delegation and Collaboration: }} \\
\hline 5. Delegation tagks & & & & \\
\hline 6. Dellegated tests & .08 & $(05)$ & 35 & $(.05)$ \\
\hline 7. Collaboration colleagues & .25 & 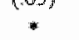 & .06 & (a1) \\
\hline 8. Collaboration direct staff & .04 & - & -00 & : \\
\hline 9. Collaboration others & -.13 & * & -10 & i \\
\hline \multicolumn{5}{|l|}{ III. Service and Organization: } \\
\hline 10. Accessiblity & -09 & $*$ & -20 & * \\
\hline 11. Surgery/availabiltity & .01 & . & .15 & . \\
\hline 12. Usage information & .06 & * & -15 & * \\
\hline 13. Organization information & $\mathrm{II}$ & * & .11 & $*$ \\
\hline 14. Organization prevention & .09 & " & .04 & * \\
\hline \multicolumn{5}{|l|}{ IV. Medical Recort Kerping: } \\
\hline 15. Surrmanyy basic data & .22 & $(05)$ & .34 & $(.01)$ \\
\hline 16. SOAP system & .23 & $(05)$ & .01 & • \\
\hline 17. Prescription & .24 & $(05)$ & a.t & * \\
\hline 18. Computerized records & .16 & * & .09 & $*$ \\
\hline 19. Usage records & .14 & * & .09 & $*$ \\
\hline \multicolumn{5}{|c|}{ V. Org. Quality Improvement: } \\
\hline 20. Quality activities & .43 & $(0 \mathrm{i})$ & .32 & (.01) \\
\hline \multicolumn{5}{|l|}{ Vl. Workdoad and Job Stress } \\
\hline 2la Primary activities & -.07 & * & .14 & * \\
\hline 2lb Secundary activities & -.07 & * & .09 & $\cdot$ \\
\hline 2le Tertiary actiwities & .22 & (.04) & 10 & * \\
\hline 2id Quartemury activities & 19 & ${ }^{*}$ & .00 & * \\
\hline Zle Total activities & .07 & * & -12 & * \\
\hline 22a Jab satasfaction & .07 & $*$ & -.02 & $*$ \\
\hline 226 thappropriate demands & .07 & * & $0 \%$ & $*$ \\
\hline 220 Sâtistied avaliable time & .14 & $*$ & 12 & $*$ \\
\hline $22 d$ Costs versus benefiti & 13 & * & -.15 & 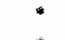 \\
\hline 220 Experiented work load & .2 & * & -.02 & $*$ \\
\hline
\end{tabular}

* is not sigzuficint

alsserned correlathons"

For dimension 21 (workload in hours/week) only, the observed correlations are represented, since no reliability, i.e. internal consistency, could be measured on this dimension.

Nine practice management dimensions correlated significantly with medical performance: "Hygiene", "Presence of equipment", "Use of equipment", and "Laboratory tasks delegated to the practice assistant"; three dimensions for medical record keeping: "Recording basic data/problem lists", "Recording using SOAP system" and "Recording of prescriptions", in addition, "Organization of quality improvernent" and "Tertiary activities" (i.e. Workload in hours per week on all 
continuing medical education activities, quality improvement and reading literature). Relatively pronounced associations were found for the dimensions "presence of equipment" and "organization of quality improvement" (assessment with the help of data from the medical insurance, prescriptions, referrals and diagnostics). Indicators of those dimensions are represented in table 4.

TABLE 4. PRACTICE MANAGEMENT DIMENSIONS WHCH CORRELATE SIGNIFICANTLY WTH ACTUAL PERFORMANCE

Dimension 1: Hygiene

Presence in the examination room of:

- Samitary pad

- Disposable baby diaper

- Bucket for used equipment.

- Roller towelidisposable towels

Presence in treatment room of:

- "Fenestrated sterile drape" minor surgery

- Routine for disinfection of table

- Use of gloves to clean instruments

- Use of indicator tape for sterilization

Dïmension 2: Presence of equipment

Presence of:

- Filugersplints

- Nasal ribbon gauze

- Caustics to treat recuring epistaxis

- lintrawenous fluid and giving set

- Plaster of Paris

- Test for microscopic blood in faeces

- Unine cultate set

- Eyedrill

- Tonometer

- IUD insertion kit

- Electrocautery equipment

- Proctoscope

- Audiometer

- Electrocardiograph

Dinension 3: Use of equipment"

- Use or application by the GP of:

- Bladder catheter insertion (P l chyear)

- Peak flow meter

- Migal forceps

- Disposable local anaesthetic eye drops

- Vibration tuming fork

- Microsc exam. of skin snip for mycosis

- Microsc exam of clue cel trictiomonas

- Taping a sprained ankle ( $1 x^{\prime} / x^{\prime}$ year)

- Pressure gradient bandage in leg ulcer

- Q. -meter (Quetelet Index)

- Stenoperic aperture

$-20 \mathrm{D}$ ragnifying glass for fundoscopy
Dimension 5: Delegation medical tasks to assistant ${ }^{2}$

- Removitig sutures

- Liquid nitroger application to warts

- Ear syringing

- Venapunction

- Exam follow-up cardiowasc patients

- Making ECG

- Audiometry

- Gluing sriall wounds

- Applying preswure gradient bandage in: leg ulcer

Dimemsion 6: Lab-tests delegated to assistant 1,2:

- Microsc. cxam urine sediment

- Blood sugar testing.

- "Test microse. blood in faeces

- Counting leucocytes in blood

Dimension 15: Summary heatth problem/background 1.2

- Problem list

- Year af diagnosis

- Family history

- Basic data

- Profession of patient

Dimension 16: Recording using the SOAP system "

- Reason for encounter ( $S=$ subjective)

- Results of exam. and investigations (Objective)

- Concise staternent of the satuation (Andlysis)

- Plan/Action/nio (Plan)

Dimension 17: Recording of prescriptions

- Strength medication

- Dosage and administration

- Duration medication

. Actual medicationi of the patient retrievable

Dimension 20: Quality activities: 2

- Presence of a year report

Asseswent with the help of dato of

- Medical insuriance

- Prescriptions

- Referrall letters

- Diagnostics

- Other feedback data

significant relationship with medical performance

${ }^{2}$ significant relationship with communication with patients 
"Time spent on direct and indirect patient care" (see table 3, page 80 dimension 21) did not correlate with the score on medical performance. Similarly neither "Service and organization", including accessibility, organization of the surgeries, availability, and organization of preventive activities, nor "Job stress" showed a significant correlation.

Five practice management dimensions correlated with communication scores of the Practice Video Assessment: "Hygiene", "Medical technical tasks delegated to the practice assistant", "Laboratory tasks delegated to the practice-assistant", "Recording basic data/problem lists" and "Organization of quality improvement activities". No significant correlations were found for "Service and organization" and "Workload and job stress". Overall, most associations were weak.

Table 5 shows the results of multiple regression analysis with the video assessment scores on communication with patients and medical performance as dependent variables and scores on the 22 practice management dimensions and data on the GP's (professional) characteristics as independent variables. The predictive value of practice management (R-square) for medical performance was moderate $(22 \%)$ and the predictive value for communication was low $(6 \%)$. The contribution of personal and professional variables of GPs to the explanation of variance in performance scores was low. Increasing age predicted lower scores on medical performance and working singlehandedly predicted lower scores on communication with patients. "Organization of quality assessment" and "Tertiary activities", such as (individual) continuing medical education activities, predicted higher scores on medical performance. "Organization of quality assessment" explained most of the variation in medical performance $(10 \%)$, followed by "Tertiary activities" (8\%).

TABle 5. MULTIPLE REgRession AMALYSIS (FORWARD); DEPENDENT VARLABLES: SCORES ON PRACTICE VDERO ASSESSMENT (PVA), INDEPENDENT VARIABLES: SCORES ON PRACTICE MANAGEMENT DIMENSIONS OF THE VIP AND GPS" CHARACTERISTICS*

Biêta $t \quad R \quad$ R Squared

(adjusted)

Medical performance PVA

Organization quality assessment

Tertiary activities

Age"

Collabortition with other careproviders

Communication PVIA

Delegated laboratory tests

Single-handed

$\begin{array}{rrrr}.39 & 4.05^{2} & .32 & .10(.09) \\ .32 & 3.26^{2} & .42 & .18(.16) \\ .23 & -2.37^{1} & .47 & .22(.19) \\ -.20 & -2.06^{1} & .51 & .26(.22) \\ & & & \\ .26 & 2.52^{1} & .25 & .06(.05) \\ -.22 & -2.13^{1} & .33 & .11(.09)\end{array}$

${ }^{1} \mathrm{p} \leq 05$

${ }^{2} \mathrm{p} \leq 01$ 


\section{Discussion}

To our knowledge this is the first study that analysed the relationship between GPs' communication with patients and medical performance (process) and practice management (structure) by observation in actual daily practice.

We realize that our study population is not representative, since GPs participated voluntarily. However, since our study is a methodological study, this non-representativeness is not a major problem. In addition, analysis of the relationship between structure and process within the same population using valid and reliable instruments allows for conclusions.

In our study we found a clear but limited relation between some aspects of practice management on the one hand and actual clinical performance on the other. A minority of practice management aspects did correlate with actual performance, but the contribution of these aspects to the explanation of variance in performance scores is low. Therefore we are tempted to conclude that for assessment process and structure are largely independent constructs and that good practice management does not guarantee good performance in general practice care.

Nevertheless, some results point to connections between specific structure aspects and process. This may have practical implications for practising GPs, for both implementation of assessment procedures into general practice and further research. Firstly, presence of appropriate equipment and adequate medical record keeping (dimensions $2,3,15,16$ and 17, see table 3 ) have a positive relationship with quality of actual medical performance. These appeared to be essential tools in the process of patient care. This may stimulate GPs to invest in diagnostic and therapeutic equipment and to keep adequate records. Secondly, time spent on (continuing) medical education (tertiary activities) is associated with GPs who performed well, which suggests that GPs' educational activities may lead to better care. Thirdly, the predictive value of organization of quality improvement, such as data collection on referrals and prescriptions, for actual medical performance pleads for quality assessment activities embedded in GPs' practices. Moreover, such good organization of data collection enables GPs to react accordingly in line with quality assurance principles. ${ }^{1}$ Finally, with regard to the relation between communication with patients and specific practice management aspects, hypothesize that delegation of tasks to the practice assistant and good record keeping (basic data, family history, profession of the patient) may be related to GPs" communication skills The negative relation between working single-handedly and a high score of communication with patients, see table 4 , may be explained by the contrasting difference with multiple partner practices, where collaboration must rely on communication and delegation of tasks within a team.

"Workload" and "Job stress" had no predictive value for performance scores, suggesting they are rather autonomous constructs. Neither was associated with actual performance or with practice management, the latter in line with previous research. ${ }^{26}$

In previous assessment procedures, some aspects of practice management (structure) such as medical record keeping, data of prescriptions and referrals, have been used as indicators for actual 
clinical performance. 27, In our study these indicators indeed had a significant relationship with actual performance but explained little wariance of actual clinical performance. The predictive value of personal (age) and professional (working single-handedly) characteristics for actual performance is limited, but in line with previous research. ${ }^{18}$

It is hazardous to draw definite conclusions from this study. Aspects of practice management are either essential catalysts for "good process" or the result of common characteristics of doctors who perform well, or even mirror images of each other. ${ }^{3}$ Further research of this relationship and the contribution of process and structure to patient outcome is required.

Most aspects of practice management had no predictive value for actual climical performance. Therefore, practice management and actual clinical performance should be considered as relatively autonomous constructs requiring separate and comprehensive assessment to improve process and structure in general practice care.

\section{References}

1. Grol $R_{,}$Werusing $M$, Jacobs $A, B a k e r ~ R$, eds. Quality assurance in generall practice. The state of the art in Europe. NHG and EQuiP, 1993. Utrecht the Netherlands.

2. Donabedian A. Evaluating the quality of medical care. Milbank Memorial Fund Quarterly 1966, 44: 166 203.

3. Donabedian A. Explorations in quality assessment and monitoring 1. The definition of quality and approaches to its assessment. Arth Arbor: Health Administration Press, 1980.

4. Rethans JJ, Sturmans F, Drop MJ, Van der Vleuten CPM, Hobus P. Does competence of general practitioners predict their performance? $\mathrm{Br}$ Med J 1991; 303: $1377-80$.

5. Southgate L. Freedom and discipline: clinical practice and the assessment of clinical conpetence (James Mackenzie lecture 1993). Br J Gen Pract 1994; 44: 87-9:2.

6. Jones RVH, Bolder KJ, Perreira Gray DJ, Hall MS. Rumning a practice, a manual of practice management. 3 md Edition. London: Chapman and Hall, 1990.

7. Berwick DM. Continuous improvement as an ideal in health care. New Engl J Med 1989;320: 53-6.

8. Vam der Veuten CPM, Swanson DB. Assessment of clinical skills with standardized patients: State of the Art. Teaching and Learming in Medicine 1990;2:58*76.

9. Cox J, Mulholland A. An instrument for assessment of wideotapes of genetal practitioners" performance. B Med J $1993 ; 306: 1043-6$

10. Bensing IM. Doctor-patient communication and the quality of care. An observation study into affective and instrumental behaviour in general practice.[Dissertation] Utrecht: WIEL, 1991.

11. Irvine Donald \& Irvine Sally. The practice of quality. Radeliffe Medical Press Ltd, 1996. Oxford and New York.

12. Grol $\mathbb{R}$. Developnients of gudelines in genefal practice. Br J Gen Pract 1993; 43: 146 51.

13. Houghton G. General practitioner reaccreditation: use of performance indicators. Br J Gen Pract 1995; 45:677-81.

14. Maxwell RJ. Quality assessment in health. Br Med J 1984; 288:1470-2.

1.5. Van den Hombergh P, Dalinuijen J, Grol R, Dijkers FW, Van der Voor JPM. Checklist praktijkvoering. IChecklist practice inanagement] Utrecht: $\mathrm{NHG} 1994$.

16. Vai den Hombergh P, Grol R, Smits AN, Wan den Bosch WJMM Visitatie van huisartspraktijken; natar tometsing wan de praiktijkvoming. [A practice visit to assess the organization of the general practitioner] Huisarts Wet 1995; 38 : $169-74$

17. Ram P, Groll R, Rethans JJ, Vleuten van der C, Schouten B. Assessment of General Practitioners by video observation of medical and communicative performance in daily practice: issues of validity, reliability and feasibility. Submitted for publication.

18. Caulford PG, Lamb SB, Kaigas TB, Hanna $\mathrm{E}_{\text {, Noman }} \mathrm{GR}, \mathrm{Devis} \mathrm{DA}$. Physician incompetence: specific problems and predictors. Acad Med 1994; 69 suppl(10): 16-20.

19. Lamberts H, Wood M, editors. International Classification of Primary Care. Oxford: Oxford University Press, 1987. 
20. Springer MP, editor. Basic job description for the general practitioner. Utrecht: Dutch National Association of Gerterial Practitioners, 1983.

21. Van Thiel J, Kraan $H_{3}$ Van der Vleuten C. Reliability and feasibility of measuring medical interviewing skills: the revised Masastricht History-taking and Advice Checklist. Med Educ 1991; 25:224-9.

22. Thiel van J, Vleuten van der CPM, Kraan H. Assessment of medieal interviewing skils: Generahizability of scores using successive MAAS-versions. In: Harten RM, Hart IR, Mulholland $\mathrm{H}$, editors. Approaches to alssessment of clinical competence-Purt 2. Norwich: Page brothers, 1992; 536-540.

23. Breman RL. Elements of Generalizability Theory. Towa City, Iowa: Amenican College Testing Publications, 1983.

24. Ram P, Van der Vleuten $C$, Rethans JJ, Aretz K, Grol R. Assessment of practising general practitioners: conparison of viceo observation in a station exam using standardized pattents with video observation of real surgery in dally practice. In press.

25. Van den Hombergh $P$, Grol $\mathbb{R}$, Van den Hoogen $H$. Assessment of management in gemeral practice: validation of a practice visit method. Submitted.

26. Van den Hombergh P, Grol R, Van den Hoogen HJM, Van den Boseh WJHM. Werkbelasting en ervaren werkdiuk wan de huisarts. [Workload and experienced job stress of the GP] HLisarts Wet 1997; 40:376-81.

27. Ramsey PG, Carline JD, Innui TS, Larson EB, LoGerfo MP, Wenrich MD. Predictivi waliduty of centification by the American Board of Internal Medicine. Ann Int Med 1989; 110:719-26.

28. Norman GR, Davis DA, Painvin A, Rath D, Ragber M. Comprehensive assessment of clinical competence of fanilygemerall physicians using multiple measures. Proceedings 28 th Conference on medical education, Washington DC, $1989 ; 357-363$ 
Chapter 6.

\section{General practitioners' communication with patients: quality assessment by peers, patients or standardized patients?}

Submitted as: General practitioners'communication with patients: quality assessment by peers, patients or standardized patients? Paul Ram, Michel Wensing, Jan-Joost Rethans, Sjoerd Hobma, Karin Aretz, Cees van der Vleuten and Richard Grol 


\section{Summary}

Objectives-To determine to what extent assessment of General Practitioners (GPs) by peers, Standardized Patients (SPs) and real patients provide relevant information about GPs communicative performance, from both the professional perspective and patients' perspective.

Design-Two groups of 43 GPs each went through a "Multiple Station Examination", i.e. a simulated surgery using SPs, and through a "Practice Assessment" in regular surgeries. GPs' communicative performance was evaluated by peers, SPs and real patients using scoring lists.

Setting-The south of the Netherlands

Subjects-86 Dutch GPs

Measures-The test score per GP, which was the mean score across all cases for each method. The correlation between the scores given by (standardized) patients and scores given by peer-observers (disattenuated bivariate Pearson correlations) in both surgeries. The significance level of differences between scores of both surgeries (possible time-order effects caused by the design).

Results-No correlation was found between the both surgeries, except for the patients' scores in one group. In the "Multiple Station Examination" SP scores correlated with the peer scores. In the "Practice Assessment" scores given by real patients did not correlate with peer scores. Real patients scores and SP scores were higher than peer scores. Only in the "Multiple Station Examination" peer scores in group 2 were higher than peer scores in group 1.

Conclusions-The quality of GPs' communicative performance in a simulated surgery may differ from $\mathrm{GPs}^{\prime}$ communicative performance in real practice. In the simulated situation SPs were consistent with peers to some extent. Both real patients and SPs valued GPs' quality of communicative performance more positively than peers. Compared to SPs and peers, real patients may have a different perspective on the quality of GPs' communicative performance. In an assessment using multiple measures a possible time-order effect has to be taken into account.

Implications-Both the assessment setting, i.e. a simulated surgery or real surgery, and the type of evaluators, i.e. peers, SPs or real patients, have their impact on scores. Peer evaluation combined with patients' evaluation provides relevant information about GPs" communicative performance from both the professional perspective and the consumers' perspective.

Keywords: general practice, communication, (standardized) patients, assessment 


\section{Introduction}

Communication between doctor and patient, such as exploring expectations and feelings, history taking, or providing information, is one of the cornerstones of clinical practice. Patients' compliance and satisfaction with care and even clinical outcomes are positively influenced by effective communication. ${ }^{1-6}$ Both patients and general practitioners (GPs) feel that conmunication is important and that its quality requires more attention. ${ }^{7.9}$ However, GPs do not always acquire sufficient communication skills through their professional training and clinical experience. 10 Therefore, additional training and quality improvement activities focused on GPS ${ }^{4}$ communication skills may be required for the improvement of professional performance and for certification and recertification. As part of it, procedures are needed to assess the quality of performance in this area, since quality improvement depends on good understanding of the process and outcomes of care provision. ${ }^{11,12}$ Many quality assessment methods have been developed ${ }^{13}$ but which are valid, reliable and feasible for use on a broad scale?

Direct observation of GPs' actuall performance in real practice approximates the real professional world as closely as possible and seems therefore to be the best approach to assess quality of communicating with patients. ${ }^{14}$ However, the case-mix of patients observed and the complexity of problems as usually presented in primary care is difficult to standardize, which may influence the findings. ${ }^{15}$ On the other hand, observation of GPs in a simulated situation can be standardized by using standardized patients (SPs) and cases, but the umnatural setting may influence GPs' performance and consequently the validity and reliability. ${ }^{16.17}$

Any observation method requires a careful selection of "observers". In both real practice and in a simulated setting the observed communicative performance can be evaluated by well-trained peers, by standardized patients or by real patients. From a professional perspective, evaluation by welltrained peers is an effective method, since peers are the natural experts with respect to the communication process between GPs and patients. However, they may mainly represent the view of professionals on quality, which may differ from the view of "consumers", i.e. patients." Moreover, the use of trained peer observers involves high cost.

Standardized patients (SPs) proved to be able to evaluate GPs" performance while presenting complaints in a simulated surgery or visiting GPs in real practice. ${ }^{18}$ Compared with real patients, SPs are less emotionally involved in the consultation and they may be better able to use explicit criteria, especially when they are trained for their evaluation task. ${ }^{19}$ From this perspective, SPs may be more objective than real patients. The use of trained SPs, who are able to observe GPs while presenting their simulated complaints, involves logistic problems as well as high cost. Using real patients to assess GPs' performance might be an attractive alternative. This method is relatively cheap, if a written questionnaire is used and if patients are not paid for their contribution. The question is, however, whether real patients, being consumers, evaluate the communicative performance of their GP differently from SPs or peer-observers. Patients may use different criteria, 
holding different beliefs and opinions on what constitutes good communicative performance in daily consultations. ${ }^{2021}$ In addition, patients" evaluations of their GP's communication may be influenced by their emotional involvement in the consultation and by their overall satisfaction with the GP's care as a result of previous experiences. Moreover, being used to their doctor's working style, they may have few experiences with other GPs, which makes their evaluation rather subjective than objective.

This study explores different quality assessment methods, applied in both daily practice and a simulated situation, using real patients, standardized patients and peer-observers to evaluate the quality of $\mathrm{GPs}^{\dagger}$ communication with patients. The study focuses on the relationship between the methods used. In addition, differences and consistencies between peers, SPS and real patients in evaluating GPs' communicative performance have been analysed.

\section{Methods}

\section{Subjects and design}

All GPs in the south of the Netherlands were invited by letter to participate in this study and 220 $(25 \%)$ reacted positively. For budgetary reasons 135 GPs were randomly selected, 100 of them to be assessed by observation, in both real daily surgery and a simulated surgery at the medical school, the other 35 served as peer-observers to assess GPs' consultations. Personal and professional characteristics such as age, gender, working full-time or part-time, working single-handed, or having a training practice were collected in order to determine representativeness. ${ }^{23}$

The study design is presented in figure 1. First, GP-participants $(\mathbb{N}=100)$ were randomly divided in two groups of $50 \mathrm{GPs}$ each, comparable on demographic characteristics, in order to check for timeorder effects as well as for reasons of feasibility. Group $\mathbb{1}$ went first through a "Multiple Station Examination", a real life-like surgery at a medical school. A few months later these GPs went through the "Practice Assessment" of regular surgeries in daily practice. Group 2 did the same assessments, but in reverse order. 


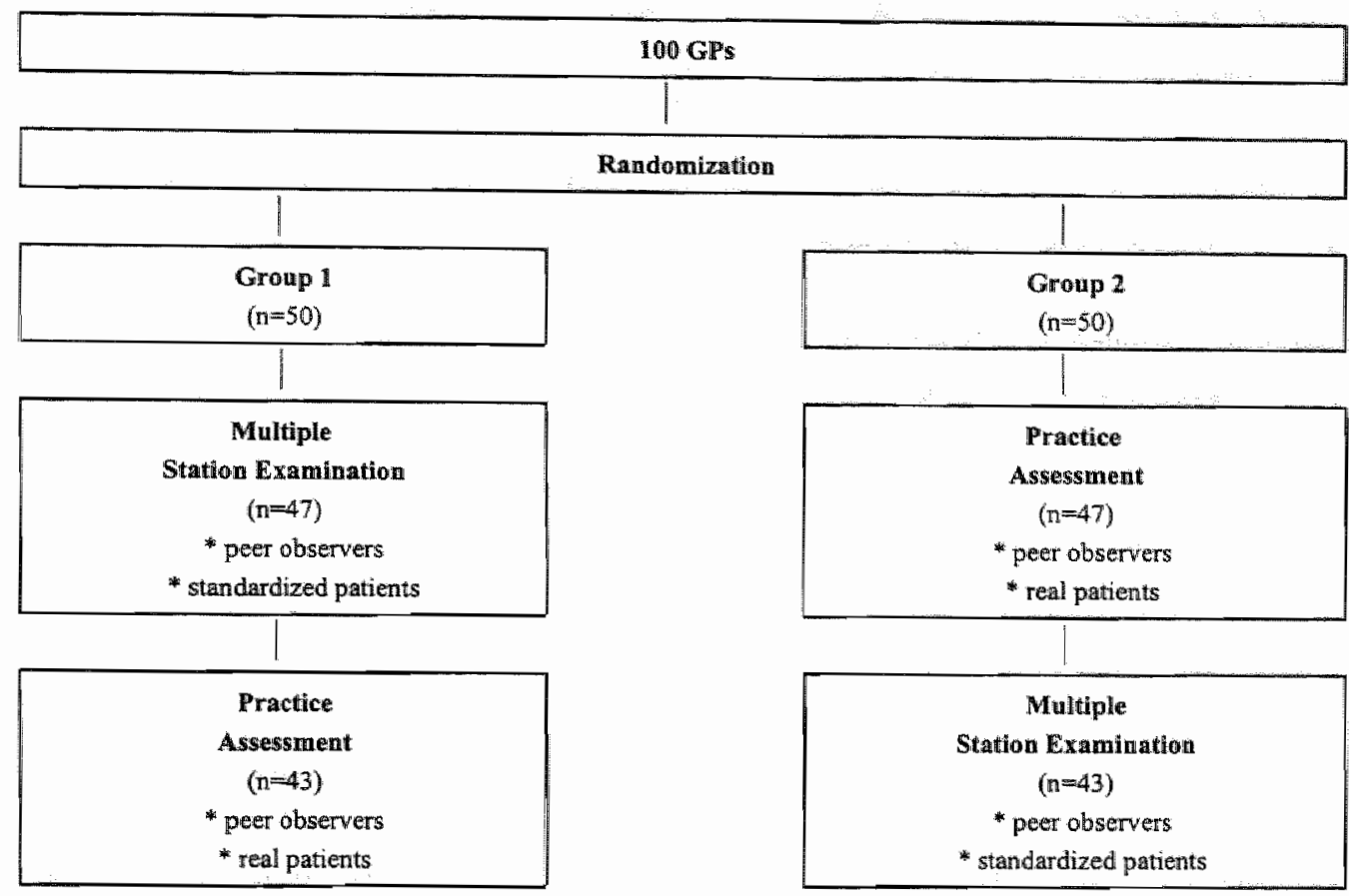

*obsenvers

\section{The Practice Assessment and the Multiple Station Examination}

In the "Practice Assessment", the communication with all patients who gave informed consent was video taped during one week, using two cameras: one for the consultation room and one for the physical examination room. For the assessment by peers, a representative sample of 16 consultations was selected from a logbook completed by the GPs, using a "blueprint" reflecting the prevalence of diseases and complaints in primary care as well as possible. ${ }^{23,24}$ For the assessment by patients, about two weeks later, real patients were randomly selected and asked in the GP's waiting room to fill in a written questionnaire. The number of patients, minimum 15 and maximum 30 , depended on the extent of the GP's working hours.

For the "Multiple Station Examination", eight cases were written by a panel of seven experienced GP's and portrayed by eight standardized patients (SPs). Again, the prevalence of diseases and complaints in primary care was reflected, including acute and chronic diseases as well as multiple problems. Rooms of the medical school were equipped as real-like surgeries and GPS were allowed 
to bring in their doctors' bag. The GPs remained in their rooms while the SPs rotated from one doctor to another, schematically following a "time pressure design" of 12 minutes per doctor (96 minutes in total). All consultations were video taped. Participants were instructed to perform as naturally as possible." ${ }^{16}$ Ss evaluated the GP"s communication immediately after each consultation. using a written questionnaire. The video taped consultations were assessed by peers.

Measurement instruments

Peer-observers evaluated the video taped consultations by using a previously validated instrument, containing 12 case-independent items (7-point Likert scale), called the MAAS-Global (Maastricht Anamnestic and Advice Scoring list-Global). ${ }^{25}$ These items were derived from literature on effective communication between GPs and patients. Seven items refer to successive phases in a consultation: entry, follow-up consultation, exploration of patients' needs, communication on physical examination, evaluation and diagnosis, communication on management plan, evaluation of consultation. The five remaining items refer to general communication skills: providing information, exploring emotions, summarizing, ordering and empathy. An extensive list of detailed criteria is available to guide the professional assessors. ${ }^{26}$ Reliability of the peer-observation, i.e. generalizability coefficients (Brennan 1.983), ${ }^{27}$ was 0.75 for the "Multiple Station Examination" and 0.83 for the "Practice Assessment".

Standardized patients evaluated GPs' performance after each case presented in the "Multiple Station Examination". Real patients evaluated GP'" performance, taken into account previous experiences. with their GP. Both standardized and real patients used a written questionnaire, containing 10 caseindependent items. Nine items of this list were based on eight indicators of the MAAS-Global: 1. exploration of patients' request for help ("wishes and expectations"', item 1);2. communication during physical examination ("touching with care and respect", item 2); 3. communication on management plan ("allows me a say in the choice of treatment", item 3); 4. ordering ("'switches not too quickly", item 4); 5. providing information ("understandable information", item 5, and "checks my understanding of the information given", item 6); 6. summarizing ("gives different meaning to my words than I intended", item 7); 7. exploring emotions ("pays attention to my feelings", item 8); and 8. naturalness/empathy/attentiveness ("gives me the chance to tell my story", item 9). A final item concerning overall satisfaction was added ("completely satisfied", item 10). Items had to be scored on a 5-point Likert scale. Reliability, i.e. Cronbach's alpha, of patients' evaluation of communication was 0.90 for the "Multiple Station Examination" (SPs) and 0.71 for the "Practice Assessment" (real patients). Items of these questionnaires are presented in figure 2. 
Figure 2: THE QUESTIONNAIRE NOTES ON PATIENTS" ENALUATION OF GPS" COMMUNICATION WTTH PATIENTS.

1. The chance to tell my story. The doctor's attitude is open, interested, attentive and inviting.

That is clear from his/her gestures and eye contact and in giving priority to you during the consultation.

2. Wishes and expectations. You may have wishes relating to how a problem is handled, for example whether or not you are referred, whether or not you receive medicines, and especially regarding receiving good advice or explanation. Your previous experiences or information from a newspaper or via television may be the source for these wishes, just as they may be for feelings of pain.

3. Careful and respectful touching during the physical examination. The doctor is polite and careful during contact, gives explanation and warns of possible pain in advance and reacts as necessary to your feelings of pain.

4. A say in what happens. The doctor consults with you about how to tackle the problem. He/she says what should happen from the medical point-of-view, but takes your wishes and possibilities into account. The pros and cons and possible alternatives are discussed.

5. Too quickly from one subject to the next. The doctor jumps from one subject to another. He/she doesn"t let you know that he/she is going to chance the subject. Because of the rapid changes you can't follow the consultation.

6. Checking the understanding of advice and information. The doctor asks you for your reaction to "information he/she has given you by asking questions such as "Do you understand what I say?" or "What do you think about it?".

7. Your words are interpreted differently from what you intended. When he/ she repeats or summarizes the information, the doctor does not express well what you mean or what you have.

8. Understandable information. You do not get too much information at one go. Nor does the doctor use difficult or medical terminology. Difficult concepts are explained to you.

9. Sufficient attention to your feelings. In every consultation feelings come up, as a result of memories, fear or happiness. The doctor asks about them, not too much, not too little, which helps to make the athmosphere of the consultation pleasant for you.

10. Fully satisfied. You can indicate your general feeling of satisfaction with the consultation here. A good guide is asking yourself if you would be happy to return to this doctor should that be necessary or if you are happy to have/keep this doctor as your family doctor. 


\section{Analysis}

All case scores in the "Multiple Station Examination" and "Practice Assessment" were calculated by summing the number of item responses for each case. All scores were expressed as percentages of the maximum score. The unit of analysis was the sumscore per GP, which was the mean score across all cases for a specific method. The correlation between SPs' scores, real patients' scores and scores given by peer-observers was assessed by calculating bivariate correlations (Pearson, corrected for attenuation, i.e. the unreliability of the instruments).

Bias caused by possible time-order effects was checked by calculating the significance level of differencess between scores of the "Multiple Station Examination" and scores of the "Practice Assessment", between and within both groups (paired and unpaired T-tests), for peer-observation and standardized patients' evaluation and evaluation by real patients separately.

\section{Results}

In total ten participants (10\%) dropped out arguing that "participation is too threatening" (1\%), "on holiday" (4\%) and "too busy to participate" (5\%). Four participants were excluded because the response rate in the evaluation by real patients in daily practice was too low $(<15)$. With respect to demographic variables the final study population $(\mathrm{N}=86)$ was representative for Dutch GPs, except for age (mean for Dutch GPs: 44.3 years, mean study population: 43.1 years, $p<0.05$ ).

An overview of the mean scores for each of the two groups in both "Practice Assessment" and "Multiple Station Examination" is presented in table 1.

TABLE 1. COMMUNICATION SCORES: EVALUATION BY PEER OBSERVERS, REAL PATIENTS AND STANDARDLED PATIENTS ON MULTHLE STATION EXAMINATION AND PRACTICE ASSESSMENT

\begin{tabular}{|c|c|c|c|c|}
\hline & \multicolumn{2}{|c|}{ group $1(n=43)$} & \multicolumn{2}{|c|}{ group $2(n=43)$} \\
\hline & mean $(S D)$ & range & mean (SD) & range \\
\hline \multicolumn{5}{|l|}{ Practice Assenswat } \\
\hline piets & $41.3(7.7)$ & $25.8-62.4$ & $42.1(7.1)$ & $29.5-63.9$ \\
\hline rexul patients & $84.0(3.3)$ & $73.7=90.3$ & $84.9(3.2)$ & $79.6-92.2$ \\
\hline \multicolumn{5}{|c|}{ Muliple Siations Examination } \\
\hline peers & $45.0(9.6)$ & $27.7-68.2$ & $52.0(8.5)$ & $35.7-67.3$ \\
\hline standardized patiett.ts & $80.9(4.7)$ & $71.3-92.5$ & $81.0(4.9)$ & $70.0-89.8$ \\
\hline
\end{tabular}

In both groups peers gave lower average scores to the communicative performance than the patients $(p<0.01)$, while Standardized Patients (SPs) gave lower scores than real patients $(p<0.01)$. On the absolute figures, it can be concluded that both standardized patients and real patients felt that the 
quality of communication was, on average, good, while peers felt that its quality was doubtful. With respect to time-order effects, the "Multiple Station Examination" scores given by peers in group 2 were higher than the scores given by peers in group $1(\mathrm{p}<0.01)$. However, SPs" scores in this station examination showed no difference between the two groups. So, a time-order effect was found only in one group, for one type of assessment and in one direction: from "Practice Assessment" to "Multiple Station Examination" evaluated by peers.

Table 2 represents the MAAS-global items, from which the patients' evaluation items has been derived. An overview is given of item scores, given by peers in both assessment methods, given by SPS in the "Multiple Station Examination" and scores given by real patients in the "Practice Assessment". Scores given by peers in the "Multiple Station Examination" are presented for each group separately, due to the time-order effect.

With regard to high scores, item 9 (naturalness, including "GP is empathic, attentive and inviting") was given the highest score by peers in both methods. Real patients gave their highest scores on item 9 ("the doctor gave me the chance to tell my story and to ask questions"), whereas standardized patients' rated this item second best. Rather high peer scores were given on item 2 (communication during physical examination) in both methods, whereas both SPs and real patients gave high scores on item 2 ("touches me with respect during physical examination") as well. So, both peers, standardized patients and real patients evaluated these aspects relatively similarly.

With respect to lower scores, both peers and standardized patients gave low scores on item 1 (exploration request for help). Scores given by real patients on this item was good in absolute sense but relatively moderate (sixth position). A similar pattern was shown in the scores on item 8 (exploring emotions): it was given the lowest score in both methods, except for peer scores in the station examination in group 1 (the last but one), whereas real patients gave relatively moderate scores on this item (and good scores in absolute sense).

From a relative perspective, for example, both standardized patients and real patients gave high absolute scores on item 5 ("the doctor checked if I had understood the advice or information"), but compared with other items of this list the scores on item 5 are relatively low (position eight for SP' scores and lowest position for real patients' scores).

Finally, from the "additional" perspective, peers gave low scores on item 10 (the GP asks the patient if all questions have been answered and asks after patient's satisfaction about the consultation), which means that GPs hardly evaluated their consultations. Patients, on the other hand, proved to be satisfied by giving high scores on their item 10. So, within each method item scores given by peers, SPs and real patients may give additional information of GPs' communcative performance. Scores which are absolutely high may be relatively low.

Concerning the relationship between methods used, disattenuated Pearson correlations between the peer assessments and patient evaluations are presented in table 3. 


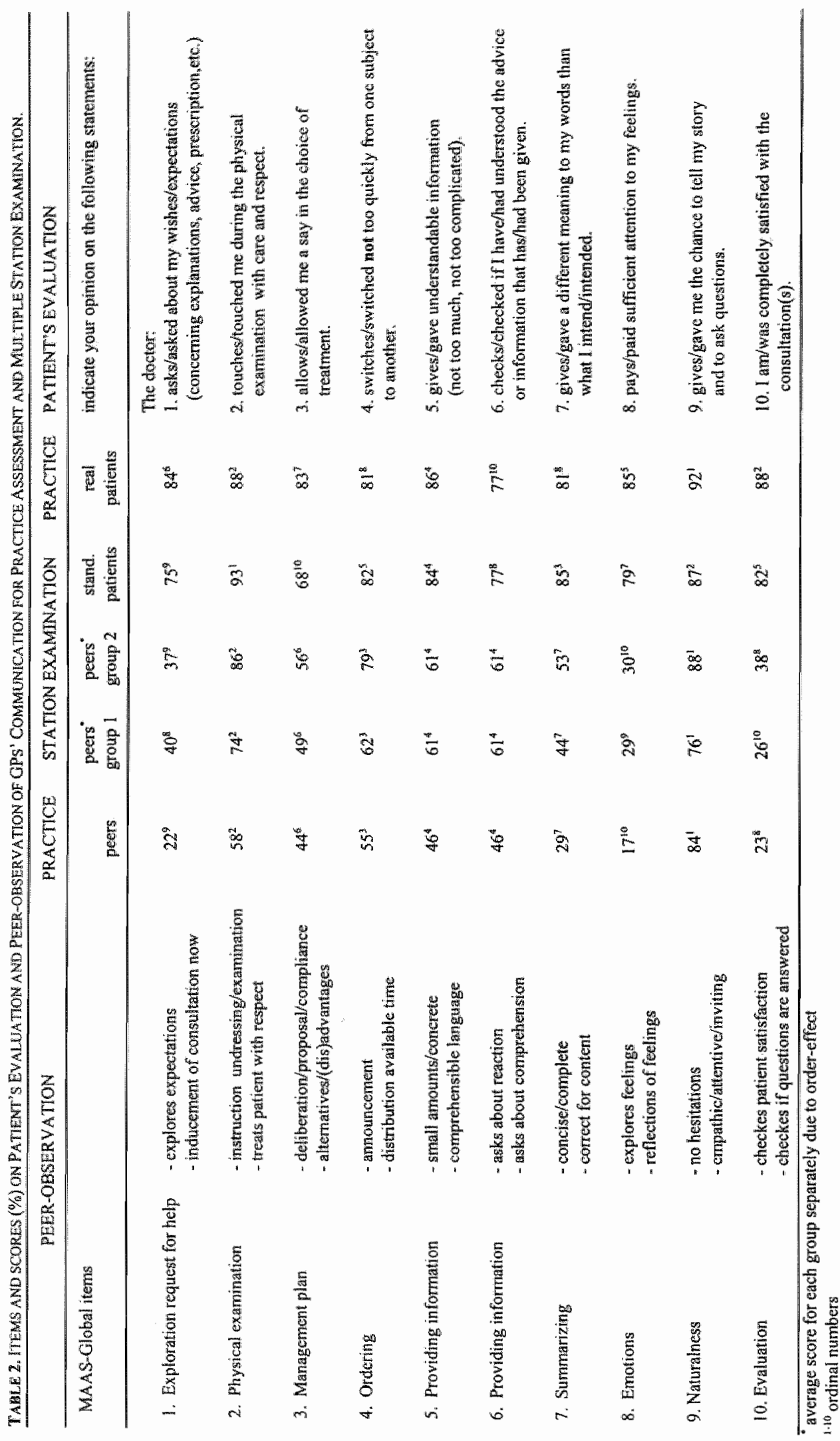


Table 3. DISATIENUATEO PEARSON CORRELATIONS BETWEEN PEER OBSERVATION AND PATHENT EVALUUATION OF COMMUINICATION IN PRACTICE ASSESSMENT AND MUL TIPLE STATION EXAMINATION

\begin{tabular}{|c|c|c|c|c|c|c|c|}
\hline & \multicolumn{3}{|c|}{$\begin{array}{l}\text { peers } \\
\text { station }\end{array}$} & \multicolumn{2}{|c|}{$\begin{array}{l}\text { stand.patients } \\
\text { station }\end{array}$} & \multicolumn{2}{|c|}{$\begin{array}{l}\text { real patients } \\
\text { practice }\end{array}$} \\
\hline & Group: & 1 & 2 & 1 & 2 & 1 & 2 \\
\hline peers practice & & $.17^{*}$ & $.25^{\circ}$ & $.14^{\circ}$ & $.36^{\prime}$ & $.08^{*}$ & $.12^{\circ}$ \\
\hline peers station & & - & - & $.51^{\prime}$ & $.35^{n}$ & $.07^{\circ}$ & $.04^{\circ}$ \\
\hline standardized patients station & & $.51^{\mathrm{t}}$ & $.35^{1}$ & - & - & $-.06^{\circ}$ & $.18^{*}$ \\
\hline $\begin{array}{l}p \leq 0.05 \\
\text { not significant }\end{array}$ & & & & & & & $\begin{array}{l}p 1: n \\
2: n\end{array}$ \\
\hline
\end{tabular}

In the "Practice Assessment" no significant relationship between peer scores and real patient scores in either group was found, whereas in the "Multiple Station Examination" there is a significant relationship between peer scores and standardized patient scores in both groups. In addition, in group 2 SPs' scores in the simulated surgery correlated with the peer scores in real practice. On the other hand, real patients' scores did not correlate with peer-scores in either methods nor with scores given by SPs in the "Multiple Station Examination". So SPs are consistent with peers with respect to scoring the quality of communication to some extent in a simulated situation; on the contrary, real patients are not consistent with either peers or standardized patients.

\section{Discussion}

This study investigated the relationship between different methods for quality assessment of the communicative performance of general practitioners (GPs), using three types of evaluating observers: peers, standardized patients (SPs) and real patients.

Five main conclusions can be drawn. First, the quality of GPs' communicative performance in. a simulated surgery may differ from the quality of GPs' communicative performance in real practice. Second, SPs might be a substitute for peer assessment in a simulated situation to some extent. Third, both real patients and SPs valued GPs" quality of communicative performance more positively than peers. Fourth, real patients differ from both SP's and peers in evaluating the quality of GPs" communication substantially, since no correlation was found between their scores and either SPs' scores or peer scores. Finally, if different methods are used in comprehensive assessment, a possible time-order effect has to be taken into account.

The difference between GPs' quality of communicative performance in a simulated situation and GPs' quality of communicative performance in real practice is in line with results of a former study on GPs' medical performance in a simulated "competence" setting and in real practice. ${ }^{28} \mathrm{GPs}^{\prime}$ communication with patients might be influenced by the unnatural setting and unfamiliar 
standardized patients. The comparison between competence assessment by peers in the "Multiple Station. Examination" and performance assessment by peers in the "Practice Assessment" has been described in detail. ${ }^{16}$ With regard to patients" evaluation, SPs proved to be consistent with peerobservers in assessing GP's' communicative performance in a simulated situation. SPs are trained persons, who meet many different GPs in relation to their patient role. They have a short and independent relationship with GPs, which is comparable with the observation "at distance" by peers. SPs in this study were healthy persons and, therefore, not anxious or worrying about the GP's final diagnosis. So, their evaluations probably compared more to the peer assessment than to the assessment by real patients. Real patients, on the contrary, may have less distance in the relationship with their GP. In addition, they seem to have a different perspective on GPs" communication with patients. Real patients may be more focused on the GP's final conclusion at the end of the consultation ("nothing to worry about" or "I'm afraid, I have bad news for you") than on the communication process itself.

From the educational perspective, peer observation or evaluation by standardized patients combined with the evaluation by real patients may provide relevant information about $\mathrm{GPs}^{\prime}$ communication with patients. SPs represent both the patients' perspective by giving high absolute scores and the professional perspective by being consistent with peers. Evaluation by real patients is important, since they represent consumers' needs. On the other hand, the low scores given by peer-observers may be an effective stimulus for GPs to improve their communicative performance. With regard to high item scores, both SPs and real patients were consistent with peers on item 2 (care and respect during physical examination) and item 9 (including empathy and attentiveness) giving relatively high scores on these items. Concerning communication during physical examination, in our study physical examination was videotaped via a camera in the examination room in both methods, which enabled peers to score this important item. Patients' report on this aspect of GPs' performance seems to be a valid alternative. With regard to quality improvement activities, these aspects may have a low priority, since these were evaluated well in an absolute sense by peers, SPs and real patients. With regard to low scores, both peers and patients indicated that item 1 (exploration request for help) needed to be improved. In both methods, peers gave low scores to item 9 (exploring emotions). From the professional perspective, this aspect should be an area of special interest in educational activities. From the patient's perspective, item 3 ("GP allows me a say in the choice of treatment") and item 6 ("GP checks if I understood the information given") were given low scores, by both SPs and real patients. So, patients probably wish to participate in the choice of treatment more actively. A better check of patients' understanding of information given may be required. Therefore, GPs should pay attention to communicative aspects which have low patients' scores even when these have been evaluated well by peers and vice versa. Finally, peers gave low scores on item 10 (GPs' evaluation of consultation), whereas both SPs and real patients proved to be satisfied. This positive feedback is a compliment for GPs, but by not asking for it GPs miss this positive appreciation of their patients, a possible source of motivation in 
dally work.

Some critical remarks should be made on our interpretations. First, SPs were sent the questionnaire with corresponding explanation one week before the "Multiple Station Examination" started. Real patients, on the contrary, were handed the questionnaire and a short written explanation in the waiting room at random. Second, real patients were asked to evaluate GP's' conmunicative performance, taking previous experiences with their GP into account, whereas SPs scored one consultation that they had just simulated. These methodological aspects may have influenced the consistency of scoring by real patients and the relationship between real patients scores and scores given by peers. On the other hand, if both peers and real patients had been asked to score the same consultations, GPs" usual performance in daily practice might have been influenced substantially by such an intensive observation. This so-called "audience effect" might have influenced the validity of the quality assessment in practice. In addition, real patients probably evaluate their GP always having previous experiences in mind. The choice for the methods followed in our study was based on these assumptions.

To conclude, if the focus is on GPs' actual performance, the assessment should be preferably performed in real practice. In addition, if the focus is on the professional view, assessment of GPs' conmunication with patients should be preferably done by well-trained peer-observers, who are experts and not involved in the communication process. The use of SPs in a simulated situation can be a valid alternative, provided that they are trained in both presenting complaints and evaluating GP's' communicative performance. Real patients represent the consumers' view and should therefore be asked for their evaluation as well. Therefore, both uninvolved observers and involved real patients should be used in evaluating GPs' communication with patients. They both have to contribute valuable information which can be used in further quality improvement activities. Training reall patients in evaluating GPs' communicative performance and the use of SPs in evaluating GPs" actual communicative performance by visiting GPs' practices may be attractive alternatives, which need further research.

\section{References}

1. Femberg $J$. The effect of patient-practitioner interaction on compliance: a review of the literature and application in rheumatoid arthritis. Patient Education and Cotnselling 1988;11:171-87.

2. Sprecher $P$, Thomas $E$, Huebner L, Norfleet J Jacoby $\mathrm{K}$. Effects of increased physician-patient commumication on patient anxiety. Professional Psychology: Research and Practice 1983;14:251-55.

3. Putman S, Stilles W, Jacob M, James. S. Patient exposition and physician explanation in initial medical interviexs and outcomes of clinic vists. Medical Care 1985;23:74-83.

4. Jung MP, Wensing M, Grol R. What makes a good general practitioner: do patients and doctors hawe different views? Br J Ger Pract 1997,47:805-09.

5. Kaplan SH, Greenfield $S$, Wace $J E$. Assessing the effects of physician-patient interactions on the outcomes of ehronic diseases. Medical Care 1989;27:S $110-27$.

6. Stewart MA. What is successful doctor-patient unterview? A study of interactions and outtcomes. Soc Sci Med $1984 ; 19: 167-75$ 
7. Bensing, J. Doctor-patient communication and the quality of care. [Thesis]. Rotterdam: Erasmus Universateit, the Netherlands 1991 .

8. Perkins J3, Sanson-Fischer $\mathrm{RW}$. Increased tocus on the teaching of interactional skills to medical practitioners. Adwances in Health Sciences Education 1996; $1: 17-28$.

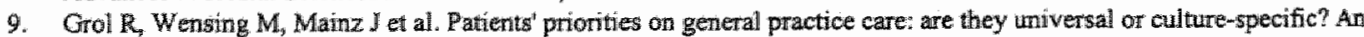
international comparison (submitted).

10. Roch A. Drug and alcohol medical coducation: Skills training for early and brief imervention. Doctioral Thesis. Newerastle: University of Wewcastle 1993

11. Grol $R$, Wensing $M$, Jacobs A Baker $R$. Quality assurance in general practice. The state of the art in Europe. Utrecht Nederlands Huisartisen Genootschap, 1993.

12. Berwick DM. Continuous impitovement as an idea in health care. Wew Engl Joum of Med 1989;320:53-56.

13. Rethans JJ, Westin $S$, Hays R. Methods for quality assessment in general practice. Fam Pract 1996;13:468-76.

14. Van der Vleuten CPM. The assessment of professional competence: developments, reserith and practical implications. Advances ir Health Seiences Education. Theory and practice 1996;1:41-67.

15. Kane MT. The assessment of professional competence. Evaluation the Health Professions 1992;15:163-82.

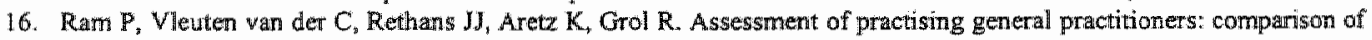
video obserwation in a station exam using standardized patients with video observation of real surgery in daily practice. Accepted by Acadertic Medicin, 1998 .

17. Waketield J. Direct Observation. In: Neufeld VR, Norman GR eds. Assessing Clinicall Competence. New Yark: Springer Publishing Company, 1985:51-71.

18. Rethans J-J, Stumans F, Drop R, Van der Vleuten $\mathrm{C}$. Assessment of the perfomance of general practitioners by the use of standardized (simulated) patients. Br J Gen Pract 1991;41:97-99.

19. Nomin GR, Neufeld VR, Walsh A, Woodward CA, McConvey Ga. Measuring physicians' performance by using simulated patients. J Med Educ 1985;60\%925-34.

20. Wensing M. Patients cvaluate general practice. A method for assessing and improving care [Thesis]. Nijmegen: SSN, the Netherlands 1997 .

21. Kaplan SH, Ware IJE. The patient's role in health care and quality assessment. In: Goldfield N, Nash DB. Providing quality, p25-68. Philadelphia, Pennsylvania: Armerican College of Physicians 1989.

22. Caulford $P G$, Lamb SB, Kaigas TB, Hama $E$, Norman GR, Davis DA. Physician incompetence: specific problems and predictors. Acal Med 1994:69 suppl(10):16-20.

23. Lamberts $\mathrm{H}_{*}$ Wood $\mathrm{M}$, eds. ICPC, International Classification of Primary Care. Oxford: Oxford University Press, 1987.

24. Ram $P$, Grol $R$, Rethans JJ, Vleuten van der $C$, Kester A. Assessment af gemeral practitioners by wideo obserwation in the daily practice: issues of walidity, reliability and Seasibility. Accepted by Medical Education.

25. Van Thiel $J$, Van der Vleuten CPM. Reliability and feasibility of measuring interviewing skills using the revised Maastricht History Taking and Advice Checklist. Med Educ 1991; 25: 224-9.

26. Van Thiel J, van Dalen J, Ram P. MAAS-globaal Criterialijst. Interne publicatie [internal Publication] Universiteit Matastricht, the Netherlands 1995.

27. Brenuan RL Elements of generalizability theory. lowa City, lowa: Amenican College Testing Publications 1983.

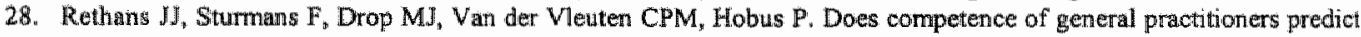
thein perfotmance? BMIJ 199 1;303:1377-80. 
Chapter 7.

General discussion

Conclusions and recommendations for research. 


\section{Aims of the study}

The aim of this thesis was to develop a valid, reliable, feasible and comprehensive procedure for assessment of practising general practitioners (GPs) for use in systematic quality improvement activities and to test this in practice. In the introductory chapter it was stated that the papers in this book concerned assessment in relation to medical education and that they were focused on three main aims.

The first of these was to develop a model for comprehensive assessment of practising GPs. A threedimensional pyramid was constructed, representing three main domains of general practice care, i.e. medical performance, communication with patients and practice management, in relation to competencies and performance to be assessed, with primary care diseases classified in 17 chapters.

The second aim was to investigate the predictive value of competence-based assessment for actual performance. For this purpose, a video assessment procedure for observation of regular consultations in daily practice was developed. This method approximated the real professional world as closely as possible and was therefore considered as the "criterion".

The third aim was to analyze the relationship between the GP's practice management (structure) and actual performance (process).

Finally, GPs' acceptance of the assessment procedure and the feedback was evaluated.

The general conclusion of our studies contends that a valid and reliable comprehensive assessment of individual practising. GPs should preferably include both an assessment method for direct (video) observation of GPs' communicative and medical, performance in daily practice and a method for practice visitation to assess GPs' practice management. Written medical knowledge tests might be alternatives for use on a broad scalle.

In addition to all the "discussion sections" in the preceding chapters, this chapter aims to extent these discussions and to give advices for further research in the field of assessment of practising GP.

\section{A new three-dimensionai model for comprehensive assessment: The Pyramid Assessment Model}

Following a literature study and discussions with experts a new pyramid model is proposed, which represents a combination of educational principles, assessment aspects and a compact domain description of general practice care (see figure 1). 


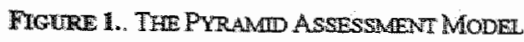

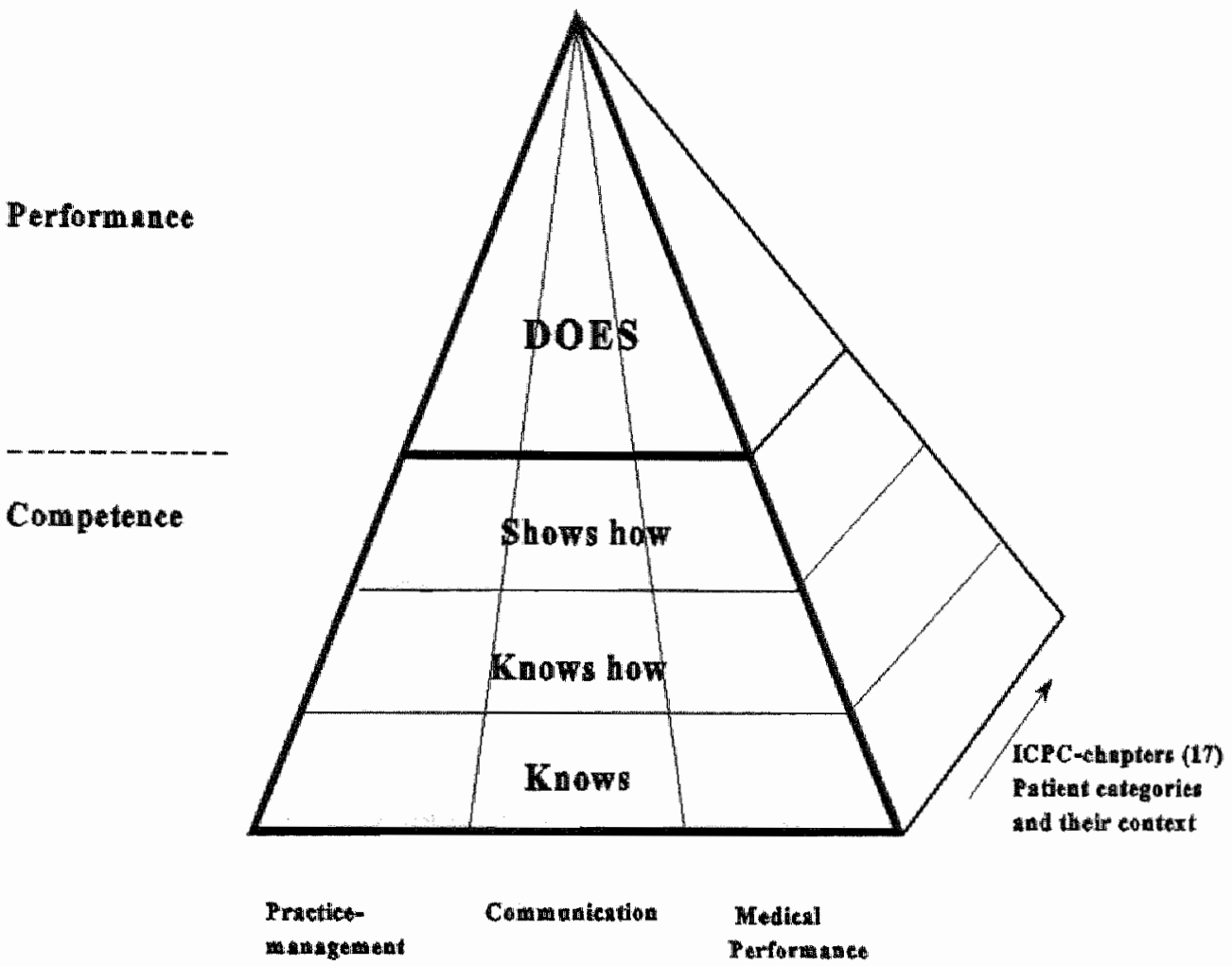

In this model, the extensive domain of general practice care has been ordered into three main dimensions in general practice care: medical performance, communication with patients and practice management. These dimensions can be "connected" with patients" complaints and diseases, classified according to 17 main chapters of the International Classification of Primary Care (ICPC)." In relation to educational principles, the model reflects the current development of theoretical views on medical expertise, and takes account of the difference between competence and performance. ${ }^{23}$ The top of this pyramid includes actual performance (process) and practice management (structure).

This model proved to be an effective guide and blueprint in the selection process of test methods for 
comprehensive assessment for our studies. It permitted a systematic analysis of the relationship between main dimensions on the performance level, i.e. practice management and actual performance (horizontal approach). Moreover, it enabled a systematic analysis to be made of the mutual relationship between competence levels and the relationship between competence levels and the performance level, for main dimensions separately (vertical approach), while also taking into account (the connection with) patients' complaints and diseases in primary care. In addition, the pyramid model was effective in facilitating international discussions about comprehensive assessment by medical educationalists effectively.

These benefits can be explained by the origin of the model. Three important existing models have been combined and reconstructed into one framework: Miller's pyramid, Donabedian's framework of structure, process and outcome, and Fabb's cube .-6 $^{4-6}$

The first model is based on educational principles whereas the other two models describe the domain of general practice care from different perspectives. We are convinced with our current experiences as a basis that our reduction of this wide domain to three main dimensions, L.e. medical performance, communication with patients (aspects of process) and practice management (structure), and the combination with educational stages (from competence to actual performance via knowledge (of skills) and demonstration of skills) in relation to internationally classified diseases in primary care, will enable others to assess GPs more effectively. Other (nationally accepted) classification systems than the ICPC can be used in this model as well, provided that such a classification includes all diseases presented in primary care.

Of course, being a reduction of reality this modell has some limitations. First, "attitude" has not been presented in this model. Recently a Dudd study has started in order to defime attitude in operationalizable terms. Therefore, in our study attitude has been left out of consideration. Second, patient outcomes, the final focus of quality improvement activities, ${ }_{3}^{7}$ have been assessed in our studies by using a questionnaire for real patients and standardized patients. However, these "outcomes" are not represented in our model, neither do other patient outcomes. Further study should be performed in order to include these patient outcomes in a model for assessment. We suggest, for example, an hour-glass model consisting of two vertically connected pyramids, the upper one our (upside- down) pyramid model including process and structure and below a mirror image pyramid "filled" by patient outcomes (Figure 2). 
FTGURE 2. HOUR-CLASS MODEL FOR COMPREHENSIVE ASSESSMMENT

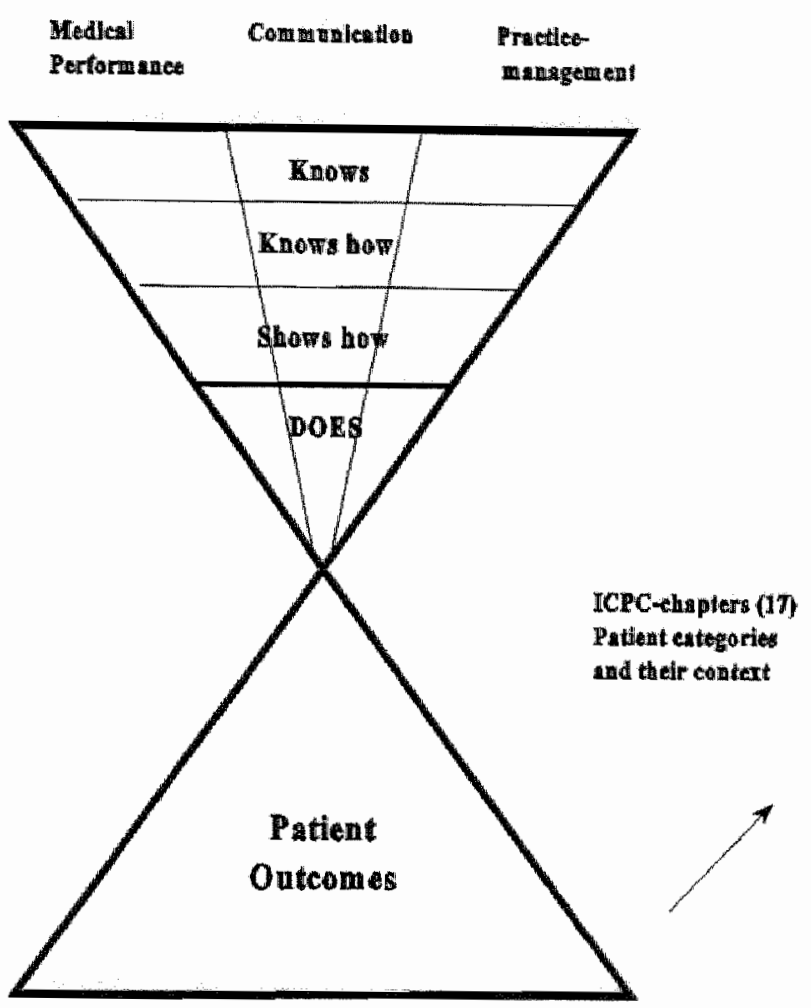

Third, our model is rather global with respect to the three main domains, which means that both communication with patients, medical performance and practice management should be specified in more detail when it comes to actually assess GPs. On the other hand, a global model can be used in the assessment of other medical specialists as well. Third, physicians" "attitude" has not been included in this model separately. Behavioural aspects of attitude were an integral part of the observation instrument for communication.

Further experiences and study in the field of (continuing) medical education, quality improvement and vocational training may contribute to the definite value of this model as a useful basic blueprint for comprehensive assessment. 


\section{Video assessment in daily practice}

In our studies, a valid, reliable and feasible method for video obserwation of the GP's performance in daily practice has been developed, particularly by addressing the "standardization problem", which is caused by the complex and unstandardized problems as they are actually presented in daily practice. ${ }^{8}$ Therefore, in an assessment experiment with the doctor as "dependent variable" these problems have to be considered as inconsistent "independent variables", which might be a substantial bias of measurement. The video assessment method is based on the idea that quality assessinent should rather be based on collecting data of actual performance. Also content validity of an assessment method improves if the real professional world can be observed as closely as possible. ${ }^{9}$

In the "Practice Video Assessment", the standardization problem has been addressed by developing criteria for the selection of consultations which will be assessed. Each pre-determined selection criterion was met in the majority of the samples. In addition, all samples represented eight or more chapters of the classification of primary care. Within one chapter of this classification different diseases were represented as well. For example, in "chapter L" different diseases of the locomotive apparatus, such as diseases of knee, hip or shoulder, may be presented. Moreover, sufficient different sorts of consultations were included, such as initial and follow-up consultations with both elderly patients and children, male and female: in daily practice no consultation is the same.

Therefore, we conclude that content validity was sufficiently obtained and that the lack of control over the case selection process, one of the major disadvantages of observation in practice, was satisfactorily addressed by the procedure used. In addition, the case specificity problem, i.e. results on one case having a low predictive value for results on other cases, ${ }^{10}$ was addressed as well since 16 different cases were included in the sample.

However, there is still an area of tension between standardization of samples of regular consultations and reaching high content validity of the assessment model. One might argue that we did not succeed in a complete standardization, since only criterion one, representativeness of eight or more classified chapters of diseases, was met in all samples. Three criteria were fully met in slightly more than $90 \%$, and another three criteria in just over $70 \%$. It is hard to define which percentage level can be considered as sufficient, to allow the conclusion that the sample has been "standardized". Strict sample uniformity may even not be desirable, since a sample has to be representative for an individual GP. It should reflect existing differences between GPs regarding characteristics of their patient population, workload, working style and their perception of tasks. In addition, there is a relation between standardization, reliability and feasibility, since strict standardization may improve reliability results. If fewer cases and raters are needed for a reliable assessment, feasibility will improve by reduction of cost and logistics. In our opinion, the question about standardization cannot be answered definitively. In practice, there will always be differences in sample characteristics. One should limit these differences by using selection criteria and the influence of differences on GPs' scores should be analysed afterwards. Our selection criteria were formulated on the supposition that 16 consultations would have to be selected. An assessment using another sample 
size requires that sample criteria have to be adjusted and checked accordingly.

In this study, only the sample characteristic "variation in total duration of consultations unchuded per $\mathrm{GP}^{\prime \prime}$ showed an influence on the scores. A limitation of the variance in the duration of consultations, for example by changing the selection criterion "duration of each consultation between 5 and 15 minutes" into a "duration between 8 and 12 minutes", might improve the standardization. However, this alternative might decrease validity, since the duration of the sample may reflect GPs' working style. Further research of sampling by using selection criteria is needed in order to improve reliability and consequently feasibility, taking into account validity aspects.

Follow-up consultations and consultations with more than one reason per encounter caused specific scoring problems. A follow-up consultation without the GPis verball recapitulation of complaints and the management planned in the previous consultation(s) was difficult for peer-observers to score, who risked possibly missing both the context and the past history. This could be solved by combining the video observation with medical record review. However, medical records are often incomplete and inconsistent, which may raise other problems. ${ }^{11}$ This problem could be addressed by comparing the reliability results of two kinds of observation: one with observers having insight into the medical records and one with observers who are blinded for patients" medical history.

Another problem with scoring at the level of consultations concerned consultations with more than two reasons for encounter. These consultations were now given an average score, i.e the average of the reasons encountered, globally calculated by the peer-observer. In the regression analysis, the sample characteristic "a maximum of two consultations with more than two reasons for encounter" had no predictive value for the performance scores, suggesting that such an amount of these types of more complex consultations within the semple had no influence on the final sum score per GP. Nevertheless, such consultations and even consultations with two reasons for encounter, frequently present in daily practice, may give rise to some problems in both scoring and giving feedback to the GP. An average score may represent a "neutral" score, based on a high score on one complaint of the patient and a low score on another complaint. Especially for the medical components of the consultation this may lead to a loss of educational information. Exclusion of these consultations from the final assessment would "solve" this problem, but would decrease content validity at the same time. A specific separate score for the medical component for each reason of encounter might: improve feedback. The communication score could remain an average score, since this score is based on items, which are more case independent. These questions need further research.

Validity of the video method improves as a result of the use of two cameras, recording the consultation as completely as possible, including both physical examination and communication with patients. Video assessment procedures usually do not record physical examination. Both technical reasons and respect for patient's privacy may account for this choice. However, physical examination and concurrent communication with patients are essential aspects in daily consultations. On the other hand, switching cameras by the GP intrudes on normal surgery routine. GPs may get used to the operation of the video equipment after a few consultations, specially when the 
equipment is continuously installed in the practice, decreasing this audience effect. An automaticly switching system however may solve this problem even more.

To draw conclusions on validity, in any assessment using regular consultations selection criteria have to be formulated. The ain of the assessment, either educative or summative, may influence the precision by which the selection criteria will be applied. Strict standardization will benefit for reliability and feasibility (fewer observations needed), but may hamper validity. The influence of differences in sample characteristics on $\mathrm{GPs}^{3}$ scores should always be analysed retrospectively in order to check for validity and to compare GPs fairly.

As far as the reliability of the assessment is concerned, our results are encouraging, particularly considering the limitations in standardization of practice assessment. After two-and-a-half hours of observation by two observers, the generally accepted benchmark of $>0.80$ for rellability coefficients was reached. This is actually comparable with or even better than test conditions using highly trained standardized patients in multiple station examinations. ${ }^{12}$ Our good results may be explained by the consistency of GPs' usual performance during video recording, confirmed by GPs recognizing their usual working style in the consultations. One might argue that "real patients" probably guarantee "naturally acting doctors", which is a positive argument for both validity and reliability.

Efforts to improve reliability should therefore primarily be focused on observer training. Both observers and sample criteria are the most important aspects of standardization, since complex daily cases and natural patients cannot be standardized. From this perspective, reliability (and validity) benefits from the availability and use of guidelines for both communication with patients and medical performance. In the Netherlands, more than sixty generally accepted guidelines for medical performance have become available so far, concerning diseases in primary care with high incidence and prevalence. ${ }^{13,14}$ In our study, criteria formulated on these guidelines have been used by the observers in evaluating GPs' medical performance on specific diseases, such as asthmatic bronchitis $_{;}$otitis media, hypertension and eczema. In this way observers may evaluate medical performance more consistently, provided that they have good knowledge of these guidelines criteria. In our study, observers were also assessed by a written medical knowledge tests, containing questions based on the guidelines mentioned. The average scores of these observers were sufficient. For communication with patients, generally accepted guidelines have only recently become available. ${ }^{15}$ At the start of our study these guidelines had not been published yet. Therefore, an extensive list was used, containing criteria for the 12 items for communication on the MAASGlobal, the observation scoring list used. ${ }^{16}$ With regard to this instrument, one might argue that there is an imbalance between the number of items for communication (12) and for medical performance (4). Medical performance was evaluated on history taking, examination, evaluation and patient management. A further differentiation of these items, for example history taking into somatic history taking and psychosocial history taking, examination into examination during

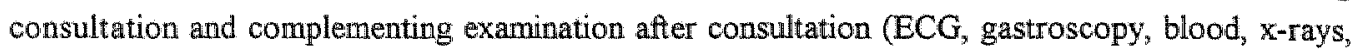
etcetera), patient management into medicinal and non-medicinal treatment, the latter into primary and secondary preventive activities and advices, etcetera, might be considered in order to score 
medical performance in more detail and to provide more specific feedback to the GPs assessed. However, complex scoring issues may arise, since the indication to perform on these aspects may differ from one consultation to another, probably leading to a frequent "not applicable score", which hampers a failr comparison of GP's' average medical performance scores

Neverthelless, further development of generally accepted guidelines for both communication with patients and medical performance is needed in order to improve both actual performance, its assessment and feedback.

With regard to feasibility, a valid and reliable video assessment in daily practice justifies considerable investment. In this study, the purchase and the installation of the video equipment was a substantial percentage (25\%) of all investment costs in the Practice Video Assessment Costs will be reduced provided that each GP has his or her own video equipment. The prevention of acts of violence in the practice may be an additional benefit of the continuous presence of this equipment. Compared with observation in a simulated surgery at the medical school using standardized patients, video assessment in daily practice is relatively cheap, since no technician, standardized patient, travelling cost or rent for rooms and equipment have to be paid for.

Finally, privacy of both GPs and patients should always be guaranteed. In this study informed consent was well organized at the desk before the consultation, which may be responsible for the high consent percentage. Transport of tapes was performed either by couriers or by registered letters, labelled medical secret. In this way no videotapes were lost.

The predictive value of competence-based tests, i.e. a multiple station examination and knowledge tests, for actual performance

Two different types of competence-based tests were selected for this study in order to analyze their predictive value for actual performance: written knowledge tests and a multiple station examination using standardized patients. The predictive value of those tests for actual performance was compared.

As a result, medical knowledge tests predicted actual medical performance to the same extent as a multiple station examination using standardized patients, whereas the communication component of the multiple station examination did not predict GPs actual communication with patients.

Moreover, the multiple station examination and the Practice Video Assessment, both being observation methods, were compared on aspects of vallidity, reliability and feasibility. Content validity of practice video assessment proved to be superior to the station examination since the domain of general practice was better covered. Participants judged the videotaped practice consultations as "natural", whereas hardly any GP recognized his usual working style in the station examination, after self reviewing the videotaped consultations. Concerning concurrent validity, only the medical component of both methods proved to correlate. Also real practice performance proved to be less influenced by the "audience effect" ${ }^{13}$ thus more stable, than behaviour during the station examination. Reliability of both methods, expected to be better in the controlled station 
examination, was comparable. Moreover, the organization of video assessment in practice was more flexible, had lower cost involved and was better accepted by GPs than the station examination. So, overall, assessment of GPs by video observation in daily practice proved to be superior compared with (video) assessment in a simulated setting using standardized patients.

Therefore, assessment in a simulated surgery at the medical school has limited value when the focus of the assessment is on actual performance, since the predictive value for actual communication is negligible, the predictive value for actual medical performance is comparable with medical kmowledge tests and both content validity and acceptance of this simulated surgery by GPS is low. Does this imply that simulated surgeries are worthless now? $\mathrm{No}$, we don't think so. We argue that the aim of the assessment is an important issue in the selection of methods. For instance, simulated surgeries using standardized patients will still have their educative value in skills training. In addition, standardized patients can be used in daily practice for educative purposes as well.

If the focus of assessment is on actual performance, one needs to go into the practice and should observe the GP's communication with patients and medical performance in regular surgeries.

Also, on grounds of feasibility, i.e. cost, logistics, high number of participants, written knowledge tests may be an appropriate alternative: these can be used on a broad scale and have a predictive value for actual performance, which is comparable with a standardized examination in a simulated surgery. In relation to the pyramid assessment model described in chapter 1, good knowledge tests should cover both medical aspects, communication with patients and practice management aspects. Finally, knowledge tests may be better predictors for actual performance than demographic variables of GPs. In this study, of all personal characteristics of GPs such as age, gender, working single-handed, being member of the Dutch College of GPs, working full-time or part-time, working in a urban area or not, only the characteristic "working single-handed" contributed (negatively) to the explained variance of the actual communication with patients. This contribution was low, whereas on medical performance there was no contribution at all. Therefore, time spent on administration and analysis of the influence of personal and professional characteristics on performance scores seems largely superfluous. One would possibly do better by performing a written knowledge test.

Still, a few critical remarks concerning written knowledge tests should be made. In relation to validity, items in the knowledge test should focus on "key-featurest": knowledge elements that are crucial to general practice care. The knowledge concept in a test should be specified. Furthermore, items should cover relevant aspects of realistic patient problems. ${ }^{17}$ In relation to comprehensiveness, more attention should therefore be paid to the development of valid and reliable knowledge tests for communication. with patients and practice management.

The reliability of knowledge tests used is too low for conclusions at the level of individual GPS. Adding more items, for example doubling the test size to 300 items, or a sequential administration of two or more tests would increase reliability. However, feasibility would decrease in this way. If these tests are used for selective purposes, reliable pass-fail decisions can be calculated without 
adding more items. In addition, the reliability of group mean scores is far better than the reliability of individual scores, which means that the reliability for screening purposes, i.e. the selection of topics for educational activities for a group of GPs, might be sufficient.

The predictive value of knowledge tests on communication and practice management for actual performance and practice management deserves to be studied as well in order to cover the domains of general practice care as completely as possible by written knowledge tests.

In this study, knowledge tests were completed at home. Feedback was given in a "norm referenced" (relative) way, i.e. individual scores were compared with scores at peer group level. If one is interested in how well scores actually represent mastery of knowledge, the "absolute perspective" is of paramount importance.

One might argue that the completion of these tests at home may be a source of cheating. However, the assessment was purely educative and GPs were asked not to look upon things for their own benefit, i.e. a valid feedback. The considerable correlation between the knowledge tests and the Practice Video Assessment support our hypothesis that GPs did not cheat their results of the knowledge tests. GPs who would have high scores in the knowledge test by cheating might have had low scores in the Practice Video Assessment, since they would have had less knowledge to hand.

Overall, competence-based tests, such as knowledge tests and multiple station examinations, do predict actual performance. In our study the explained variance in actual performance by these tests was moderate (about $25 \%$ ). Therefore, these tests approximate actual medical performance but they still keep at a considerable distance from actual performance. Depending on the aim the assessment and budgetary facilities, a choice should be made between a multiple station examination (high cost) and a knowledge test (lower cost). If the focus of the assessment is on evaluation of actuall performance, direct observation in daily practice is to be preferred.

The relationship between actual performance (process) and practice management (structure) in general practice care

An important conclusion of this study is that practice management (structure) and actual performance (process) seem largely independent constructs. Quality improvement and assessment activities should emphasize that the relationship between practice management and actual performance is weak. Structure and process may contribute to patient outcome largely independently from each other. In our study, only a few practice management dimensions have a predictive value for actual performance. Of course, structural deficiencies, such as inaccessibility of the practice, lack of telephone or equipment, will hamper quality of care. However, in almost all of the practices these "basic" essential structural aspects are available and accessible, which means that they do not discriminate between GPs. As a matter of fact, a well organized practice with good management does not guarantee a good clinical performance. ${ }^{18}$ For example, even when perfect equipment is available in the practice, it may still be questionable whether a GP uses the equipment 
adequately or not. Only in the process, i.e. in regular consultations, can the quality of the GP's use of structural aspects such as equipment or medical records be observed and evaluated.

Neverthelless, when studied in more detail, nine of 22 practice management dimensions correlated significantly with medical performance and so did frve dimensions with actual communication with patients (see table 3, page 72) ${ }^{19}$ Overall, most associations were relatively weak and the predictive value for actual performance was low. Of all personal characteristics, only "age" in the case of medical performance and "working single-handed" in the case of communication contributed to the explained variance. The contribution was lower than specific scores on some practice dimensions. For example, one practice dimension (delegation of medical tasks to the practice assistant) explained six percent of variance in communication with patients. Organization of quality assessment activities, such as data collection on referrals and prescriptions, explained most of the variation in medical performance (ten percent). Overall, variance in medical performance scores could be explained by only three practice management dimensions. From this perspective, one should be cautious to use practice management aspects as performance indicators. ${ }^{20}$

On the other hand, conclusions can be drawn from the positive relationship between actual performance and some practice management dimensions. Firstly, the presence of appropriate equipment and adequate medical record keeping can be seen as essential tools in the process of patient care. This may stimulate GPs to invest in diagnostic and therapeutic equipment and to keep adequate records. Secondly, time spent on (contiming) medical education (tertiary activities) is associated with doctors who perform well, which suggests that GPs" educational activities may lead to better care. Thirdly, the predictive value of "organization of quality improvement" for actual medical performance pleads for quality assessment activities embedded in GPs' practices. ${ }^{21}$ Good practice of the organization of data collection, such as data on prescriptions, referrals or diagnostics, enables GPs to react in accordance with quality assurance principles, i.e. the process of evaluating the current level of performance and the process of change and improvement. ${ }^{22}$

Overall, we conclude that some structural (practice management, aspects may indicate quality of performance, but the indication is weak. So, assessment of process, i.e. GP's medical performance and communication with patients, should be included into a comprehensive procedure.

Finally, with regard to the relation between GPs' communication with patients and specific practice management aspects, delegation of tasks to the practice assistant and good record keeping (basic data, family history, profession of the patient) may have some roots in GPs' communication skills. The negative relation between working single-handed and high score of communication with patients may be connected with the contrasting difference between working single-handedly and working in multiple partner practices, where collaboration must rely on communication and delegation of tasks within a team. These hypotheses need further research, since communication with patients is an important dimension of general practice care. Patient outcomes will benefit from good communicative performance. 
"Workload" and experienced "Job stress" had no predictive value for performance scores, suggesting that they are rather autonomous (perhaps personal) constructs. Neither were associated with actual performance or with practice management. The instrument used may not have measured what it was supposed to measure and may therefore be invalid. It is hard to ignore the possible (negative) effects of the GP's feelings about work (and life) on the quality of performance. Therefore, further research on these aspects is necessary.

It is hazardous to draw definitive conclusions from this part of our study. Aspects of practice management are either essential catalysts for "good process" or the result of common characteristics of doctors who perform well, or even mirror images of each other. Further research of this relationship and particularly research on the contribution of process and structure to patient outcome is required.

\section{Assessment of GPs' performance by peers, standardized patients (SPS) and real patients}

In our study we explored the assessment of GP' communication with patients by peers and standardized patients (SPs) in a Multiple Station Examination and by peers and real patients in a Practice Assessment. In absolute sense, both real patients and standardized patients gave higher scores than peers. With regard to the relationship, i.e. Pearson correlation, between peers and both standardized patients and real patients, SPs proved to be consistent with peer-observers to some extent in assessing GPs' communicative performance in a simulated surgery, whereas real patients were not consistent with peers in the Practice Assessment.

We hypothesize that SPs have a short and independent relationship with GPs, which may be comparable with the observation "at a distance" by uninvolved peers. In addition, in this study SPs were healthy persons and, therefore, not anxious or worrying about the final diagnosis. Real patients, on the contrary, may be more distressed and, therefore, have less distance in the relationship with their GP. Real patients may be more focused on the GP's final conclusion at the end of the consultation than on the communication process itself. In addition, they seem to bave a different perspective on GPs' communication with patients than professionals, since no correlation was found between peer scores and scores given by real patients in the Practice Assessment.

From an educational perspective, peer observation or evaluation by standardized patients combined with the evaluation by real patients give additional information about GPs' communication with patients. Evaluation by real patients is important, since they represent consumers' needs whereas peer scores, and to some extent SP's scores, represent the view of professionals. In addition, the low scores given by peer-observers may be a better stimulation for GPs to improve their communicative performance than the relative high scores given by patients.

The differences between the evaluation by standardized patients and peer-observers on the one hand and the evaluation by real patients on the other may be influenced by methodological aspects of our study. Peers were trained extensively in observing and evaluating $\mathrm{GP}^{\prime}$ communicative performance, whereas SPs were experienced in observing and evaluating the communication skills 
of medical students. Real patients were not trained at all in evaluating the communication process between their GP and themselves. SPs were sent the questionnaire with corresponding explanation one week before the start of the Multiple Station Examination and they evaluated about a hundred GPs. Real patients, on the other hand, were handed the questionnaire and a short written explanation in the waiting room at random and they evaluated only their "own GP". Moreover, real patients might have taken previous experiences with their GP into account, while scoring the communicative performance of their GP. The relationship between real patients' evaluation and peers' evaluation might be influenced as a consequence.

With regard to the ranking of item scores by peers and patients, the item "exploring emotions" on the peer scoring list was lower ranked than a similar item "asks about my feelings" within both patients' scoring lists. This makes it questionable whether patients do wish GPs to explore patients' feelings more extensively. On the other hand, the item "the GP allowed me a say in the choice of treatment" was evaluated relatively low, both by standardized patients and real patients", which suggests that patients would like more participation in the choice of treatment.

To conclude, if the focus is on the professional view, assessment of GPs' communication with patients probably concerns "process". If so, it should be preferably done by well-trained peer observers, who are experts and, being at distance from the observed colleague, not involved in the communication process. The use of SPs in a multiple station examination can be a valid alternative, provided that they are trained in both presenting complaints and evaluating GP's communicative performance. Real patients represent the consumers' view and their evaluation might be considered as "outcome". Therefore, both disinterested observers and involved real patients should be used in evaluating GPs" communication with patients. Effects of training real patients in evaluating GPs' communicative performance and the effects on item scores need further research. In addition, the use of SPs in evaluating GPs' actual communicative performance by visiting GP's practices may be an attractive alternative which should be studied as well.

\section{The evaluation of the comprehensive assessment procedure by GPs}

GPs' acceptance of the comprehensive assessment procedure was evaluated with a questionnaire, which contained four main questions concerning the following aspects: 1 , the benefit of participation in the assessment versus the effort required; 2 . the effects of the assessment and feedback on GPs' insight into their way of functioning; 3. GPs' plans for concrete changes in daily practice care and 4. GPs' educational activities as a result of participation (see table 1.). In addition, GPs' preferences for methods used and for the way of getting feedback were evaluated as well. 


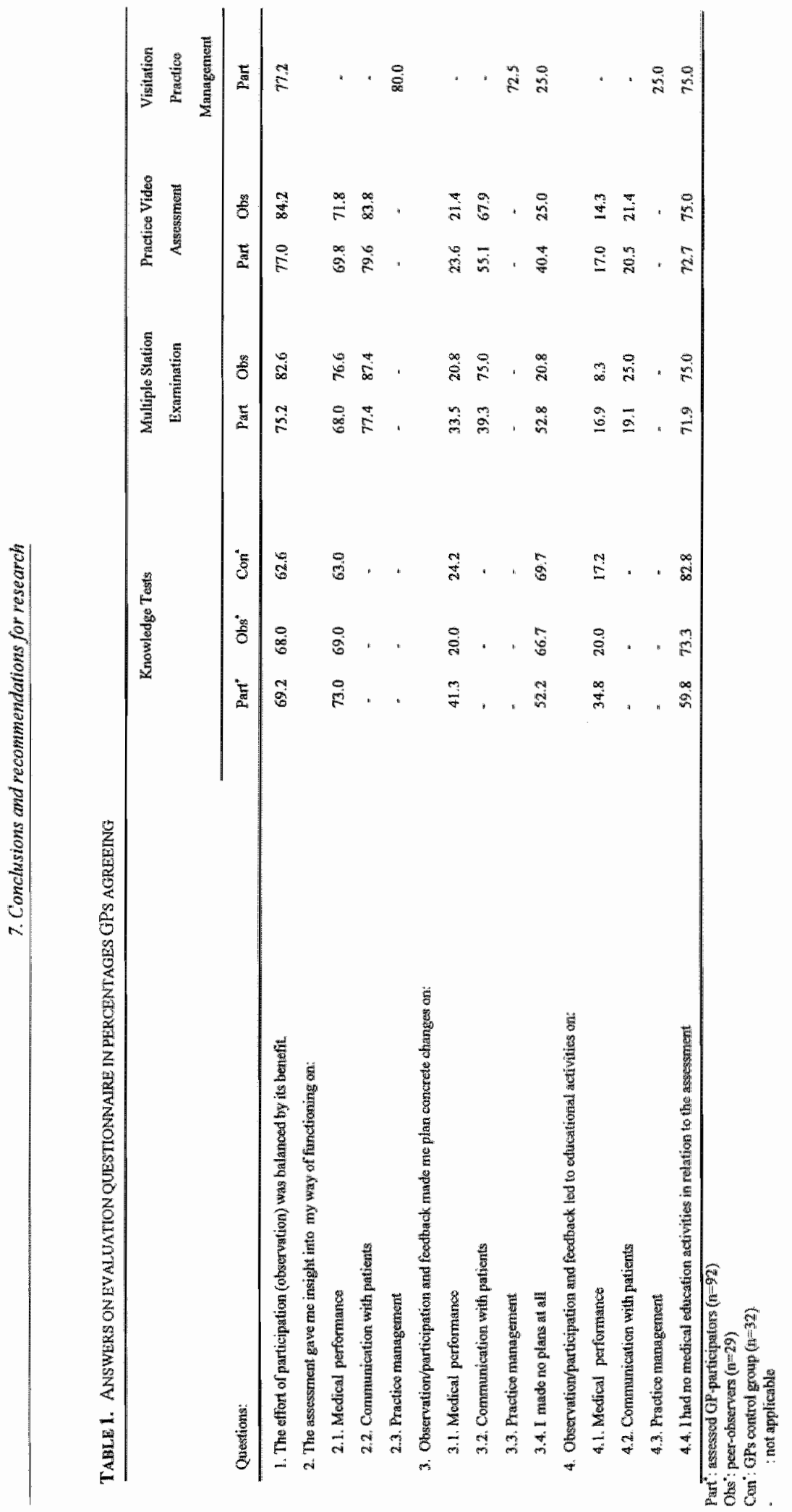


On question 1 (benefit versus effort), a majority of GPS viewed a positive balance between benefit and effort of participation. Even peer-observers, who had to score about 100 consultations each, were highly positive about their benefits due to their observation efforts. GPs in the control group, who participated in the knowledge tests only, viewed the balance as less positive than observers and assetsed GPs.

Answers on question 2 (insight into my way of functioning) showed a moderate score for GPs in the control group on the knowledge tests, whereas observers and assessed participants viewed both the medical knowledge test, the multiple station examination and the practice video assessment as methods which gave them insight into the way of functioning, the latter two for communication aspects particularly. A high score too was found for the participants in the practice management method with regard to their insight into their practice management.

Question 3 (plans for concrete changes) shows a high score for all groups on "I made no plans at all for concrete changes" as an effect of the knowledge tests and, less negatively, of the multiple station examination. Both assessed GPs and observers are strikingly positive in making concrete plans on communication aspects as a result of the practice video assessment. Observers are even more positive on this issue in the multiple station examination than in the practice video assessment. The highest score on this question was given by GPs on practice management ( $75 \%$ of the GPs reported making concrete plans for changing aspects of practice management).

On question 4 (activities on medical education) a majority of all GPs said that they initiated no activities at all as a result of the assessment, no matter what assessment method was used. Comparatively, the knowledge test did have some effect in making GPs active in medical education activities.

The question "What kind of medical education activities were performed due to the assessment and its feedback?" showed that GPs performed individual educational activities mainlly, i.e. selfdirected learning (assessed GPs $40 \%$, observers $20 \%$ ) and immediate changes in performance or practice management (assessed GPs $40 \%$, observers $48 \%$ ). In addition, $35 \%$ of the assessed GPs and $20 \%$ of the observers confirmed that they performed regular continuing educational activities and $30 \%$ of the GPs and $17 \%$ of the observers said that they performed medical education activities within the local GP group. On all these items GPs in the control group were less active than the assessed GPs and peer-observers. As the results show, peer-observers were activitated by their observation to lesser extent than their observed colleagues, except for immediate changes in performance.

GPs' preference for assessment methods to be included in a comprehensive procedure favoured the combination of video-assessment in daily practice (focused on both communication with patients and medical performance) with an assessment of practice management by visitation and a written medical knowledge test.

Table 2 shows that a majority of all GPs prefer a combination of written and oral feedback. In addition, GPs showed no distinct preference for the sort of person who should mediate the feedback. There is a slight preference for an unknown colleague, provided that it was a GP. 
TAEL 2. GPS' PREFERENCES FOR FEEDEACK METHODS IN PERCENTAGES

\begin{tabular}{|c|c|c|c|}
\hline Feedback method: & $\begin{array}{c}\text { participants } \\
(n=92)\end{array}$ & $\begin{array}{c}\text { control group } \\
(n=32)\end{array}$ & $\begin{array}{c}\text { observers } \\
(\text { yowas }\end{array}$ \\
\hline Written & 181 & 43.7 & 20.7 \\
\hline oral & 12.8 & 6.3 & 13.8 \\
\hline combination & 69.1 & 50.0 & 65.5 \\
\hline \multicolumn{4}{|l|}{ Mediator: } \\
\hline unknown colleague & 24.2 & 188 & 13.8 \\
\hline known oollieague & 6.6 & 9.4 & 6.9 \\
\hline non-GP consultant & 11.0 & 6.3 & 3.4 \\
\hline no preference & 58.2 & 65.5 & 75.9 \\
\hline
\end{tabular}

These results may have been influenced by the decision to give limited feedback after each method in order to prevent a possible order-effect: feedback on one assessment method could influence GPs' performance on the next method. Since the study was a methodological one and focused on psychometric characteristics of different methods only, feedback played a secondary role.

All feedback was presented to the GPs in written letters only, except for the results on the assessment of practice management where feedback was mediated by a consultant as an implicit part of the assessment procedure. Such feedback is known to be more effective than written letters. ${ }^{24}$ Therefore, educational effects of such a comprehensive assessment procedure might increase if feedback is mediated by a consultant on each method.

In addition, two more criticall remarks should be made in relation to the educational impact. Firstly, there was no offer of regular medical education programmes based on the results of the assessment, which may have hampered adequate educational activities at group level. Secondly, the assessment procedure was not systematically embedded in quality improvement activities. "The "quality circle" correctly started in practice abservation and collecting data from practice. However, the next stages of this circle have not been performed; these would cover the evaluation of information (performance versus targets) including setting priorities in implementing changes, the agreement of criteria including setting target standards and a subsequent observation of practice to evaluate changes. In this study, priorities had to be set as well.

Finally, the educational effects of training and observations by peers are encouraging. Further research on these aspects is necessary.

The educational character of the assessment and the woluntary participation may be responsible for the positive commitment and acceptance by all GPs. Drop-out was extremely low. Compulsory or selective assessment may decrease this acceptance, which has to be taken into account in the development of assessment procedures.

GPs' preference for video assessment in daily practice and assessment of their practice management by visitation in combination with a written medical knowledge test fits perfectly in with our results on the psychometric characteristics of performance-based assessment in daily practice. In this way 
GPs confirm that assessment should gather data from daily practice care according quality improvernent principles and recent assessment strategies to approximate the real professional world as closely as possible.

Further study of the educational efffects of comprehensive assessment for both observers and observed GPS is of great value, especially when such an assessment is embedided in regular quality improvement activities. A well designed trial which includes both assessment and all other phases of a quality plan may yield more insight into the educational value of comprehensive assessment.

\section{Overall conclusion}

From the educational perspective, a valid comprehensive assessment procedure should include at least (video) observation of GPs" performance, a visitation to assess practice management and feedback linked up with systematic quality improvement. Written knowledge tests are good alternatives for screening purposes. Analysis of data focused on patient outcomes, an important issue in quality assessment, was beyond the scope of our work. This study provides a substantial contribution to formal implementation of valid, reliable and feasible comprehensive assessment pracedures. Further research is needed in order to improve the quality of general practice care by assessment, focused on process, structure and patient outcomes, taking advantage of the driving force of assessment.

\section{References}

1. Lamberts $\mathrm{H}_{3}$ Wood M, eds. Intemational Classification of Primary Care. Oxford: Oxford University Press 1987.

2. Schmid $\mathrm{H}_{\text {, Noman }} \mathrm{G}$, Boshwizen HA. Cognitive perspective on medical expertise: theory and implications. Acad Med 1990,65:611-21.

3. Rethans I-J. Does competence predict performance? Standardized patients as a mean to investigate the rellationship between comptence and performance of general practitioners. [Thesis] Amsterdam: Thesis Publishers 1991.

4. Miller GJ The assesment of clinical skills/competence/performance. Acad Med 1990;65: \$63-\$67.

5. Donabedian A. Explorations in quality assessment and monitoring. 1. The definition of quality and approaches to its assiessmemt. Anr Avbor: Heat th Administrationi Press 1980.

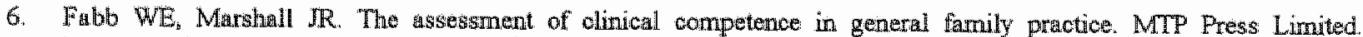
Lancaster, England and Hingham, USA 1983.

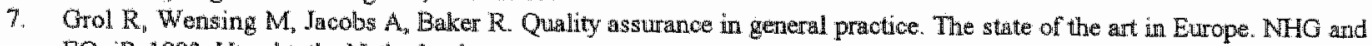
EQuip, 1993 . Wtrechtit; the Netherlands.

8. Kane MT. The assessment of prolessional competence. Evaluation \& the Health Professions 1992:15:163-82.

9. Van der Vleuten CPM. The assessment of professional competence; developments, research and practical implications. Adwances in Health Scienoss Education. Theory and Practice. Schmidt $H_{3}$ Noman G, editors. Dordrecht, the Netherlands, Kluwer Academic Publishers 1996;1:41-67.

10. Elstein A, Shulimar. LS, Spratka SA. Medical problem solving: An analysis of clinical reasoning, Cambridge Massidohusetts: Harvard University Press, 1978

11. Rethan J.J. Martir $E$, Metsernakers J. To what extent do clinical notes by general practitioners reflect actual performance? A study using simulated patients. Br I Gen Pract 1994;44:153-6.

12. Norciti II, Swansion D. Factors influencing testing time, requinements for simulation-based measurements: do sirmulations ever yield reliable scores? Teaching and Leaming in Medicine 1989;1:85-91.

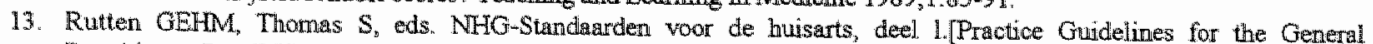
Practitioner, Part 1] Utrecht: Bunge 1993. 
14. Rutten GEHM. Thomas S, eds. NHG-Standaarden voor de huisarts, deel MI.Practice Guidelines for the Getheral Practitioner, Fart il] Utrecht Bunge 1996.

15. Rutten GEHM, redactie. Huisarts en patient, tichtijnen en uitgangspunten [General Practitioner and Patient, Guidelines and Premises] Utrecht: NHG 1996.

15. Neufeld VR, Norman GR, eds. Assessing alinical competence. New York: Springer Publishing Company, 1985:51-71.

16. Van Thiel J, Van der Vleuten CPM Kram H. Assersmerat of medical interviewing skills: generdizability of scores using successive MAAS-versions. In: Harden RM, Hart IR, Mulholland H, editors. Approaches to the Assessment of Clinical Competence. Dundee: Centre for Medical Education, 1992.

17. Pollemans $M$ Kemintoetsing bij huisarisen. [Thesis]. [Assesment of knowledge of genteral pratitioners]. Maastricht: Rijksuniversiteit Limburg, 1994 .

18. Irvine Donald Irvine Sally. The practice of quality. Radcliffe Medical Press Lid, 1996. Oxford and Nlew York.

19. Hombergh wan den $P$, Grol R, Smits AIN, Bosch van der WJMM. Visitatie van huisartspraktijken; narar toetsing wan de praktij]koering. [A practice visit to assess the organization of the general practitioner] Huisarts Wet 1995;38:169-74.

20. Houghton G. General practitioner reaccreditation: tse of performance indicators. Br J Gen Pract 1995;45:677-81.

21. Berwick DM. Continuous improvement as an idea in health care. New Engl Joum of Med 1989;320:53-56.

22. Lawrence M, Schofield T eds. Medical audit in primary health care. Oxford University Press, Oxfond 1993.

23. Newble $\mathbb{D}$, Jolly $B$, Wakeford $R$. The tertification and recertification of doctors: issues in assessment of clinioal competence. Cambridge University Press, 1994.

24. Brinko KT. The practice of giving feedback to improve teaching. Journal of Higher Education 1993;64:574-92.

25. Fredriksen N. The real test bias: Influence of testing on taaching and leaming. American Psychologist 1984;39:193 w 202. 


\section{Summary}

Quality of care in general practice has evolved into a new important field of work and research including research on quality assessment, i.e. the process of evaluating the current level of performance of General Practitioners (GPs), and quality improvement. The assurance of good quality of care in general practice requires a continuous repetition of the process of quality assessment and improvement. Within this frame, the idea of formal (re)assessment of practising GPs is becoming more and more an accepted fact, although a formal assessment procedure enabling a systematio valid, reliable and feasible assessment of practising GPs is still lacking. This educational study focuses on the development of such an assessment procedure that can be used as part of quality improvement in general practice.

The introduction of this thesis contains a description of the research problem at hand, the area of assessment of GPs and the high-stake issues in this field. This is followed by the research questions and the study design. It is obvious that no single assessment method can cover the extensive and complex domain of general practice care. Therefore, a comprehensive assessment approach is needed. It is also made clear that no assessment model exists which is able to cover all aspects of general practice care such as communication with patients, medical performance and practice management including GPs' knowledge and skills. It is concluded that it is desirable to develop such an assessment model, which can be used as a blueprint in the selection of assessment methods. Further, appropriate methods for the assessment of each separate aspect of general practice care are needed. It should be established under which conditions the assessment is best to be conducted. Should it take place in clinical practice, in a simulated situation, or by means of direct observation or by indirect tests such as written papers?

The relationship between the scores of different methods is unclear as is the predictive value of scores of written tests or tests in a simulated situation for actual performance. The relationship between process, i.e. communication with patients and medical performance, and structure, i.e. practice management, and the relationship between competence (knowledge and demonstrated skills) and actual performance are questionable as well.

Three research questions were therefore formulated on the development and testing of an appropriate model for comprehensive assessment of practising GPs, including different methods, which should cover the domain of general practice care as completely as possible. More specifically the following research questions are addressed:

1. What would be an appropriate model for comprehensive assessment of practising GPs, which covers the domain of general practice care as completely as possible?

2. To what extent do competence-based tests predict actual clinical performance?

3. What is the relationship between the GP's practice management (structure) and actuall clinical performance of GPs in that practice (process)?

The study design showed the following steps (see figure I page 16). First, a literature search was carried out into models and blueprints for assessment of family practice care, leading to a new pyramid assessment model. Second, existing assessment instruments and methods were screened on their psychometric qualities, i.e. validity, reliability and feasibility. The methods with the best psychometric characteristics were selected for the main study by using the pyramid model. Third, 
in a cross sectional study, GPS were assessed comprehensively. Knowledge tests were completed at home first, followed by a randomization of participants in order to control for order effects. Three groups of 50 GPs each, two groups of participants and one control group, comparable on personal and profesisional characteristics and on results on the knowledge tests, were formed. Group 1 and 2 were observed directly in both a simulated situation and daily surgeries, but in reverse order. Consultations were scored by peer-observers $(N=35)$ on both medical performance and communication with standardized patients in the simulated situation and with real patients in daily practice. These patients participated as evaluators of the communication component as well. After observation of actual performance, GPs' practice management was assessed by non-physician observers visiting the practices. Finally, participants were sent a questionnaire about their acceptance of each method and their educational activities and plans as a result of their participation in the assessment and the feedback received.

Chapter I describes the development of a theoretical and practical model to be used as a blueprint for comprehensive assessment of practising GPs, taking into account recent views on medical expertise, the distinction between competence and performance, the state of the art in Continuing Medical Education (CME) and quality improvement, and recent developments in assessment methodologies. Computerised and hands-on literature searches were performed, focused on collecting models. Three existing frameworks were transformed into a new three-dimensional pyramid: Fabb's model, a systematic approach of the domain of general practice care; Miller's pyramid, reflecting the processes of clinical reasoning and the distinction between competence and actual performance; and Donabedian's framework, including process, structure and outcome of general practice care. For logistical and complexity reasons, patient outcomes were not included in the new Pyramid Assessment Model, except for the evaluation of quality of GPs' commumication with patients by standardized patients and real patients.

Three subdomains in general practice were represented on one axis: medical performance, communication with patients, and practice nanagement. Diseases of patients, classified in chapters of the International Classification of Primary Care (ICPC) and contextual factors were represented on the second axis. The third axis represented the different assessment levels: competence, i.e. knowledge and demonstration of skills, at the basis and actual performance at the top. Using this model, tasks related to the three subdomains could be connected with different diseases and complaints of patients and their contexts, whereas a proper assessment level, i.e. a level of competence or performance, could also be selected.

This model allows test developers to define precisely their objective for testing, i.e what should be assessed, and where and how. For each of the domains and for each level (different) assessment instruments can be chosen (see figure 1, page 16).

A practical approach in using this blueprint is presented in this first chapter. Concerning the competence level, knowledge levels were assessed by written tests and the "shows how" level, i.e. the demonstration of skills, were assessed by a standardized observation test in a simulated situa- 
tion. Actual performance and practice management ("does") were assessed by video observation of regular consultations (performance) and by a practice visit to assess practice management.

Chapter 2. In this chapter issues of validity, reliability and feasibility of video assessment of actual performance of GPs are described. These focused on the following questions: how can consultations be identified and selected for a valid assessment; how reliable is video assessment considering the number of consultations and observers required; how feasible is this method concerning technical aspects, logistics, costs and acceptance by GPs and patients?

Regular consultations of 93 GPs were video recorded during one week using two cameras, one in the consulting room and the other in the examination room. The receptionist informed patients about the video recording and asked permission. The GPs registered consultation and patient data in a logbook, from which 16 consultations per GP were selected. Preset criteria based on prevalence of complaints and diseases in general practice and on a nationally accepted job description were used in the selection procedure. The quality of communicative and medical performance of these consultations was assessed by trained peer-observers with a validated scoring instrument (MAASglobal).

The validity of the procedure was evaluated by checking the content of GPs' samples of consultam tions using specific sample criteria. Selection bias was estimated by multiple regression analysis, with sample characteristics as independent variables and scores on communication and medical performance as dependent variables. In this way the influence of GPs' personal characteristics on scores was estimated as well. The influence of observation on GPs and patients was assessed by a questionnaire. Generalizability theory was used to estimate reliability. Feasibility was assessed by a questionnaire, by keeping accounts, and by checking the technical quality of the video taped consultations.

The domain of general practice proved to be covered well in the samples; content validity was satisfactory. As regards the sample characteristics, only the total duration of consultations appeared to correlate significantly with the scores on both communication and medical performance: the longer the total duration of the 16 consultations the higher the performance scores. A majority (71\%) of GPs reported not having been influenced by the observation, except in the first cases, and recognizing their usual daily performance in the videotaped consultations. An acceptable level of reliability was reached after 2.5 hours of observation, i.e. 12 cases observed by a single observer. The method was well accepted by both GPs and patients. The costs ( $£ 250$ per GP) were acceptable. Video assessment of GPs in daily practice, performed as described, proved both to be valid by approximating real professional life as closely as possible, and appeared reliable and feasible for use in educational and quality improvement activities.

Chapter 3 reports on the comparison between observation of GPs' performance in a multiple station examination using standardized patients and observation of real surgeries in daily practice. Consultations of $90 \mathrm{GPs}$, divided into two groups, were videotaped both in a multiple station examination at the medical school using standardized patients and in their daily practice surgery with regular patients. Peer-observers assessed GPs' communication with patients and medical 
performance with a validated instrument (MAAS-Global). Both groups passed through both assessments, but in reverse order. Content validity, criterion validity, reliability, i.e. generalizability, and feasibility of both methodss were compared, taking time-order effects into account.

Content validity of practice video assessment was superior to the multiple station examination, since the domain of general farmily practice care was better covered. Regular consultations in practice were more authentic than the simulated cases, since initial and follow-up consultations with children and older patients in the natural daily context were included. Moreover, participants judged the videotaped practice consultations as "natural", whereas hardly any GP recognized his usual working style in the multiple station examination. Concerning concurrent validity between the two test methods, only the communication component of both methods correlated. In addition, real practice performance proved to be less influenced, thus more stable, than behaviour during the station examination: scores on the multiple station examination increased significantly when the practice video assessment had been done previously (group 2), whereas practice scores appeared to be consistent, irrespective of whether GPs had passed through the station examination before or not. Reliability of both methods, expected to be better in the more controlled multiple station examination, was comparable. The organization of practice vidieo assessment was more flexible, less costly and better accepted by GPs than the multiple station examination.

Therefore it has to be concluded that assessment for quality improvement of GPs by video observation in daily practice is superior to video assessment in a simulated situation.

Chapter 4 compares the predictive values of two written medical knowledge tests and a standardized multiple station examination for GPs' actual medical performance in daily practice.

Two groups of GPs ( $N=46$ and $N=44)$ were assessed using a general medical knowledge test and by a knowledge test on technical skills, followed by the multiple station examination using standardized patients and the practice video assessment of real surgeries according the study design described. In both groups the predictive value of medical knowledge tests, ranging from 0.43-0.56 (disattenuated Pearson correlation), proved to be comparable with the predictive value of the multiple station examination for actual medical performance (0.33-0.59). The overall explained variance of scores of the practice video assessment by scores on the knowledge tests was moderate (35\%). GPs' professional characteristics did not contribute to the explanation of variation in performance scores.

In conclusion, medical knowledge tests can predict actual clinical performance to the same extent as a multiple station examination. Compared with a station examination, a knowledge test may be a good alternative method for assessment procedures of a large number of practising GPs, since knowledge tests can be used on a broad scale with relatively low resource investments. In addition, these tests have a far better predictive value for actual performance than GPs' personal characteristics, such as age, gender, College membership or working single-handedly.

Chapter 5 describes the relationship between practice management (structure) and actual clinical performance (process) in general practice. The precise relationship between these dimensions is tenuous. Analysis of their mutual relationship may yield insight into the way they contribute to 
outcome. A study is described in which the practice management of 93 GPs was assessed by a practice visit performed by a non-physician observer using a validated instrument (VIP), directly after the GPs had been videotaped in their daily surgeries,

Pearson correlations (observed and disattenuated for unreliability of the instruments) between scores on 22 practice management dimensions and scores of 16 selected cases on medical performance and communication were calculated. The predictive value of specific practice management aspects for actual performance was determined by multiple regression analysis.

Nine practice management dimensions proved to correlate significantly with medical performance and so did five dimensions with actual communication. Overall, most associations were weak.

Combined with demographic variables (age for medical perfomance and working single-lhandedly for communication), 26 percent of variance in medical performance scores and 11 percent of variance in scores of communication with patients could be explained by only five practice management dimensions. Organization of quality assessment activities, i.e. assessment with the help of data from the medical insurance, prescriptions, referrals and diagnostics, explained most of the variation in medical performance (ten percent). Two practice dimensions, i.e. delegation of medical tasks to the practice assistant and working single-handedly, explained six respectively five percent of variance in communication with patients scores.

In conclusion, practice management (structure) and actual performance (process) seem largely independent constructs. Howewer, some practice management dimensions might be linked up with. GPs' performance. In all, quality improvement and assessment activities should emphasize that practice management is different from actual performance. Structure and process may contribute to patient outcome independently from each other.

Chapter 6 contains an explorative study concerning observation of GPs' communication with patients assessed by peers, real patients and standardized patients (SPs), focused on the question. whether such assessments of GPs provide relevant additional information about GP's' communicative performance, from both the professional perspective and patients" perspective.

Two groups of $43 \mathrm{GPs}$ each went through the "Multiple Station Examination" using SP's and through the "Practice Assessment" in regular surgeries, following the situdy design described before (see page 16). GPs' communicative performance was evaluated by peers with the MAASGlobal, and by SPs and real patients with an instrument derived from the MAAS-Global.

The correlation between the scores given by standardized patients, scores given by real patients and scores given by peer-observers was assessed. Results showed that SPs were to some extent consistent with peers in the simulated situation. Second, both reall patients and SPS valued GPS" quality of communicative performance more positively than peers. Third, real patients probably differ from both SPs and peers in evaluating the quality of GPs' communication substantially, since no correlation was found between patients' scores and SPs' scores or peers' scores.

Finally, the quality of GPs" communication with SPs in a simulated situation may differ from the quality of GPs" actuall communication with real patients in daily practice. This aspect has been analysed in detail in Chapter 3. 
It has been hypothesized that SPs' evaluation of GPs' communicative performance was comparable with the observation "at distance" by peers, since they evaluated as uninvolved healthy persons about hundred GPs in a short and independent relationship with the observed GP. Real patients, on the other hand, are more involved in the lasting relationship with their GP. Moreover, real patients may be focused on the GP"s final conclusion, i.e. bad or good news, conceming their serious complaints and therefore they may be less interested in the communication process. Being consumers, they seem to have an other perspective on GPs' communication with patients than professionals.

From the educational perspective, peer observation or evaluation by standardized patients combined with the evaluation by real patients may provide relevant information about GPs" communication with patients. SPs represent patients' perspective by giving high absolute scores as well as the professional perspective by being consistent with peers. Evaluation by real patients is important, since they represent consumers' needs. On the other hand, the low scores given by peers may be an effective stimulus for GPs to improve their communicative performance.

Finally, within the scoringlists used, absolute high scores might be relatively low, which is useful for the selection of topics for quality improvement.

Therefore, both not-involved observers (peers and SPs) and involved real patients should be used in evaluating GPs' communication with patients.

Chapter 7 contains the general discussion and recommendations for research, and describes GPs" evaluation of the assessment procedure. The overall conclusion of the study is that a valid and reliable comprehensive assessment of individual practising GPs should include both an assessment method for direct (video) observation of GPs' communicative and medical performance in daily practice and a method for practice visitation to assess GP's practice management. Concerning the pyramid assessment model, it is argued that further study should be performed in order to include Gps' attitude and patient outcomes in a model for assessment. Clinical tasks to be assessed should be formulated before the implementation of a procedure for comprehensive assessment, since the model is global. In relation to video assessment in daily practice, the area of tension between standardization of samples of regular consultations, content validity and reliability needs further research. Strict standardization may decrease content validity, since each sample has to be representative for the working style of each GP. Assessment in a simulated situation may be useful in specific CME activities focused on specific skills. For screening purposes on a broad scale this method is costly, not well accepted by GPs and therefore less useful than video assessment in daily practice.

Moreover, less costly medical knowledge tests predict actual clinical performance to the same extent as a multiple station examination and are therefore a good alternative method. Since these tests have a far better predictive value for actual performance than GPs personal characteristics, such as age, gender, College membership or working single-handedly, it is concluded that these tests should be developed for the assessment of GPs' communication with patients and practice management as well. Conceming practice management, it is argued that this aspect of general 
practice care has a low predictive value for actual performance. Structure and process may contribute to patient outcomes independently from each other, which needs further research. Finally; with regard to patients' evaluation of GPs' communicative performance, real patients being consumers may have another perspective than peers or standardized patients. Real patients" satisfaction with GPs" communicative performance, which may be considered as patient outcome, showed no relationship with peers" scores of this communicative process. This finding requires further research as well.

The participation in the comprehensive assessment including the feedback given was evaluated by the GPs using a questionnaire. Peer-observers and GPs of the control group were sent a questionnaire as well. In this study feedback was given in a limited extent in order to minimize a possible order effects, which would bias the relationship between methods used. The questionnaire contained four main questions concerning the following aspects: the profit of participation in the assessment versus its efforts (1), the effects on GPs' insight in their way of functioning (2), GPs' plans for concrete changes in daily practice care (3) and GPs' activities on medical education as a result of participation (4). GPs and peer observers viewed a positive balance between profit and effort of participation. GPs of the control group, who participated on the knowledge tests onlly, viewed the balance as less positive than observers and assessed GPs. Observers and assessed participants viewed both the medical knowledge test, the assessment of practice management, the multiple station examination and the practice video assessment as methods which gave them insight in their way of functioning, the latter two for communication aspects particularly. However, a majority made no plans for concrete changes, whereas a minority performed individual educational activities mainly, i.e. self directed learning and immediate changes in performance or practice management.

GP's' preference for assessment methods to be included in a comprehensive procedure favoured the video-assessment in daily practice (medical and communicative performance) combined with the assessment of practice management by visitation and a written medical knowledge test.

A majority of GPs preferred a combination of written and oral feedback and showed a slight preference for an unknown colleague, provided that a GP would be the mediator.

In this study, the "quality circle" correctly started in practice observation and collecting data from practice. However, the next stages of this circle, i.e. the evaluation of information (performance versus targets) including setting priorities in implementing changes, the agreement of criteria including setting target standards and a subsequent observation of practice to evaluate changes, have not been performed, since this methodological study was focused on the relationship between methods used. In relation to these limitations, the educational effects of the study on the participants are encouraging. Further research on feedback as a part of continuous quality improvement activities is necessary, in order to make assessment activities including feedback as effective as possible. 
doctor: mame

registration number

case

patient

observer

$0=$ not present $\quad 2=$ unsatisfactory

$1=$ poor $\quad 3=$ doubtful

$$
\begin{aligned}
& 4=\text { satisfactory } \\
& 5=\text { good }
\end{aligned}
$$$$
6=\text { excellent }
$$

n.a. $=$ not applicable

The rating boxes are intended only as a reminder for the observer.

Circle the relewant score for each item.

\section{COMMUNICATION SKILLS DURING EACH PHASE}

1. OPENDNG

greeting: attention and inviting

name and function where necessary

turning to reasons for the visit

asking about other reasonsi for the visit

(after asking about main reasons and before history taking)

2. FOLLOW-UP CONSULTATION

referring to complaints and requests for help

referring to agreements made and checking up

on implementation

asking about how things have been

3. CLARIFICATION

naming/clarifying requests for help, wishes

or expectations

naming/elarifying reasons for present visit

continuing to ask questions in the patient's frame of

meference and investigating cues only with respect to

clarifying questions

4. PHYSICAL EXAMINATION

instructing the patient:

informing about the examination

treating the patient with care and respect

n.a. 0123456

5. EVALUATION AND DLAGNOSIS

narning findings and diagnosis/hypothesis

naming causes or the link between findings and diagnosis

naming prognosis or course of events to be expected

6. TREATMENT AND APPOINTMENTS

consulting about reatment plan

discussing the feasibility and the behaviour to be

complied with

making appointments: who, what, when

7. EVALUATING THE CONSULTATION

general question

answering requests for help

provisional/interim outlook 


\section{GENERAL COMMUNICATION SKMLLS}

8. CONVEYTNG NFORMATION

announcing, categorizing

in small quantities, concrete explanations

0123456

comprehensible use of language

asking about reactions and whether patient understands

9. EMOTIONS

asking or continuing to ask about feelings

0123456

reflecting feelings (including nature and intensity)

sufficiently throughout the whole consultation

coping reactions: first going into feelings

10. SUMMARIZNG (both summarizing and repeating)

briefly, in own words

correct regarding content, complete

checking

sufficiently throughout the whole consultation

11. ORDER OF INFORMATION

logical order of the phases

$\square$

$\mathrm{DC}$

$\square$

$\square$

balanced division of time

announcing (consultation plan, history taking,

examination, other phases)

$\square[$

DL

$\square$

$\square$

$\square$

미

\section{FLEXIBILITY}

empathizing, attentive and open in intonation, gesture and eye contact

adequate time/space for the patient

no disrupting hitches or interruptions

\section{MEDICAL ASPECTS}

Where necessary, rate as best as you can. Consult if available

National GP standards, guidelines, protocols or

speciall observer instructions.

HISTORY TAKNNG

EXAMTNATION

1..201233456

EVALUATION AND DLAGNOSIS

0123456

TREATMENT AND APPONTMENTS

0123456

\section{OTHER FEEDBACK}




\section{CURRICULUM VITAE}

Paulus Maria Ram was born on the twelfth of July 1948 in Arnhem, the Netherlands. In 1966 he finished his gymnasium after which he studied medicine at the University of Nijmegen. He graduated in 1975. From 1977 till 1985 he set up and coordinated a health centre in Oss, the Netherlands, where he worked as a general practitioner untill 1994. He combined this job with education in medical health professions and presented medical education courses on radio and television ("Dag Dokter"' by Teleac) from 1983 untill 1988. In 1985 he became tutor in vocational training at the Department of General Practice at the University of Mastricht. Since the end of 1993 he worked as a researcher on the Comprehensive Assessment Project (CAP), initiated and supported by the Centre for Quality of Care Research (WOK) and by the Department of Medical Education of the University of Maastricht, which finally has resulted in this thesis.

He was adviser of the comprehensive assessment of GP-trainers at the University of Nijmegen. At the end of 1997 he finished to be a practising general practitioner and started as a part-time member of staff at the Dutch College for General Practitioners (NHG) in Utrecht, working on the implementation of comprehensive assessment methods in quality improvement activities in general practice. In 1998 he continued his career as adjunct-director at the vocational training section of the Department of General Practice at the University of Maastricht combining management tasks with teaching the teachers. 